Universidade de São Paulo.

Instituto de Astronomia, Geofísica e Ciências Atmosféricas

Departamento de Ciências Atmosféricas

\title{
Yusvelis Maribel Barzaga Ramirez
}

\section{Inferência de hidrometeoros a partir de um radar meteorológico de dupla polarização banda $X$.}

Versão Corrigida. O original encontra-se disponível na Unidade.

São Paulo

2018 


\section{Inferência de hidrometeoros a partir de um radar meteorológico de dupla polarização banda $X$.}

Dissertação apresentada ao Departamento de Ciências Atmosféricas do Instituto de Astronomia, Geofísica e Ciências Atmosféricas da Universidade de São Paulo como requisito parcial para a obtenção do título de Mestre em Ciências.

Área de concentração: Ciências Atmosféricas

Orientador:

Prof. Dr. Carlos Augusto Morales Rodriguez

São Paulo

2018 


\section{FOLHA DE APROVAÇÃO}

Barzaga, Y. M. Inferência de hidrometeoros a partir de um radar meteorológico de dupla polarização banda X. Dissertação (Mestrado em Meteorologia) - Instituto de Astronomia, Geofísica e Ciências

Atmosféricas, Universidade de São Paulo, São Paulo, 2018.

Aprovada em:

Banca Examinadora

Prof. Dr.

Instituição:

Julgamento:

Prof. Dr.

Instituição:

Julgamento:

Prof. Dr.

Instituição:

Julgamento: 
"El genio es uno por ciento de inspiración y noventa y nueve por ciento de sudor."

Thomas Edison. 
Dedicatória

A mami y papi 


\section{Agradecimentos}

A minha mãe e meu pãe, pelo seu amor e apoio, pelo seu esforço e sacrifício para que chegasse até esta estapa de minha vida.

Ao Professor Morales, que teve muita paciência comigo, pelo incentivo e apoio, isso foi muito importante.

A Andrea, não tenho palavras para dizer tudo o que você significa para mim, obrigada pela força que você me deu mesmo quando ficava sem colher.

A Ramón pela paciência que teve comigo e ajuda incondicional, por aprender minhas questões de radar para eu poder entender e por ser já mais meteorólogo que físico.

A Keyla por seu tempo perdido comigo, mas eu acho que valeu a pena.

A Dayne e Maciel, Janet e Jose, Darsys e Raydiel, pelos conselhos, ajuda, alegrias, tristezas e dores compartilhadas, vocês são minha familia aqui, eu amo vocês.

A Diaslen e a Rocio, minhas amigas da distância, vocês estiveram a meu lado neste longo caminho.... e está faltando muito mais.

A todos meus amigos cubanos pela preocupação.

A minha familia pelo seu amor incondicional.

A minha turma e as pessoas da sala da mesa sumida.

A CAPES pelo sua apoio financeiro.

E a todos que direita ou indiretamente fizeram parte da minha formação, o meu muito obrigado. 


\author{
Universidade de São Paulo. \\ Instituto de Astronomia, Geofísica e Ciências Atmosféricas \\ Departamento de Ciências Atmosféricas
}

\title{
Resumo
}

por

\section{Yusvelis Maribel Barzaga Ramírez}

Este estudo apresentou uma metodologia para inferir hidrometeoros a partir de medidas polarimétricas de um radar meteorológico de dupla polarização banda $X$. A metodologia consiste em uma abordagem teórica baseada em simulações numéricas com um modelo de espalhamento Mie (T - Matrix e Mueller) e uma experimental pautada na aplicação de um algoritmo de classificação de hidrometeoros (Dolan and Rutledge [2009]). As simulações teóricas foram utilizadas para estudar os efeitos da distribuição de tamanho de gotas, temperatura dos hidrometeoros, ângulo de elevação e mistura de hidrometeoros a partir do fator de refletividade do $\operatorname{radar}(Z)$, refletividade diferencial $\left(Z_{D R}\right)$, fase diferencial especifica $\left(K_{D P}\right)$ e coeficiente de correlação $\left(\rho_{H V}\right)$. Os valores de $Z_{D R}$ são $0.5 d B Z$ maior para a frequência de banda $X$ do que para um banda $S$. A partir de $Z$ maior que $45 d B Z K_{D P}$ começa a ficar maior que 0 . Já $\rho_{H V}$ começa a diminuir quando $Z$ é maior que $25 \mathrm{dBZ}$. Não se observa variações significativas para o graupel, porém para granizo $K_{D P}$ é maior que 0 quando $Z$ é maior que $15 d B Z$, entretanto, para água, os valores são consideravelmente menores. Os efeitos de temperatura só são notados quando $Z$ é maior 
que $60 \mathrm{dBZ}$. Ao analisar o efeito da elevação, observa-se que $Z_{D R}$ diminui com o aumento da elevação, sendo mais sensível para $Z$ maiores, o mesmo efeito é observado para $K_{D P}$ e $\rho_{H V}$. Estas variações são mais sensíveis para água e granizo do que para o graupel. Comparando as distribuições exponencial e gama para considerar os efeitos da distribuição do tamanho de gotas para o caso da chuva, nota-se que a distribuição exponenciais é maior que a gama quando as gotas aumentam seu tamanho e diminui sua concentração, devido que na simulação teórica foi utilizado $N_{0}$ fixo.Ao analisar os efeitos da co-existência de água e graupel, temos que as gotas de água dominam o sinal de $Z$ quando $Z$ for maior que $30 d B Z$, já $K_{D P}$ será positivo(negativo) quando $Z$ for maior(menor) que $35 d B Z$ da água, desde que $Z$ do graupel seja menor que $10 d B Z$, já $\rho_{H V}$ tende a ficar próximo de 1 quanto mais graupel é observado. Para a mistura de granizo e água, $Z$ da água domina o do granizo quando $Z$ é maior que $45 \mathrm{~dB} Z, K_{D P}$ é maior(menor) que zero quando $Z$ for maior (menor) que $25 \mathrm{dBZ}$ desde que $Z$ do granizo seja menor que $10 \mathrm{dBZ}$, já $Z_{D R}$ da água(granizo) domina o do granizo(água) quando $Z$ for maior(menor) que $45 \mathrm{dBZ}$. Na parte experimental, dois casos observados durante o experimento de campo do Projeto CHUVA no Vale do Paraíba em 8 de Fevereiro e 22 de Março de 2012 foram utilizados. A classificação de hidrometeoros segundo Dolan and Rutledge [2009] indicaram a presença de chuva próximo da superfície proveniente de graupel e granizo. Acima dos $5 \mathrm{~km}$ foram identificados a presença de graupel,granizo e cristais de gelo. Ao examinar as regiões classificadas como granizo e graupel dentro da região de 0 e $-15^{\circ} \mathrm{C}$ com os resultados teóricos, é possível explicar a presença concomitante de água e granizo e água e graupel nestas regiões.

Palavras Chaves:Hidrometeoros, T-matrix, Mueller-matrix, radar, variáveis polarimétricas. 


\author{
Universidade de São Paulo. \\ Instituto de Astronomia, Geofísica e Ciências Atmosféricas \\ Departamento de Ciências Atmosféricas
}

\title{
Abstract
}

by

\section{Yusvelis Maribel Barzaga Ramírez}

This study presents a methodology for inferring hydrometeors from polarimetric measurements of a $X$-band double polarization meteorological radar. The methodology consists of a theoretical approach based on numerical simulations with a Mie scattering model (T-Matrix and Mueller) and an experimental approach based on the application of a classification algorithm of hydrometeors (Dolan and Rutledge [2009]). The theoretical simulations were used to study the effects of droplet size distribution, hydrometeor temperature, elevation angle and mixture of hydrometeors from radar reflectivity factor $(Z)$, differential reflectivity $\left(Z_{D R}\right)$, specific differential phase $\left(K_{D P}\right)$ and correlation coefficient $\left(\rho_{H V}\right)$. The values of $Z_{D R}$ are $0.5 d B Z$ higher for the $X$ band frequency than for the $S$ band frequency. From $Z$ greater than $45 \mathrm{dBZ}, K_{D P}$ starts to get higher than 0 . When $Z$ is greater than $25 \mathrm{dBZ}, \rho_{H V}$ starts to decrease. No significant variations are observed for the graupel, however for hail, $K_{D P}$ is greater than 0 when $Z$ is greater than $15 d B Z$, but these values were much lower than for water. Temperature effects are only noticed when $Z$ is greater than $60 \mathrm{dBZ}$. When analyzing the effect of elevation, it is observed that $Z_{D R}$ decreases with increasing elevation, being more sensitive to $Z$ larger; the same effect is observed for $K_{D P}$ and $\rho_{H V}$. These variations are more sensitive to water and hail 
than to the graupel. Comparing the exponential and gamma distributions to consider the effects of droplet size distribution in the case of rain, it is noted that the exponential distribution is larger than the gamma when the droplets increase in size and decrease in concentration, due to the fact that in the simulation was used $N_{0}$ fixed. When analyzing the effects of co-existence of water and graupel, we have that the water droplets dominate the $Z$ signal when $Z$ is greater than $30 \mathrm{dBZ}, K_{D P}$ will be positive (negative) when $Z$ is greater (lower) than $35 \mathrm{dBZ}$ of water, since $Z$ of the graupel is less than $10 \mathrm{dBZ}$ and $\rho_{H V}$ tends to be close to 1 when more graupel is observed. For the mixture of hail and water, $Z$ of water dominates that of hail when $Z$ is greater than $45 \mathrm{dBZ}, K_{D P}$ is larger (smaller) than zero when $Z$ is larger (smaller) than $25 \mathrm{dBZ}$ since $Z$ of hail is less than $10 \mathrm{dBZ}$ and $Z_{D R}$ of water (hail) dominates hail (water) when $Z$ is greater (lower) than $45 \mathrm{dBZ}$. In the experimental part, two cases observed during the field experiment of the RAIN Project in Vale do Paraíba on February 8 and March 22, 2012 were used. The classification of hydrometeors according to Dolan and Rutledge [2009] indicated the presence of rain near the surface coming of graupel and hail. Above $5 \mathrm{~km}$ were identified the presence of graupel, hail and ice crystals. When examining the regions classified as hail and graupel within the region of 0 and $-15^{\circ} \mathrm{C}$ with the theoretical results, it is possible to explain the concomitant presence of water and hail and water and graupel in these regions.

Keywords: Hydrometeors, T-matrix, Mueller-matrix, radar, polarimetric variables. 


\section{SUMÁRIO}

Dedicatória

Agradecimentos

Resumo

Abstract

vi

Lista de Figuras $\quad$ x

Lista de Tabelas $\quad$ xiii

1 Introdução 1

1.1 Hidrometeoros nos trópicos . . . . . . . . . . . . . . . . . . 1

1.2 Formação dos hidrometeoros. . . . . . . . . . . . . . . . . 5

1.3 Algoritmo de Identifição dos Hidrometeoros . . . . . . . . . . . . . . . . . 6

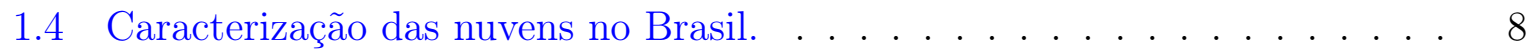

1.5 Motivação e objetivos. . . . . . . . . . . . . . . . . . . . . . . 10

2 RADAR: Principais elementos. $\quad 12$

2.1 Funcionamento do RADAR . . . . . . . . . . . . . . . 12

2.1.1 Espalhamento . . . . . . . . . . . . . . . . . 13

2.1.1.1 Espalhamento Rayleigh e Mie . . . . . . . . . . . . 13

2.1 .2 Atenuação . . . . . . . . . . . . . . . . . . . . . . . . . . . . . . . . . 16

2.2 Propagação de onda electromagnética e polarização . . . . . . . . . . . . 17

2.2.1 Variáveis polarimétricas . . . . . . . . . . . . . . . . . . . . . . . . . . . . 24

2.3 Classificação de hidrometeoros. . . . . . . . . . . . . . . . . . . 24

2.3.1 Métodos e algoritmos de identificação para radar Banda S . . . . . 25

2.3.2 Métodos e algoritmos de identificação para radar Banda C . . . . . 26

2.3.3 Métodos e algoritmos de identificação para radar Banda X . . . . . 27

2.3.4 T-matrix e Mueller-matrix . . . . . . . . . . . . . . 30

2.3.4.1 T-matrix. . . . . . . . . . . . . 30

2.3.4.2 Mueller-matrix ................ 30 
3 Simulações teóricas: efeitos dos hidrometeoros, DSD, temperatura e elevação nas variáveis polarimétricas.

3.1 Efeito de comprimento de onda e refletividade . . . . . . . . . . . . 33

3.1 .1 Chuva . . . . . . . . . . . . . . . . . 34

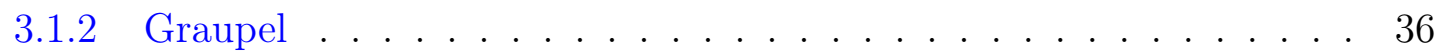

3.1 .3 Granizo . . . . . . . . . . . . . . . . . 37

3.2 Efeitos para diferentes temperaturas. . . . . . . . . . . . . . . . . . 39

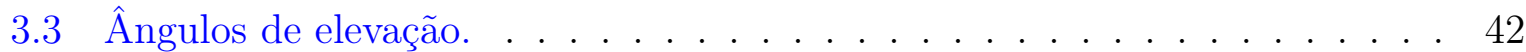

3.4 Efeito da distribuição de tamanho de gotas. . . . . . . . . . . . . . . . 46

3.5 Resultados das simulações com dois hidrometeoros . . . . . . . . . . . . . . 49

3.5.1 Mistura água-graupel . . . . . . . . . . . . . . . . . . 50

3.5.2 Mistura água-granizo . . . . . . . . . . . . . . . . 51

4 Classificação de hidrometeoros: estudo de casos.

4.1 Experimento CHUVA. . . . . . . . . . . . . . . . . 53

4.2 Classificação de hidrometeoros: estudo de casos. . . . . . . . . . . . . . . . . 56

4.2.1 Caso de estudo: 8 de fevereiro de $2012 \ldots \ldots$. . . . . . . . 56

4.2.1.1 Variáveis polarimétricas . . . . . . . . . . . . . 57

4.2.2 Caso de estudo: 22 de Março de $2012 \ldots \ldots$. . . . . . . . . . . 60

4.2.2.1 Variáveis polarimétricas . . . . . . . . . . . . 62

4.2.3 Diferenças entre as simulações teóricas e a classificação de Dolan and Rutledge [2009]. . . . . . . . . . . . . . . . . 76

Conclusões.

Referências Bibliográficas

$\begin{array}{ll}\text { Apêndice } & 91\end{array}$

.1 Distribuição exponencial e gama dos hidrometeoros. . . . . . . . . . . . . . 92

.2 Diferencas Exponencial- Gama dos hidrometeoros (ângulo de elevação) . . 94

.2.1 Graupel . . . . . . . . . . . . . . . . . . . . . . 94

2.2 Granizo . . . . . . . . . . . . . . . . . . . . . 95 


\section{LISTA DE FIGURAS}

1.1 Habitat de formação dos cristais de gelo em função da supersaturação e da temperatura. Fonte: Mason [1971] . . . . . . . . . . . . . . 5

2.1 Funcionamento do radar. Fonte:(Autores [2017] . . . . . . . . . . . . . . . 12

2.2 Espalhamentos sobre uma partícula. (a)Espalhamento Mie; (b) Espalhamento Rayleigh. . . . . . . . . . . . . . . . . . . . . . . 14

2.3 Partículas espalhadoras do radar em função do comprimento de onda e o diâmetro da partícula. Adaptado:(Navarro [2012] . . . . . . . . . . . . . . 14

2.4 Esquema de emisão de um radar de dupla-palarização. Adaptado da fonte: NSSL/NOAA. . . . . . . . . . . . . . . . . . . . . 19

2.5 Refletividade diferencial(chuva).(Fonte: Yusvelis Barzaga) . . . . . . . . . 21

2.6 Fase diferencial para uma gota de chuva.(Fonte: Yusvelis Barzaga) . . . . . 22

2.7 Fase diferencial especifica para uma simulação de chuva.(Fonte: Yusvelis Barzaga . . . . . . . . . . . . . . . . . 23

2.8 Coeficiente de correlação (chuva)(Fonte: Yusvelis Barzaga). . . . . . . . . 24

3.1 Simulações teóricas para a água para diferentes radares. (a)Fator de refletividade do radar $(Z)$; (b) Refletividade diferencial $\left(Z_{D R}\right)$; (c) Fase diferencial específica $\left(K_{D P}\right) ;(d)$ Coeficiente de correlação $\left(\rho_{H V}\right) \ldots \ldots . .$.

3.2 Simulações teóricas para o graupel para diferentes radares. (a)Fator de refletividade do radar $(Z)$; (b) Refletividade diferencial $\left(Z_{D R}\right)$; (c) Fase diferencial específica $\left(K_{D P}\right) ;(d)$ Coeficiente de correlação $\left(\rho_{H V}\right) \ldots$. . . . .

3.3 Simulações teóricas para o granizo para diferentes radares. (a)Fator de refletividade do radar $(Z)$; (b) Refletividade diferencial $\left(Z_{D R}\right)$; (c) Fase diferencial específica $\left(K_{D P}\right) ;(d)$ Coeficiente de correlação $\left(\rho_{H V}\right) \ldots$. . . .

3.4 Simulações teóricas para chuva para diferentes temperaturas. (a)Fator de refletividade do radar $(Z)$; (b) Refletividade diferencial $\left(Z_{D R}\right)$; (c) Fase diferencial especifica $\left(K_{D P}\right) ;(d)$ Coeficiente de correlação $\left(\rho_{H V}\right) \ldots$. . . . .

3.5 Simulações teóricas para graupel para diferentes temperaturas. (a)Fator de refletividade do radar $(Z)$; (b) Refletividade diferencial $\left(Z_{D R}\right)$; (c) Fase diferencial específica $\left(K_{D P}\right) ;(d)$ Coeficiente de correlação $\left(\rho_{H V}\right) \ldots$. . . .

3.6 Simulações teóricas para granizo para diferentes temperaturas. (a)Fator de refletividade do radar $(Z)$; (b) Refletividade diferencial $\left(Z_{D R}\right)$; (c) Fase diferencial especifica $\left(K_{D P}\right) ;(d)$ Coeficiente de correlação $\left(\rho_{H V}\right) \ldots \ldots$. . . 
3.7 Simulações teóricas para chuva para diferentes ângulos de elevação. (a)Fator de refletividade do radar $(Z)$; (b) Refletividade diferencial $\left(Z_{D R}\right)$; (c) Fase diferencial específica $\left(K_{D P}\right) ;(d)$ Coeficiente de correlação $\left(\rho_{H V}\right) \ldots$. . . . . 43

3.8 Simulações teóricas para graupel para diferentes ângulos de elevação. (a)Fator de refletividade do radar $(Z)$; (b) Refletividade diferencial $\left(Z_{D R}\right)$; (c) Fase diferencial específica $\left(K_{D P}\right) ;(d)$ Coeficiente de correlação $\left(\rho_{H V}\right) \ldots \ldots . . .44$

3.9 Simulações teóricas para granizo para diferentes ângulos de elevação.. (a)Fator de refletividade do radar $(Z)$; (b) Refletividade diferencial $\left(Z_{D R}\right)$; (c) Fase diferencial específica $\left(K_{D P}\right) ;(d)$ Coeficiente de correlação $\left(\rho_{H V}\right) \ldots \ldots$. . . 46

3.10 Diferenças das distribuições exponencial e gama da chuva para $Z=30 \mathrm{dBZ} .47$

3.11 Distribuição de partículas exponencial e gama para a) graupel e b) granizo. 48

3.12 Simulações teóricas para mistura entre água e graupel: (a) Fator de refletividade do radar $(Z)$; (b) Refletividade diferencial $\left(Z_{D R}\right)$; (c) Fase diferencial especifica $\left(K_{D P}\right) ;(d)$ Coeficiente de correlação $\left(\rho_{H V}\right) \ldots \ldots$. . . . .

3.13 Simulações teóricas para mistura entre água e granizo: (a) Fator de refletividade do radar $(Z)$; (b) Refletividade diferencial $\left(Z_{D R}\right)$; (c) Fase diferencial especifica $\left(K_{D P}\right) ;(d)$ Coeficiente de correlação $\left(\rho_{H V}\right) . \ldots . . . .$.

4.1 Localização do radar Doppler banda X de dupla polarização durante o experimento de campo no Vale do Paraíba. . . . . . . . . . . . . . . 54

4.2 PPI da chuva observada no dia 02/08/2012 as 19 : 54 GMT. . . . . . . . . 57

4.3 Imagens $\boldsymbol{R H I}$ das variáveis polarimétricas e classificação de hidrometeoros: (a) Fator de refletividade do radar $(Z)$; (b) Refletividade diferencial $\left(Z_{D R}\right)$;

(c) Fase diferencial especifica $\left(K_{D P}\right)$; (d) Coeficiente de correlação $\left(\rho_{H V}\right)$;

(e) Velocidade Doppler (v); (f) Classificação dos hidrometeoros(Dolan and Rutledge [2009]) (v) para a chuva observada em 02/08/2012 as 19 : 52 GMT. 58

4.4 Imagens PPI do radar meteorológico Banda X Polarimétrico do dia 22 de março de 2012 para o intervalo entre às $19: 34$ e $20: 16$ GMT. . . . . . . . . . . . . 62

4.5 Imagens $\boldsymbol{R H I}$ do fator de refletividade medido pelo radar desde 19 : 34 até $20: 16$ GMT. . . . . . . . . . . . . . . . 65

4.6 Imagens $\boldsymbol{R H I}$ do diferença de refletividade desde $19: 34$ at $20: 16$ GMT. 68

4.7 Imagens $\boldsymbol{R H I}$ da fase diferencial específica de $19: 34$ a $20: 16$ GMT. . . . 71

4.8 Imagens $\boldsymbol{R H I}$ do coeficiente de correlação desde $19: 34$ at $20: 2016$ GMT. 73

4.9 Classificação entre os hidrometeoros segundo Dolan and Rutledge [2009] de $19: 34$ a $20: 16$ GMT. . . . . . . . . . . . . . . . . . . 75

4.10 Caso de estudo do 22/03/2012 19:34 GMT. Medições radar XPOL a) Classificação do hidrometeoro segundo Dolan and Rutledge [2009], b) Z, c) $Z_{D R}$,

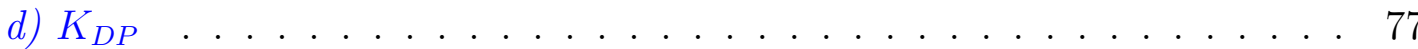

11 Distribuição de tamanhos de gotas de chuva para diferentes refletividades; (a) Distribuição Exponencial; (b) Distribuição Gama. . . . . . . . . . . . . 92

12 Distribuição de tamanho do graupel para diferentes refletividades; (a) Distribuição Exponencial; (b) Distribuição Gama. . . . . . . . . . . . . . . . . 
13 Distribuição de tamanho do granizo para diferentes refletividades; (a) Distribuição Exponencial; (b) Distribuição Gama. . . . . . . . . . . . . . 93 


\section{LISTA DE TABELAS}

2.1 Valores de $|\kappa|^{2} \ldots \ldots \ldots \ldots \ldots \ldots \ldots$

3.1 Parâmetros termodinâmicos e microfísicos dos hidrometeoros . . . . . . . . 33

3.2 Frequência e comprimentos de ondas dos radares. . . . . . . . . . . . . . 33

3.3 Diferenças entre as refletividades obtidas da simulação da chuva para a distribuição e a gama $Z_{\exp }-Z_{\text {gama }}$, levando em conta o ângulo de elevação. 49

4.1 Parâmetros operacionais do radar XPOL durante a Campanha do Vale do Paraíba. (Fonte: Mattos et al. [2016]) . . . . . . . . . . . . . . . . 54

4.2 Comparação entre dados medidos e simulados. Caso 1 . . . . . . . . . . 78

4.3 Comparação entre dados medidos e simulados. Caso $2 \ldots$. . . . . . . . . 78

4 Diferenças entre as refletividades obtidas da simulação da graupel para a distribuição e a gama $Z_{\text {exp }}-Z_{\text {gama }}$, levando em conta o ângulo de elevação. 94

5 Diferenças entre as refletividades obtidas da simulação da granizo para a distribuição e a gama $Z_{\text {exp }}-Z_{\text {gama }}$, levando em conta o ângulo de elevação. 95 


\section{CAPÍTUlo 1}

\section{INTRODUÇÃO}

Quando nos referimos a um hidrometeoro, estamos falando de uma partícula em suspensão na atmosfera, composta de água que pode estar tanto na fase líquida como sólida. Os hidrometeoros podem ser classificados de maneiras diferentes: partículas de água líquida e sólidas que permanecem suspensas no ar (nuvens, nevoeiro); precipitação líquida (garoa e chuva); e precipitação congelada (granizo, graupel e neve).

\subsection{Hidrometeoros nos trópicos}

Nos trópicos, as nuvens cumulus freqüentemente produzem chuvas sem atingir o nível de congelamento(nuvens quentes). As nuvens quentes estão compostas de gotículas de água líquida porque estão localizadas abaixo da isoterma de $0^{\circ} \mathrm{C}$. As bases das nuvens tropicais são mais quentes e as velocidades verticais mais fracas em seus níveis mais baixos, fazendo que contenham tempo suficiente para a ocorrência da chuva pelo processo de chuva quente sem a presença da fase de gelo, Stith et al. [2002].

As gotículas de nuvens de menor tamanho retardam o processo de coalisão-coalescencia e a iniciação de chuva para alturas maiores (mais frío), levando assim água líquida superresfriada para região de fase mista, Wendisch,M. et. al [2016]. A distribuição do tamanho de gotículas de nuvem com a altura, é segundo Wendisch,M. et. al [2016], influenciada pela poluição ambiental, sendo que em condições mais poluídas observa-se mais gotículas pequenas e poucas gotículas grandes de nuvens, o que pode levar a supressão de precipitação. 
Em observação realizada em furações do Atlântico, Black and Hallett [1986,1999], encontraram gotículas de água super-resfriadas só em correntes ascendentes convectiva maiores que $5 \mathrm{~m} / \mathrm{s}$ e nem todas as correntes ascendentes maiores que $5 \mathrm{~m} / \mathrm{s}$ tinham gotas super-resfriadas. Também encontraram nas correntes ascendentes mais frias que $-2^{\circ} \mathrm{C}$ a presença de graupel, o que sugere a presença de gotas super-resfriadas. Nas regiões estratiformes das tempestades, observaram cristais de gelo colunar e partículas de gelo. Também concluíram que um fator para a glaciação rápida das nuvens foi a circulação de gelo de altos níveis das nuvem para as regiões baixas.

Em nuvens convectivas mais profundas e em regiões com fortes correntes ascendentes, acima do nível de congelamento, Stith et al. [2002] observaram a formação e o crescimento do gelo pela difusão seguida de coagulação, processos primários que produzem partículas de tamanho de precipitação.

Já Heymsfield et al. [2002], coletaram medidas in situ durante as campanhas experimentais do Tropical Rainfall Measuring Mission (TRMM), a fim de conhecer a evolução da distribuição de partículas na vertical e a estrutura vertical das propriedades microfísicas em nuvens tropicais. As nuvens geralmente tinham uma profundidade entre 3.0 e $4.5 \mathrm{~km}$, as regiões com gelo, ou seja acima os $4.5 \mathrm{~km}$ do nível médio acima do mar, tinha fator de refletividade do radar variando entre $5-25 \mathrm{dBZ}$, e tem geralmente um aumento com a diminuição da altura. Observações indicaram que o fator de refletividade não tinha variação com a altura.

Stith et al. [2002], realizaram medidas microfísicas em duas regiões tropicais a partir de um avião instrumentado que coletou dados de: pressão, temperatura do ar e ponto de orvalho, posição, velocidade vertical, distribuição e concentração de tamanho de hidrometeoros, conteúdo de água líquida e contadores de aerossóis e de núcleos de condensação. Durante os vôos realizados na Amazônia, eles observaram uma linha de instabilidade com uma refletividade superior a $60 \mathrm{dBZ}$ e echos top até $19 \mathrm{~km}$, além de dois sistemas convectivos menos organizados, mas ainda fortes, que tinham em seu interior partículas de gelo. Durante estes vôos, eles encontraram água líquida super resfriada a temperaturas mais quentes que $-7^{\circ} \mathrm{C}$ na presença de partículas de gelo, graupel e agregados.

Eles concluíram que as correntes ascendentes intensas eram um fator importante na determinação das características microfísicas dos hidrometeoros. Nas regiões com correntes 
ascendentes fracas, observaram um processo de chuva quente bem desenvolvido até o momento em que as gotículas atingiam o nível de congelamento. Além disso, as correntes ascendentes mais fortes $(>5 \mathrm{~m} / \mathrm{s})$ continham gotículas menores ou partículas de gelo no nível médio da nuvem do que as regiões com correntes ascendentes mais fracas. A parte mais significativa da nuvem que tinha água super-resfriada foi encontrada apenas em temperaturas mais quente que $-12^{\circ} \mathrm{C}$, embora tenha sido observada água líquida em regiões com temperaturas tão frias quanto $-18^{\circ} \mathrm{C}$.

Lawson et al. [2015] usaram as observações in situ de Ice in Clouds Experiment-Tropical, ICE-T, (Heymsfield and Willis [2014]) e observaram um processo de coalescência ativo em todas as correntes ascedentes e gotas de diâmetro milimétrico muitas vezes foram produzidas quando a base da nuvem atingiu o nível de $5^{\circ} \mathrm{C}$. Observou-se um aumento da concentração e do tamanho das gotas milimétricas até o início da glaciação. Baseado nas medições feitas no ICE-T, a primeira região de gelo, foi encontrada entre os -8 até $-11^{\circ} \mathrm{C}$.

Além das medidas com avião, os radares polarimétricos tem sido utilizados para descrever os tipos de hidrometeoros nas nuvens, como por exemplo:

Vivekanandan et al. [1991] tem interesse nas medidas dos radares polarimétricos e nos efeitos da propagação dos tipos de hidrometeoros, levando em conta a mistura e da queda dos mesmo. Ele inclui no seu estudo o efeito da orientação da partícula e o ângulo de elevação o radar usando Mueller-matrix. As formas, tamanhos e densidade das partículas relacionadas com o fator de refletividade, a refletividade diferencial e a fase diferencial especifica. Eles consideraram os modelos harmônico simples e a gaussiana, para a distribuição da orientação das partículas. Além disso utilizaram o T-matrix para calcular o espalhamento das partículas assimétricas. A aproximação feita, fazendo as simulações de queda de cristais de gelo, facilita o cálculo dos parâmetros do radar para qualquer orientação especifica do eixo das partículas simétricas e o ângulo do radar com um ângulo de elevação arbitrário.

Straka et al. [2000] apresentaram informações para deduzir os tipos de hidrometeoros dominantes a partir dos dados de radar polarimétrico banda $S$ precisos para fazer uma discriminação e quantificação dos mesmos. Analisaram as variáveis polarimétricas: fator de refletividade, refletividade diferencial, diferença de refletividade, fase diferencial, fase diferencial específica, fase diferencial de retroespalhamento, coeficiente de correlação e 
radio de depolarização linear. Usando a lógica fuzzy, mostraram as relações entre as variáveis e os hidrometeoros. Os tipos gerais de hidrometeoros considerados foram chuva, graupel, cristais, agregados (geralmente refere-se a neve). Além disso eles apresentam os limites das subdivisões das espécies gerais de hidrometeoro, gotas pequenas, gotas médias e grandes gotas de chuva.

Em Ryzhkov et al. [2005] usaram um radar polarimétrico Doppler (WSR - 880) e fazem uma demonstração operacional da sua utilidade. Com o uso dos algoritmos convencionais e polarimétricos estruturam os totais de chuva de uma hora e são comparados com as acumulações horárias medidas. Além disso, foi desenvolvido um algoritmo de precipitação para a estrutura da mesma, que mostra um melhor desempenho em relação aos erros de calibração do radar, variação da distribuição do tamanho da gota, incertezas das formas de gotas de chuva, e a possível presença de granizo. Eles encontraram uma grande variedade de regimes de chuva decorrentes a diferentes distribuições de chuva. A partir dos valores do fator de refletividade do radar e refletividade diferencial se podem conhecer as propriedades microfísicas da chuva. Eles concluíram que as gotas de chuva para a parte estratiforme da tempestades geralmente se originam a partir de grandes flocos de neve na camada de derretimento, e no caso da parte convectiva fraca são dominadas por gotas produzidas a partir do graupel de menor tamanho.

Dolan and Rutledge [2009]) utilizam a lógica fuzzy para desenvolver um novo algoritmo de identificação de hidrometeoros para dados de radar polarimétrico de banda X, usando simulações de espalhamento para determinar os valores das variáveis polarimétricas para sete diferentes tipos de hidrometeoros (garoa, chuva, agregados, cristais de gelo, graupel de baixa densidade, graupel de alta densidade e gelo alinhado verticalmente). Eles compararam as simulações feitas com simulações de radar banda S. Para comprimentos de ondas mais curtas foram observados efeitos de não espalhamento de Rayleigh, fundamentalmente para chuva e graupel. Também mostram o valor das variáveis polarimétricas na identificação da chuva acima da camada de derretimento, fazendo uma diferença entre os hidrometeoros congelados, por exemplo, graupel e agregados, e possibilitando a distinção de gelo verticalmente alinhado.

Basicamente, as variáveis polarimétricas tais como refletividade horizontal e vertical, fase diferencial, fase diferencial específica e correlação entre as polarizações horizontal e vertical conseguem descrever de certa maneira a oblaticidade do hidrometeoro (forma), o tamanho e até o tipo de hidrometeoro. 


\subsection{Formação dos hidrometeoros.}

Quando uma parcela de ar não saturada (Umidade Relativa, UR <100 \%) ascende ela sofre expansão adiabática de acordo com a primeira lei da termodinâmica, diminuindo a temperatura. Se a parcela de ar atinge a saturação $(\mathrm{UR}=100 \%)$, uma nuvem pode-se formar através da condensação do vapor de água sobre núcleos de condensação de nuvens. Com a contínua ascensão, pode haver um aumento da supersaturação(excesso de umidade relativa em relação ao valor de equilíbrio do 100\%), gerada pela corrente ascendente, logo que os núcleos de condensação menores podem ser ativados. Portanto, inicialmente a nuvem crescerá pelo processo de condensação. A medida que as gotículas atingem raios maiores de $20 \mu m$, aumenta-se a probabilidade de colisão entre elas. Logo, o processo de colisão seguido de coalescência torna-se eficiente, o que pode levar a um tamanho precipitável. Se a parcela de ar continua ascendendo e atinge temperaturas abaixo de $0^{\circ} \mathrm{C}$ podemos ter a formação de cristais de gelo a partir da sublimação de vapor de água sobre núcleos de gelo ou mesmo através do congelamento das gotículas de água superresfriada, ou seja, a formação do graupel (Mason [1971]). De acordo com Mason [1971] a temperatura do ar e a supersaturação presente definem o tipo de cristal de gelo a ser formado, figura 1.1, durante o processo de sublimação.

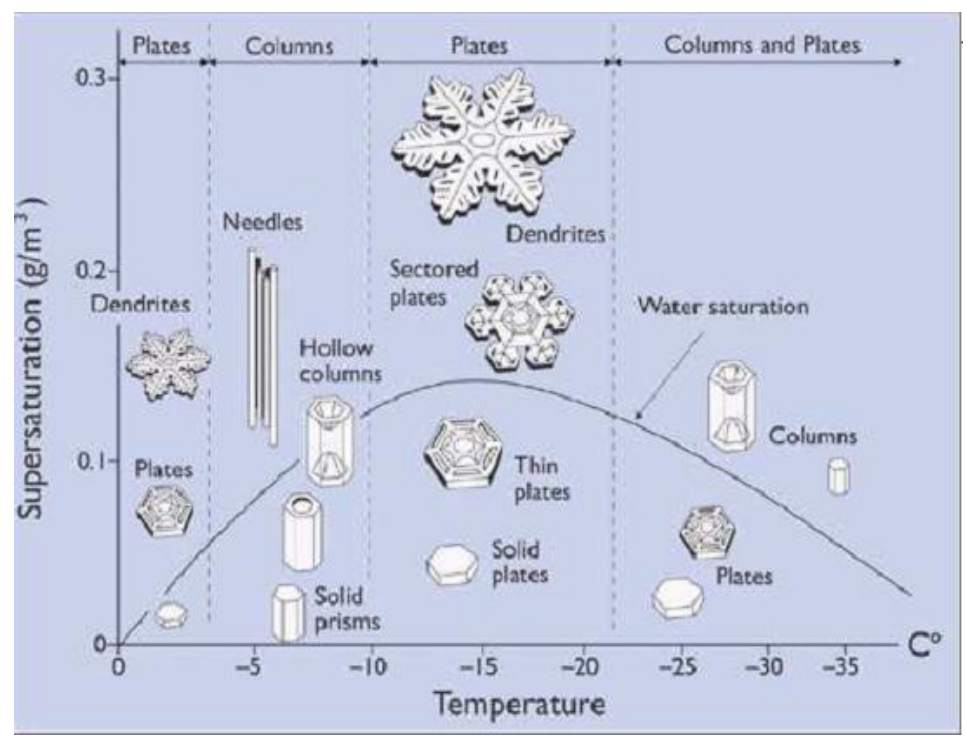

Figura 1.1: Habitat de formação dos cristais de gelo em função da supersaturação e da temperatura. Fonte: Mason [1971] 
Tal qual as gotículas de água os cristais de gelo também podem colidir após um certo tamanho. Quando a colisão é entre cristais de gelo temos a agregação e quando é entre cristais de gelo e gotículas de água super-resfriada temos a acreção, o que aumenta a diversidade de cristais de gelo dentro de uma nuvem, que podem ser em formas de prismas, pratos, dendrites, colunas, agulhas, cristais singulares, etc. Finalmente, se a parcela de ar ascender a níveis mais altos ainda, as gotículas de água super-resfriada desaparecem (evaporação, congelamento ou acreção) e os processos de nucleação do gelo e colisão seguida de agregação predominam, em geral acima da isoterma de $-30^{\circ} \mathrm{C}$.

\subsection{Algoritmo de Identifição dos Hidrometeoros}

Os algoritmos de identificação de hidrometeoros baseados em medidas polarimétricas foram essencialmente aplicados em radares Banda S (Vivekanandan et al. [1991]; Straka et al. [2000]; Liu and Chandrasekar [2000]). Eles fazem a classificação de hidrometeoros a partir da lógica fuzzy e uma rede neural. Eles usaram a refletividade horizontal $\left(Z_{H}\right)$, refletividade diferencial $\left(Z_{D R}\right)$, fase diferencial especifica $\left(K_{D P}\right)$, coeficiente de correlação $\left(\rho_{H V}\right)$ e razão de despolarização linear $(L D R)$ e a altitude correspondente, medidas do radar, usadas como entrada para a rede neuro-fuzzy. Quando eles fizeram as comparações da classificação feita concluíram que os resultados obtidos estavam em concordância com as medidas in situ realizadas. Este algoritmo neuro-fuzzy tem os seguintes hidrometeoros: garoa, chuva, neve seca, cristais de gelo seco, neve molhada e derretido, graupel seco, graupel úmido, granizo e uma mistura de chuva e granizo.

Ryzhkov and Zrnic [2005] fizeram simulações das variáveis polarimétricas para radares bandas $C$ e $X$ com base nos campos medidos obtidos a partir do radar $W S R-88 D$ de dupla polarização, para abordar os problemas mais comuns dos efeitos da atenuação, do espalhamento, da ressonância, etc, relacionados com os comprimentos de onda mais curtos. Eles fazem correção de atenuação usando a fase diferencial $\left(\phi_{D P}\right)$, usam a refletividade diferencial $\left(Z_{D R}\right)$ e o coeficiente de correlação $\left(\rho_{H V}\right)$ para a classificação de hidrometeoros e fazem comparações entre os valores de $Z_{D R}$ obtidos da banda $C$ e banda $X$, os quais são superiores aos valores obtidos para o banda S. Eles concluíram que $\rho_{H V}$ decai no caso do radar banda $\mathrm{C}$ em presença de gotas grandes. Além disso, observaram que podem ser identificadas mais eficientemente as áreas com gotas grandes associadas a correntes ascendentes ou granizo derretendo, com as medidas polarimétricas do banda $C$. 
Tessendorf et al. [2005] usam o algoritmo de classificação de lógica fuzzy adaptada de Liu and Chandrasekar [2000] e Straka et al. [2000]. Eles usam os dados de radar polarimétrico banda $S$ unido com um modelo de crescimento de partículas, examinando a evolução das propriedades cinemáticas e microfísicas. São apresentados, além dos ventos derivados do Doppler e a refletividade do radar, as classificações de hidrometeoros. Eles observaram que as tempestades estudadas, com estrutura supercelular com forte fluxo de curvatura cíclica nos níveis baixos, com um núcleo de corrente ascendente, possibilitam que o graupel e o granizo cresçam ao longo da corrente ascendente, a partir de gotas milimétricas. Além disso indicaram a presença de gotas grandes de água líquida em lugares onde poderiam crescer granizo. Encontraram que as taxas de crescimento das partículas milimétricas podem ser rápidas para que elas possam alcançar tamanhos de precipitação e granizo antes de passar pela camada de água líquida das nuvens altas. Também descrevem quatro condições básicas a partir dos cálculos de crescimento da precipitação, para que as tempestades produzam granizo: presença de partículas milimétricas, deve haver um mecanismo de transporte destas partículas em correntes ascendentes, o fluxo ascendente deve ter um tamanho e intensidade suficiente para fazer crescer essas partículas como granizos e os ventos horizontais devem manter as partículas em crescimento.

A técnica mais adequada e mais utilizada nos radares para o problema da identificação dos hidrometeoros talvez seja a lógica fuzzy. Para comprimentos de onda mais curtos, como a banda X, existe um desafio maior devido aos efeitos do não espalhamento Rayleigh e a atenuação de chuva presente, que geralmente podem ser desprezv́eis na banda S.

A transição para fora do regime de espalhamento Rayleigh é fortemente dependente do comprimento de onda e do tamanho de hidrometeoro, mas também depende da fase do hidrometeoro, devido às alterações nas constantes dieléctricas de água e de gelo(Dolan and Rutledge [2009]).

Dolan and Rutledge [2009] realizaram simulações que caracterizam o comportamento de espalhamento Rayleigh e Mie, usando os modelos T-matrix e Mueller-matrix Vivekanandan et al. [1991]. O modelo T-matrix toma as características microfísicas dos hidrometeoros (diâmetro, temperatura, etc.) e calcula a seção transversal de espalhamento para um comprimento de onda específico. O modelo Mueller-matrix calcula as variáveis do radar (refletividade, refletividade diferencial, fase diferencia especifica, etc.) para uma distribuição de hidrometeoros definidas em volume específico a partir das seções transversais e os retroespalhamento calculado no T-matrix. Eles determinaram a partir de um novo 
algoritmo de identificação de hidrometeoro baseado na logica fuzzy e usando as simulações teóricas de retroespalhamento, um intervalo aproximado das variáveis polarimétricas para sete tipos de hidrometeoros.

\subsection{Caracterização das nuvens no Brasil.}

Na última década foram realizados diferentes experimentos e projetos no Brasil a fim de investigar os processos meteorológicos que predominam na região, validar os modelos de estimativa de precipitação e caracterizar os hidrometeoros e nuvens.

No Amazon Boundary Layer Experiment (Garstang et al. [n.d.]), foram examinados processos meteorológicos responsáveis pelo transporte vertical e horizontal. Eles mostraram duas nuvens características, uma com formação linear que desenvolveu uma estrutura mais celular e outra com uma estrutura linear durante toda a missão. Eles observaram que os movimentos descendentes na superfície; no momento da altura máxima do topo da nuvem, a convenção perde parte de sua estrutura linear para outras células que se desenvolvem ao redor da linha original.

Em Fevereiro-Junho de 1994, foram realizadas campanhas experimentais no Estado de Ceará, Brasil. Os dados foram obtidos a partir das medidas in situ em nuvens cúmulos usando um avião instrumentado da FUNCEME (ALPA-Avião Laboratório para Pesquisas Atmosféricas, Almeida et al. [1992]). Costa et al. [2000] observaram diferenças significativas em relação à concentração de gotas e à forma do espectro para as nuvens marítimas, costeiras, continentais e urbanas. Eles propuseram, para a região metropolitana de Fortaleza, uma classificação de nuvens levando em conta os efeitos urbanos sem considerar as nuvens costeiras. As características microfísicas das nuvens urbanas variam entre nuvens marítimas moderadas e poluídas.

Geralmente, nas nuvens estudadas durante a campanha de campo os valores do conteúdo máximo de água líquida foram baixos. Isto indica que só uma pequena fração corresponde a uma corrente ascendente adiabática ativa. Além disso, pode indicar a intensificação da produção de aerossóis em Fortaleza(Costa et al. [2000]).

Já em 1999, no Estado de Rondônia, foi realizado o Large Scale Biosphere-Atmospheric Experiment, como parte de Tropical Rainfall Measuring Mission (TRMM), nos meses de 
Janeiro e Fevereiro. Durante este experimentos diversos voos foram realizados. Stith et al. [2004] mostraram que a maior variação na estrutura vertical de precipitação ocorre acima do nível de congelamento. Além disso as nuvens convectivas tropicais congelam mais rápido quando estão acima do nível de congelamento e que a água líquida presente é removida nos níveis médios dessas nuvens. Eles indicaram que as correntes ascendentes nos níveis baixos de nuvens tropicais são geralmente fracas, ou seja, permitindo que o processo de chuva quente produza precipitação. Além disso, eles encontram que as correntes ascendentes são mais fortes quando as gotículas de água estão presentes e levam água líquida para altitudes mais altas devido à liberação de calor latente do processo de congelamento.

Mais tarde em 2002, com o objetivo de compreender a convecção durante a transição entre os períodos seco e chuvoso, e impacto dos aerossóis de queimadas na formação das nuvens e precipitação, foi feita a campanha DrytoWet/RACCI(Radiation, Cloud and Climate Interactions) (Silva Dias et al. [2005]). Com as observações destas campanhas, definiu-se a estrutura interna características das nuvens para cada período, baseadas nas distribuições dos hidrometeoros observados.

Finalmente ao longo dos anos 2010 - 2014, foi realizado o projeto CHUVA que conduziu uma series campanhas no Brasil com o objectivo de compreender os sistemas precipitantes atuantes. Como parte deste projeto foi feito de maneira preliminar a campanha em Alcântara, Maranhão, entre o 1 - 25 de Março do ano 2010. Nesta região, a precipitação está diretamente relacionada com a formação de nuvens quentes, as quais são o centro do experimento. Neste experimento foi utilizado, além dos instrumentos do projeto CHUVA, o Advanced Microwave Radiometer for Rain Identification(ADMIRARI), Battaglia et al. [n.d.]. Durante as medições foram observadas no primeiro período nuvens dispersas e chuvas escassas devido à convecção suprimida. O segundo período, coincidiu com o início do período chuvoso, caracterizado geralmente por processos de convecção local isolada, com predomínio de nuvens quentes. No último período do experimento, observaram convecção intensa com convecção quente e profunda(nuvens frias, ou seja, na fase de gelo), Machado, L. A. et al. [2014].

Foi feita a campanha ACRIDICON, entre o 1 de Setembro e o 4 e Outubro de 2014, fazendo medições de avião e sensoramento remoto em Manaus(Wendisch,M. et. al [2016]). O projeto tinha como objetivo principal de estudar a evolução das nuvens convectivas 
tropicais sobre o Brasil e investigar a interação com as partículas de aerossol, gases trazes, etc., a partir da realização de 14 voos científicos com o HALO (High Altitude and Long-Range Research Aircraft). Eles observaram que em um ambiente limpo as nuvens crescem e formam chuva, e no caso da nuvem convectiva poluída as gotas não coalescem e formam gotas pequenas de precipitação insignificantes. Concluíram que as nuvens limpas contêm menos gotas pequenas que grandes em comparação com as nuvens convectivas poluídas(Wendisch,M. et. al [2016]).

\subsection{Motivação e objetivos.}

No transcurso dos anos diversos estudos tem demonstrado que a representação dos processo microfísicos possuem un papel fundamental nos modelos de previsão. Especificamente, eles conseguem quantificar as transformações de calor latente para calor sensível e vice-versa, o que impacta no desenvolvimento das tempestades. Estes esquemas microfísicos levam em conta a distribuição de tamanho dos diferentes tipos de hidrometeoros e a interação entre eles. Logo, a correta validação destes esquemas vai depender de uma identificação exata dos hidrometeoros nas tempestades simuladas.

O reconhecimento de hidrometeoros potencialmente perigosos, como os granizos de grande tamanho, servem na previsão imediata de tempestades severas. Estas previsões são particularmente úteis na região sul do Brasil, onde é frequente o desenvolvimento de sistemas convectivos intensos. Além disso, através destes métodos de identificação é possível determinar o tipo de precipitação e as áreas de transição entre diferentes hidrometeoros.

O uso do radar permite fazer uma estimativa de precipitação, que é obtida selecionando uma boa relação polarimétrica para quantificar a precipitação através de relações como $Z-R$, onde $Z$ é o fator de refletividade do radar $\left(m m^{6} / m^{3}\right)$ e $R$ é a taxa de precipitação(Marshall and Palmer [1948]). No entanto, na estimativa de precipitação com radar pode ser afetada quando o volume iluminado pelo feixe do radar contém hidrometeoros sólidos como o granizo. Pelo que a identificação deste tipo de hidrometeoro contribuiria na melhora da estimativa de precipitação.

Os hidrometeoros também são importantes na deposição úmida, que consiste na remoção dos poluentes por gotículas de nuvem, gotas de chuva, cristais de gelo, neve, etc. A 
deposição úmida é importante no transporte de poluentes atmosféricos e se a nuvem tem maior altura e maior tempo de precipitação, a remoção será maior e mais eficiente.

Além disso, ao longo dos anos tem sido estudados os mecanismos de eletrificação das tempestades. A partir de estes estudos conhece-se que o carregamento elétrico das tempestades surge como consequência da transferência de cargas nas colisões entre hidrometeoros como o graupel e os cristais de gelo. Porem, ainda existe grandes incertezas nos processos microfísicos que determinam a polaridade e a quantidade de carga transferida apos as colisões. Sendo que muitas das hipóteses desenvolvidas para explicar estes processos estão baseadas em experimentos de laboratórios devido a dificuldade de fazer observações acuradas nas tempestades.

Apesar dos aviões usados para fazer as medições nas campanhas e os experimentos antes ditos conseguirem caracterizar os hidrometeoros in situ, a logística e o tipo de amostragem não permitem descrever a evolução temporal dos hidrometeoros, por tanto técnicas de sensoriamento remoto são úteis para descrever estas características. Sendo assim, baseado no fato que foram coletadas medidas polarimétricas em diversos sistemas precipitantes do Brasil, este projeto se propõe a fazer como objetivo principal, uma caracterização da distribuição vertical dos hidrometeoros em função do tipo de sistema precipitante (isolados, frentes, linhas de instabilidade, etc.) a partir de um radar polarimétrico Doppler Banda X. Os objetivos secundários são:

- Através da literatura estudar a fundamentação teórica e a metodologia para aplicar os modelos T-matrix e Mueller-matrix usando o radar polarimétrico banda $X$.

- Simular casos específicos usando diferentes hidrometeoros.

- Avaliar o algoritmo de classificação de hidrometeoro.

Entretanto, para testar o conceito, este estudo ficará restrito somente as medidas do Vale do Paraíba, campanha feita durante a realização do projeto CHUVA. 


\section{CAPÍTULO 2}

\section{RADAR: PRINCIPAIS ELEMENTOS.}

\subsection{Funcionamento do RADAR}

O RADAR (Radio Detection and Ranging) é um dispositivo que é usado como um sistema para a detecção, localização e caracterização de objetos por meio da transmissão e recepção de ondas eletromagnéticas em micro-ondas. Os objetos detectados têm uma ampla gama de tamanhos, desde um avião de passageiros até as gotas de chuvas.

O princípio fundamental de funcionamento de um radar é o de emitir uma onda eletromagnética em uma direção determinada e a medida que o feixe atinge objetos na atmosfera, a energia é espalhada pelo alvo e uma parte dela retorna para o radar. Esta fração de energia é proporcional à secção transversal de retro-espalhamento, que está relacionado ao tamanho da partícula, figura 2.1.

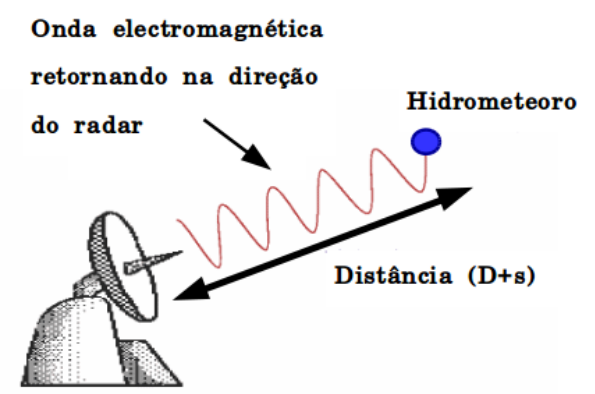

Figura 2.1: Funcionamento do radar. Fonte:(Autores [2017] 


\subsubsection{Espalhamento}

O espalhamento é um processo físico que ocorre quando as ondas eletromagnéticas são interferidas ao incidir sobre partículas ou alvos. O espalhamento (difusão ou dispersão) corresponde a uma mudança aleatória da direção de propagação das ondas electromagnéticas devido a sua interação com os componentes que se encontram em seu caminho. A suposição comum é que a onda espalhada não é atenuada, mas sim redirecionada.

O espalhamento depende fundamentalmente das características físicas das partículas espalhadoras, assim por exemplo, o tamanho, a forma, a composição, as propriedades elétricas e também do comprimento de onda da sinal de microondas que interage com as partículas. Porém o espalhamento pode apresentar variações: retroespalhamento e espalhamento frontal.

\subsubsection{Espalhamento Rayleigh e Mie}

Dentro da região de microondas existem 3 tipos de espalhamento: óptico, Mie e Rayleigh.

Quando o tamanho da partícula é muito maior que o comprimento de onda, o espalhamento pode ser determinado usando as leis da óptica geométrico. Nesta região são determinantes as leis clássicas de reflexão, refração e absorção da luz, onde tem um papel importante o ângulo de incidência da onda na partícula, o índice de refração e as propriedades absorbentes da partícula. A intensidade da onda espalhada é proporcional ao quadrado fotor e forma $x=\frac{2 \pi a_{p}}{\lambda}$, onde $a_{p}$ é o tamanho da partícula e $\lambda$ é o comprimento de onda da onda incidente.

Quando as dimensões das partículas são proporcionais ao comprimento de onda, ocorre o espalhamento de Mie. O espalhamento neste regime não é igual em todas as direções (figura 2.2(a)). A teoria de espalhamento Mie é necessária para partículas espalhadas com área igual a $1 / 10$ ou maior que o comprimento de onda.

Já na região onde o diâmetro $(D)$ é pequeno comparado com o comprimento de onda do radar $(\pi D / \lambda<<1)$, temos regime de espalhamento Rayleigh. Nesta região a seção transversal do hidrometeoro é considerado quase isotrópico (figura 2.2(b)). 
Espalhamento Mie
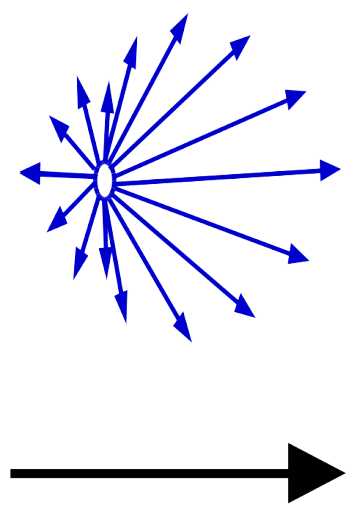

Direção da onda incidente

\section{Espalhamento Rayleigh}
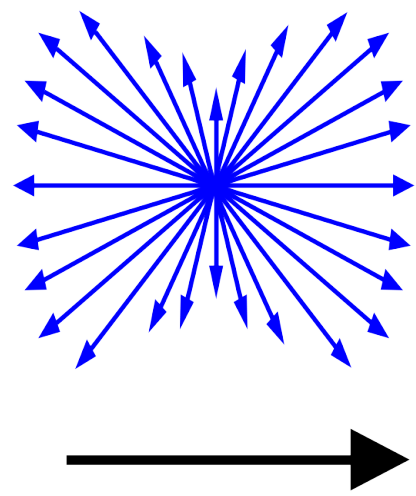

Direção da onda incidente

(a)

(b)

FigurA 2.2: Espalhamentos sobre uma partícula. (a)Espalhamento Mie; (b) Espalhamento Rayleigh.

Para ilustrar melhor os regimes de espalhamento a figura 2.3 mostra um esquema entre o tamanho aproximado das partículas espalhadoras observadas pelo radar e o $\lambda$ da onda incidente.

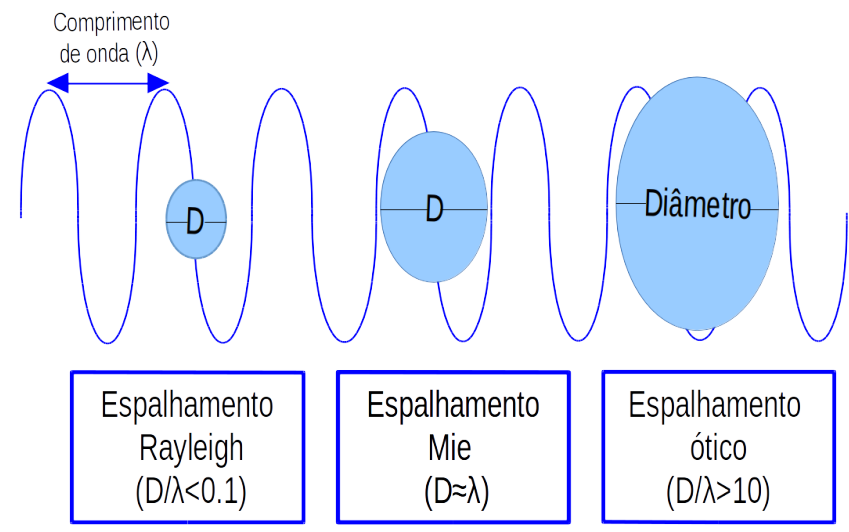

Figura 2.3: Partículas espalhadoras do radar em função do comprimento de onda e o diâmetro da partícula. Adaptado:(Navarro [2012] 
O espalhamento Rayleigh é aplicado para partículas de precipitação porque os diâmetros são menores que o comprimento de onda utilizado pelos radares. A energia recebida é espalhada em todas as direções, até mesmo na direção da onda incidente. A onda espalhada que retorna na mesma direção do radar, é conhecida como retroespalhamento e é utilizada para calcular a potencia de retorno e inferir as propriedades do alvo.

A relação entre o comprimento de onda e o tamanho da partícula, influi fortemente na forma de espalhamento. Não obstante, a aproximação de Rayleigh não pode ser aplicada quando as partículas são da mesmo ordem que o comprimento de onda do radar, porque neste caso a onda espalhada pelo alvo não é a mesma em todas as direções, ou seja não é isotrópica, logo de espalhamento Mie (Fukao et al. [2014]). As partículas de precipitação, ou seja, as partículas espalhadoras absorvem e transformam uma parte da onda incidente, e dispersam o resto em todas as direções como radiação.

Quando a dispersão tem uma direção oposta ao da onda incidente temos retroespalhamento. Portanto, define-se como seção transversal de retroespalhamento, $\sigma$, como a seção transversal de uma partícula que espalha isotropicamente e retorna a mesma potência para o radar como o alvo.

A partir da teoria de espalhamento Mie, considerando que o alvo absorve e espalha, a seção transversal de retroespalhamento pode ser expressa como:

$$
\sigma=\frac{\lambda^{2}}{4 \pi}\left|\sum_{n=1}^{\infty}(-1)^{n}(2 n+1)\left(a_{n}+b_{n}\right)\right|^{2} \quad\left[m^{2}\right]
$$

onde $a_{n}$ e $b_{n}$ são os coeficientes de Mie que tem dependência com o diâmetro e do índice de refração complexo, $m$ da partícula (Fukao et al. [2014]).

Considerando a aproximação Rayleigh, quando o raio da partícula é muito menor que o comprimento de onda do radar, a seção transversal de espalhamento pode ser expressa como:

$$
\sigma_{i}=\frac{\pi^{5}}{\lambda^{4}}|K|^{2} D_{i}^{6}
$$

onde $D_{i}$ é o diâmetro da partícula e $K$ e o índice de refração das partículas dado por: 


$$
K=\frac{m^{2}-1}{m^{2}+2}
$$

A partir de distribuição do tamanho das gotas, pode-se obter a refletividade do radar a partir da seção de retroespalhamento por unidade de volume(Fukao et al. [2014]). Sendo assim pode-se definir o fator de refletividade do radar como:

$$
Z=\int_{0}^{\infty} N(D) D^{6} d D \quad\left[\frac{m m^{6}}{m^{3}}\right]
$$

onde $N(D)$ é a distribuição do número de gotas com diâmetro $D$ do volume observado.

\subsubsection{Atenuação}

Quando a onda electromagnética interage com partículas de nuvens e precipitação podem existir perdas de potência na sua propagação. Basicamente quando uma partícula esférica é atingida pelo sinal do radar, parte da energia é absorvida e parte é espalhada causando sua atenuação e até extinção.

A atenuação depende das condições atmosféricas e da frequência do radar, por isso para os radares meteorológicos é significativa, o que pode provocar limitações nas observações feitas(Fukao et al. [2014]). Tem-se maior atenuação quando ao longo do percurso tem uma quantidade maior de hidrometeoros.

As partículas de nuvens e de precipitação podem provocar atenuação, devido as secções transversais de espalhamento e absorção, que pode ser significativa quando, por exemplo sob condições de chuvas fortes, entram no regime Mie. Como os radares polarimétricos transmitem radiação electromagnética em diversas polarizações, quando os hidrometeoros não são esféricos, a atenuação é distinta para cada polarização. Sendo assim que para radares de dupla polarização, a polarização horizontal atenuará mais rápido que a vertical, quando os hidrometeoros são oblatos, logo o fator refletividade diferencial do radar terá uma tendencia negativa quando a atenuação por chuva aumenta. 


\subsection{Propagação de onda electromagnética e polarização}

O campo electromagnético é gerado pela combinação dos campos elétricos e magnéticos. A eletrostática é o ramo da física que estuda o campo elétrico constante e estabelece que é produzido a partir de uma distribuição de cargas invariantes com o tempo. Por outro lado a magnetostática estuda o campo magnético constante produzido pelo movimento de cargas elétricas através de correntes elétricas. Para campos variáveis, a interpretação física é um pouco mais complexa, já que o campo elétrico, por exemplo, depende da distribuição de cargas mas também da variação do campo magnético, o qual, por sua vez, depende das correntes elétricas e do campo elétrico. O acoplamento do campos elétrico e magnéticos é explicado pelas equações de Maxwell (Fukao et al. [2014]).

$$
\begin{array}{r}
\nabla \times \mathbf{E}=-\frac{\partial}{\partial t} \mathbf{B}\left(\frac{V}{m^{2}}\right), \\
\nabla \times \mathbf{H}=-\frac{\partial}{\partial t} \mathbf{D}+\mathbf{J}\left(\frac{A}{m^{2}}\right), \\
\nabla \cdot \mathbf{D}=\rho\left(\frac{C}{m^{3}}\right), \\
\nabla \cdot \mathbf{B}=0\left(\frac{T}{m}\right) .
\end{array}
$$

Onde $\mathbf{E}$ é o campo elétrico, $\mathbf{B}$ o campo magnético, $\mathbf{J}$ a densidade de corrente elétrica, $\mathbf{D}$ o campo de deslocamento elétrico, $\mathbf{H}$ o campo magnético auxiliar e $\rho$ a densidade de carga elétrica. Os vetores anteriores são relacionados por:

$$
\begin{gathered}
\mathbf{D}=\varepsilon \mathbf{E}, \\
\mathbf{B}=\mu \mathbf{H}, \\
\mathbf{J}=\sigma \mathbf{E} .
\end{gathered}
$$

Sendo $\varepsilon$ a permissividade do meio, $\mu$ a permeabilidade do meio e $\sigma$ a condutividade elétrica. 
No vácuo a onda electromagnética se propaga na velocidade da luz, mas quando entra em meio diferente do vácuo, as moléculas interagem com a onda electromagnética e a velocidade de propagação será menor que a da luz no vácuo. As ondas eletromagnéticas podem interagir de diferentes maneiras: absorção, reflexão, refração, difração e espalhamento.

Um importante resultado das equações de Maxwell é que elas podem ser reduzidas a equações de ondas transversais com campos elétricos e magnéticos por separados. Por exemplo, uma onda electromagnética plana que se propague na direção do eixo $x$, o campo elétrico é perpendicular esta direção e o campo magnético $\boldsymbol{B}$ é perpendicular a $\boldsymbol{E}$. Essa onda é chamada plana porque o vetor $\tilde{\mathbf{E}}$ elétrico tem o mesmo valor em todos os pontos de qualquer plano perpendicular à direção do movimento.

Uma onda transversal é chamada polarizada quando o vetor do campo eléctrico $\tilde{\mathbf{E}}$ (por tanto do campo magnético também $\mathbf{B}$ ), oscila no plano perpendicular à direcção de propagação da onda. Para o caso dos radares meteorológicos, é muito importante a polarização linear, que acontece quando o campo elétrico sempre oscila no mesmo plano que contém o campo de propagação da onda. Quando esse plano é horizontal temos a polarização horizontal e quando é vertical a polarização é vertical (figura 2.4).

A polarimetria foi introduzida inicialmente por Seliga and Bringi [1976] com o objetivo de melhorar a estimativa de precipitação, pois as secções transversais do retroespalhamento horizontal e vertical caracterizavam os hidrometeoros. A partir das medidas na polarização horizontal e vertical é possível inferir sobre a forma e a orientação dos hidrometeoros e sobre os alvos não meteorológicos, (Meischner [2003]). 


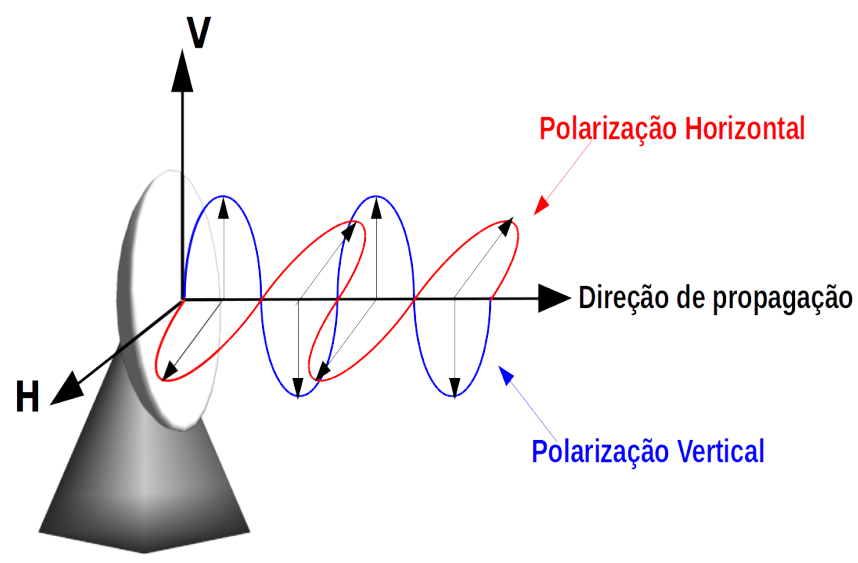

Figura 2.4: Esquema de emisão de um radar de dupla-palarização. Adaptado da fonte: NSSL/NOAA.

Dessa forma, os radares com polarização diversificada podem estimar diversas propriedades do sinal retroespalhado, ao contrário dos radares convencionais que tem somente uma polarização horizontal ou vertical. Se considera um radar de dupla polarização linear quando é possível transmitir e receber polarização horizontal $(\boldsymbol{H})$ e vertical $(\boldsymbol{V})$.

Além das melhoras na estimativa de chuva, (Zrnic and Ryzhkov [1999]), as medidas polarimétricas podem ser usadas para discriminar granizo, identificar tipos de hidrometeoros, assim como determinar se são espalhadores biológicos(insetos e pássaros).

\subsubsection{Variáveis polarimétricas}

As variáveis polarimétricas são sensíveis ao tamanho, forma, orientação, densidade e conteúdo de água líquida dos hidrometeoros, e por exibirem assinaturas específicas que podem auxiliar a estimativa do conteúdo de hidrometeoros presentes nas nuvens.

De acordo com Bringi [2001] podemos destacar as seguintes variáveis polarimétricas, definidas por

- Fator Refletividade do Radar (Z): é proporcional à energia espalhada pelo volume amostrado, ou seja, é a soma da sexta potência dos diâmetros de todas as 
gotas contidas nesse volume. $Z$ depende do diâmetro da partícula e do número de partículas contido no volume amostrado (equação 2.4).

Além do tamanho, forma e concentração, $Z$ também depende das propriedades dielétricas e está relacionada pelo índice de refracção, $|\kappa|^{2}$. Para água líquida é 0.93 e para o gelo é 0.197 .

- Refletividade diferencial $\left(Z_{D R}\right)$ : razão entre as refletividades horizontal e vertical para um dado volume iluminado pelo radar que transmite na polarização horizontal e vertical.

Indica a proporção média entre os eixos horizontal e vertical dos hidrometeoros.

$$
Z_{D R}=10 \log \left[\frac{Z_{h h}}{Z_{v v}}\right] \quad[d B]
$$

onde:

$Z_{h h}=$ Refletividade do volume iluminado pelo feixe com polarização horizontal recebido pelo canal horizontal, $\left[\mathrm{mm}^{6} / \mathrm{m}^{3}\right]$.

$Z_{v v}=$ Refletividade do volume iluminado pelo feixe com polarização vertical recebido pelo canal vertical, $\left[\mathrm{mm}^{6} / \mathrm{m}^{3}\right]$.

Como $Z_{D R}$ é uma relação entre os eixos vertical e horizontal dos alvos, que para alvos esféricos(gotas de chuva pequenas) o valor de $Z_{D R}$ é zero perto de zero. Para alvos que tem maior área horizontal(gotas grandes, flocos de neve molhada ou cristais de neve) o $Z_{D R}$ é positivo, mas se a orientação do eixo maior é vertical o valor de $Z_{D R}$ é negativo(Bringi [2001]).

A figura 2.5, ilustra um exemplo de $Z_{D R}$ para uma simulação de chuva levando em conta um aumento do fator de refletividade. Neste caso, para valores de refletividade menores, o valor de $Z_{D R}$ é perto de zero ou zero, ou seja as gotas são pequenas e esféricas. Com o aumento do tamanho das gotas de chuva, elas se formam mais oblatas, logo aumentando a refletividade e o $Z_{D R}$. 


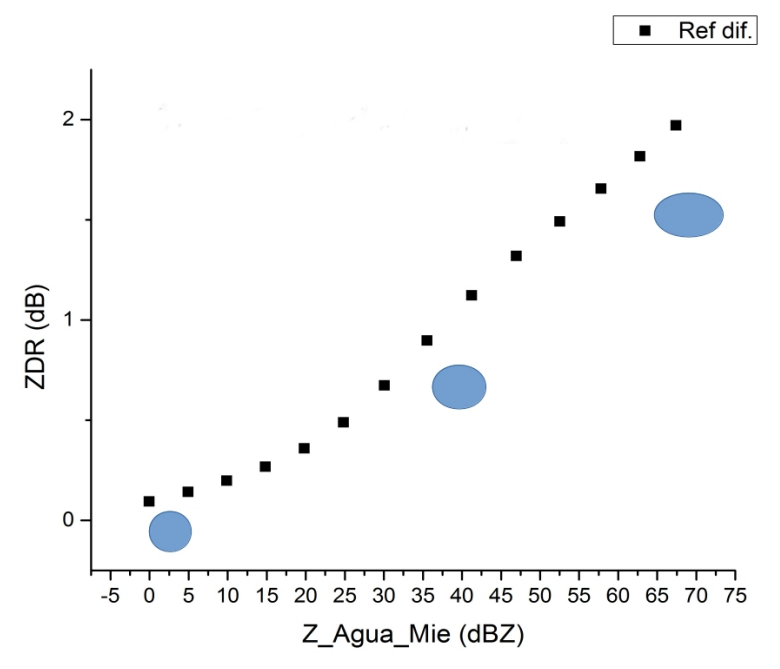

Figura 2.5: Refletividade diferencial(chuva).(Fonte: Yusvelis Barzaga)

- Fase diferencial $\left(\Phi_{D P}\right)$ : diferença de fase entre a onda eletromagnética com polarização horizontal e vertical ao longo da trajetória do feixe.

$$
\Phi_{D P}=\Phi_{h}(r)-\Phi_{v}(r) \quad\left[{ }^{\circ}\right]
$$

onde: $\Phi_{h}(r)=$ Fase do feixe de onda eletromagnética com polarização horizontal numa dada distância do radar (r).

$\Phi_{v}(r)=$ Fase do feixe de onda eletromagnética com polarização vertical numa dada distância do radar $(\mathrm{r})$.

A diferença de fase, está associada com a velocidade de fase da onda em que se propaga no meio e interage com os alvos. Se $\Phi_{h}(r)$ e $\Phi_{v}(r)$ são iguais então o alvo é isotrópico. Porém, se são diferentes então são consideradas partículas não isotrópicas.

Na figura 2.6 é possível observar duas ondas se propagando no meio. A onda com polarimetria vertical se propaga mais rápido que a horizontal. Como a velocidade de fase está associada com o meio, temos que existe muito mais a fase na polarização horizontal do que na vertical, assim $\Phi_{D P}>0$. Portanto, quanto maior o atraso maior o volume de chuva. Além disso, $\Phi_{D P}$ também depende da orientação. 


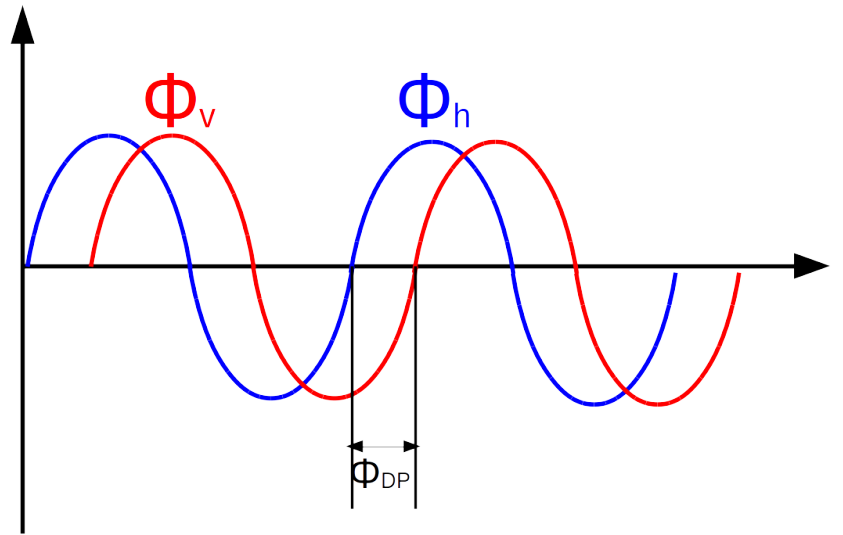

Figura 2.6: Fase diferencial para uma gota de chuva.(Fonte: Yusvelis Barzaga)

- Fase diferencial específica $\left(K_{D P}\right)$ : razão entre as diferenças fase diferencial na posição $r_{1}$ e $r_{2}$ e a distância ao longo da trajetória do feixe de onda eletromagnética, ou seja, é a mudança da fase diferencial por unidade de distância, entre os pontos $r_{1}$ e $r_{2}$.

$$
K_{D P}=\frac{\Phi_{D P}\left(r_{2}\right)-\Phi_{D P}\left(r_{1}\right)}{2\left(r_{2}-r_{1}\right)} \quad[\% / k m]
$$

onde: $r_{2}, r_{1}=$ Distância ao radar $[\mathrm{km}]$ no ponto 1 e 2 (relacionados com o valor de ida e volta), tal que: $r_{2}>r_{1}$

Quando a onda electromagnética transita em um volume determinado que contém em seu interior hidrometeoros com orientação horizontal(chuva), a onda com polarização horizontal experimenta uma mudança de fase maior do que a onda vertical, $\operatorname{assim} K_{D P}$ tem valores positivos. Se as partículas estão orientadas verticalmente, a onda com polarização vertical sofre mais atraso, logo $K_{D P}$ tem valores menores que zero. Mas se os hidrometeoros são esféricos $K_{D P}$ tem valores próximos de zero. 


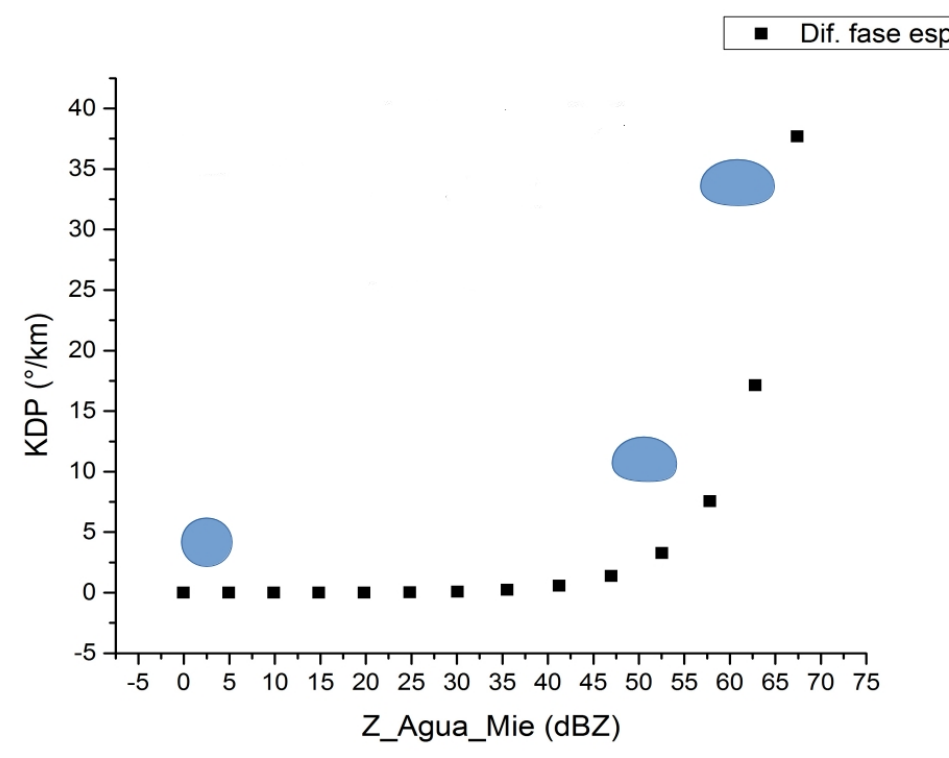

Figura 2.7: Fase diferencial especifica para uma simulação de chuva.(Fonte: Yusvelis Barzaga)

A figura 2.7, apresenta um exemplo $K_{D P}>0$. Nota-se que os valores de $K_{D P}$ estão perto de zero para valores baixos de fator de refletividade do radar, ou seja, as partículas esféricas pequenas. A medida que o tamanho das partículas aumenta os valores de $K_{D P}$ vão aumentando, o que pode indicar que as gotículas são oblatas. $K_{D P}$ é uma variável que não tem variação com a atenuação das ondas electromagnéticas do radar durante a propagação de fase e é muito importante para poder distinguir entre gotas e granizo.

- Coeficiente de Correlação $\left(\rho_{H V}\right)$ : é a correlação em um ponto no espaço determinado dos sinais horizontais e verticais polarizadas, ou seja, é o grau de concordância entre as medidas instantâneas de polarização vertical e horizontal.

Este coeficiente determina a correlação entre a refletividade horizontal e vertical devolvida pelo radar. Este coeficiente fornece informação dos diferentes tamanhos e orientação dos alvos contidos no volume iluminado pelo radar.

$\rho_{H V}$ oscila entre 0 e 1 . Quando os valores estão perto de 1 a região observada tem alvos com tamanho e formas homogêneas, ou seja, podem ser alvos esféricos. 
Entretanto, se o valor começa a decair até chegar a valores perto de zero, indica um aumento na mistura de hidrometeoros com diferentes formas e tamanhos.

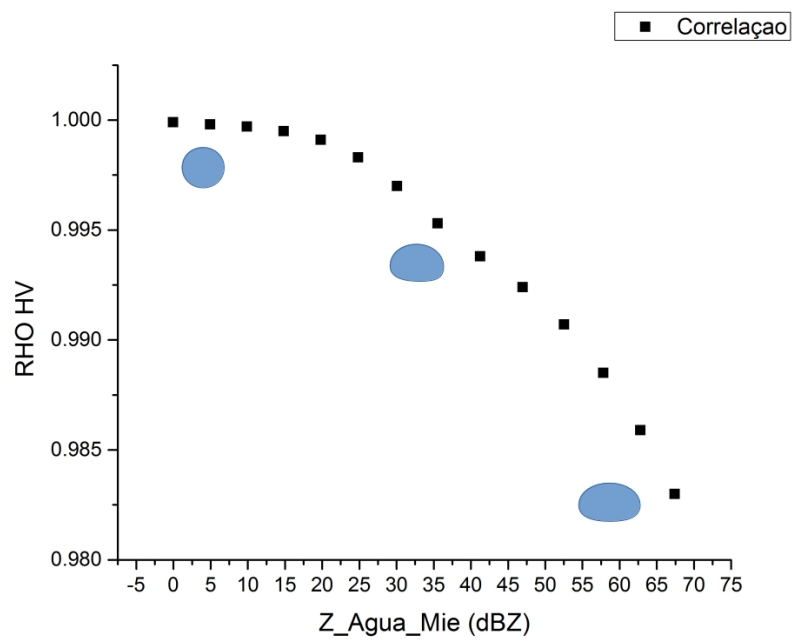

Figura 2.8: Coeficiente de correlação (chuva)(Fonte: Yusvelis Barzaga).

Na figura 2.8 é apresentado um exemplo do comportamento do coeficiente de correlação para a chuva onde a medida que $Z$ aumenta o coeficiente de correlação diminui.

A partir de $\rho_{H V}$, pode-se descrever as características físicas dos hidrometeoros, assim como as formas, suas inclinações e as misturas.

\subsection{Classificação de hidrometeoros.}

Como visto anteriormente as variáveis polarimétricas indicam algumas propriedades dos alvos, logo é possível inferir os hidrometeoros a partir de estas medidas. A identificação de hidrometeoros tem como objetivo encontrar padrões polarimétricos com características similares e mais relevantes, apesar de considerar as diferenças de forma e tamanho dos hidrometeoros.

Atualmente existem várias técnicas e algoritmos para fazer classificação de hidrometeoros usando dados de radar polarimétrico. Em geral usa-se a refletividade horizontal $\left(Z_{h}\right)$, a refletividade diferencial $\left(Z_{D R}\right)$, o coeficiente de correlação $\left(\rho_{H V}\right)$ e a fase diferencial 
especifica $\left(K_{D P}\right)$, para obter informações da precipitação, como por exemplo, que tipo de hidrometeoro ou mistura predomina em um volume iluminado(Vivekanandan et al. [1991], Ryzhkov and Zrnic [1998], Liu and Chandrasekar [2000], Straka et al. [2000], Dolan and Rutledge [2009]).

Neste sentido podemos destacar as seguintes metodologias: Bringi et al. [1984] usou a refletividade horizontal $\left(Z_{h}\right)$ e a refletividade diferencial $\left(Z_{D R}\right)$ para delimitar as zonas entre granizo e chuva em tempestades convectivas, assim como a detecção de granizo. Seus perfis verticais são efetivos para a classificação de graupel e granizo no centro da tempestade convectiva (Bringi, Rasmussen and Vivekanandan [1986], Bringi, Vivekanandan and Tuttle [1986]). Zrnic et al. [1993] usou a fase diferencial especifica $\left(K_{D P}\right)$ e o coeficiente de correlação $\left(\rho_{H V}\right)$ para detectar granizo e as misturas de hidrometeoros nas em tempestades severas.

Em geral os métodos e algoritmos de identificação dos hidrometeoros está baseada fundamentalmente em definir o número e o tipo de classes dos hidrometeoros para classificar. Logo, fazendo uso de simulações de espalhamento Mie para calcular as variações polarimétricas, as observações do radar podem ser associadas as classes dos hidrometeoros (Grazioli et al. [2015]).

Os principais algoritmos abordados por vários autores nas ultimas décadas são baseados fundamentalmente na utilização de diferentes técnicas(lógica fuzzy, neuro-fuzzy, estatística bayesiana, simulações teóricas), e para diferentes frequências pois existem diferentes respostas para cada um.

\subsubsection{Métodos e algoritmos de identificação para radar Banda $S$}

Straka et al. [2000] usaram um algoritmo de classificação baseado na lógica fuzzy para a partir dos dados do radar polarimétrico para fazer um resumo de informações baseadas nas observações e modelagem de assinatura dos hidrometeoros para deduzir seus tipos e quantidades, além disso fizeram a identificação, a estimação e a quantificação dos hidrometeoros baseados na espécie, tamanho, concentrações e quantidades. 
Vivekanandan et al. [1999] desenvolveram um classificador de chuva e granizo baseado na teoria de lógica fuzzy,usando as seguintes variáveis polarimétricas: a refletividade horizontal, a refletividade diferencial e a razão de depolarização linear $(L D R)$. A partir da implementação da lógica fuzzy entre tipos de precipitação fizeram uso de operações matemáticas simples, para implementar em tempo real. A aplicação de este método não é afetado de forma negativa pelos erros típicos de medição de algumas variáveis de entrada.

Liu and Chandrasekar [2000] desenvolveram uma lógica fuzzy acoplada a classificação de redes neurais. Este algoritmo usava como variáveis polarimétricas de entrada: refletividade horizontal $\left(Z_{H}\right)$, refletividade diferencial $\left(Z_{D R}\right)$, fase diferencial específica $\left(K_{D P}\right)$, coeficiente de correlação $\left(\rho_{H V}\right)$ e razão de depolarização linear $(L D R)$ e altitude correspondente, e como saída conseguiram classificar garoa, chuva, neve seca de baixa densidade, cristais secos de alta densidade, neve úmida e derretida, graupel seco e molhado, granizo pequeno e grande e uma mistura de chuva e granizo.

Já (Ryzhkov et al. [2005]) se concentraram na capacidade de classificar e validar a qualidade das medições de granizo do radar polarimétrico WSR-88D. Neste método usava-se as variáveis polarimétricas $Z_{H}$ e $Z_{D R}$ e $\rho_{H V}$. A partir das variáveis $Z_{H}$ e $Z_{D R}$ foi classificado casos sem chuva, chuva leve moderada, chuva forte, mistura de chuva e granizo e grandes gotas.

\subsubsection{Métodos e algoritmos de identificação para radar Banda $C$}

Keenan [2003] mostra empiricamente um esquema baseado na lógica fuzzy descrita para os radares banda C. Neste método é levado em conta as medições da diferença de fase para definir uma função de associação em espaços dimensionais, onde também é acoplada a temperatura, para realizar a classificação de dez tipos de hidrometeoros. O classificador utiliza as variáveis $Z_{H}, Z_{D R}, \rho_{H V}$ e $K_{D P}$ e temperatura. Os resultados alcançados foram bons, mas tiveram dificultais nas regiões.

Para a classificação e estimação supervisada de hidrometeoros Marzano et al. [2008] usam a estatística Bayesiana a partir dos dados polarimétrico banda C. Este algoritmo Bayesiano é supervisado por um modelo microfísico de retroespalhamento, que representa dez classes de hidrometeoros diferentes em água, gelo e fase mista. 
Dolan et al. [2013] realizaram simulações teóricas de espalhamento, para desenvolver um novo algoritmo de identificação de hidrometeoros aplicado em sete estações chuvosas na Austrália. Eles encontraram efeitos significativos do espalhamento Mie em granizo grandes, e observaram uma diminuição da refletividade e um aumento na refletividade diferencial e na fase diferencial especifica. Além disso, analisaram que as grandes gotas de chuva oblatas podem produzir as mesmas assinaturas que o granizo derretendo caindo.

\subsubsection{Métodos e algoritmos de identificação para radar Banda X}

O principal problema para os radares de banda X, é fundamentalmente a aproximação Rayleigh e a atenuação por chuva. Já para radares banda S estes efeitos são desprezível, por tanto isso pode ser um problema para a classificação de hidrometeoro. O comprimento de onda e o tamanho dos hidrometeoros influi fortemente na transição para fora do regime de espalhamento Rayleigh, mas também é dependente da fase do hidrometeoro, ou seja, da constante dielétrica.

Marzano et al. [2010] desenvolveram um modelo supervisionado Bayesiano, para a classificação dos hidrometeoros para radar banda X. Neste algoritmo também foi acoplado a correção de atenuação para estimar o conteúdo de água líquida. Este método é usado para radares banda X e banda S, com a mesma estratégia de varredura estreitamente combinadas, o que permite fazer comparações experimentais entre medições coincidentes em diferentes frequências. Eles mostram como resultados gerais uma melhoria significativa no desempenho da correç̧ão de atenuação.

Bringi, Rasmussen and Vivekanandan [1986] fizeram um cálculo rigoroso da $Z_{H}, Z_{D R}$, e $L D R$ usando o modelo eletromagnético que é acoplado com um modelo microfísico de derretimento do graupel. O mesmo foi inicializado com medidas de avião e dados de sondagem.

Snyder et al. [2010], usam a atenuação para estimar a distribuição tridimensional de hidrometeoros dentro das tempestades de estudo. Logo, usam um algoritmo de classificação baseado na lógica fuzzy, modificado para o radar banda $X$ para identificar diferentes tipos de hidrometeoros em tempestades convectivas.

Dolan and Rutledge [2009] desenvolveram um algoritmo de identificação dos hidrometeoros para um radar banda X, baseado em simulações teóricas para diferentes hidrometeoros. 
Os resultados destas simulações fizeram parte de um esquema de identificação de lógica fuzzy a fim de definir uma função $\operatorname{beta}(\beta)$ de associação (eq 2.8).

$$
\beta=\frac{1}{1+\left[\left(\frac{x-m}{a}\right)^{2}\right]^{b}}
$$

onde:

- x é o valor do dado observacional,

- a é a diferença entre os valores máximos e mínimos da simulação divido entre 2,

- b é a largura do valor mínimo da simulação e

- $\mathbf{m}$ é o índice complexo da refracção.

Para fazer as simulações teóricas eles utilizaram o modelo de espalhamento T-matrix e Mueller-matrix (Vivekanandan et al. [1991]). Foram feitas as simulações para sete tipos de hidrometeoros( garoa, chuva, agregados, cristais de gelo, graupel de baixa densidade, granizo, gelo verticalmente alinhado) levando em consideração a temperatura, distribuição de tamanho das partículas e ângulo de elevação. Além destas informações, também é definido a densidade do hidrometeoros, a constante dielétrica(tabela 2.1), o diâmetro médio da partícula, a excentricidade e o coeficiente de interceptação.

TABELA 2.1: Valores de $|\kappa|^{2}$

\begin{tabular}{|c|c|c|c|c|c||}
\hline \hline Temperatura $\left({ }^{\circ} \mathrm{C}\right)$ & 20 & 10 & 0 & -10 & -20 \\
\hline Aidrometeoros & 0.928 & 0.9313 & 0.9340 & & \\
\hline Água & & & 0.197 & 0.197 & 0.197 \\
\hline Gelo
\end{tabular}

As gotas de chuva foram descritas para uma função gama normalizada(Ulbrich [1983]), variando $0.5 \mathrm{~mm}$ e $10 \mathrm{~mm}$ (equação 2.9 ).

$$
N(D)=N_{w} f(\mu)\left(\frac{D}{D_{0}}\right) \exp \left[-(3.67+\mu) \frac{D}{D_{0}}\right]
$$


onde $D_{0}$ é o diâmetro médio do volume, $\mu$ é o parâmetro de forma, $N_{w}$ é o parâmetro de intercepto da distribuição de tamanho de gota gama normalizada, $N(D)$ é o número de gotas de diâmetro entre $D_{\max }$ e $D_{\min }$ em unidades de volume no espaço e $f(\mu)$ é uma função empírica que depende do tamanho da forma(equação 2.10). As unidades de $N(D)$ e $N_{w}$ é $m m^{-1} m-3$.

$$
f(\mu)=\frac{6}{(3.67)^{4}} \frac{(3.67+\mu)^{\mu+4}}{\Gamma(\mu+4)}
$$

Para a garoa foi usado a distribuição exponencial de Marshall and Palmer [1948] para valores de $0.1 \mathrm{~mm}$ e $10 \mathrm{~mm}$.

$$
N(D)=N_{0} \exp (-\Lambda D)
$$

$\Lambda$ está relacionado com a taxa de precipitação:

$$
\Lambda=4.1 R^{-0.21}
$$

Para o caso do graupel de baixa densidade, também foi utilizada a equação exponencial 2.11, mas o parâmetro $N_{0}$ é calculado como:

$$
N_{0}=A \Lambda^{B}
$$

de $A=115, B=3.63$. Além disso foi assumido como $D_{0}=3.67 / \Lambda$.

já as simulações feitas para graupel de alta densidades(granizo) levaram-se em conta os mesmo parâmetros usados para o graupel, assumindo a equação 2.13, mas para temperaturas mais frias. 


\subsubsection{T-matrix e Mueller-matrix}

\subsubsection{T-matrix.}

O T-matrix é o algoritmo que calcula o espalhamento de partículas assimétricas (Bringi [2001]). Vivekanandan et al. [1991] estudaram as características de polarização das partículas de precipitação em função da distribuição do tamanho, forma, composição e orientação no volume no radar contido. Além disso levaram em conta os efeitos do ângulo de elevação e a polarização do radar.

Basicamente o T-matrix é uma matriz(T) de transição que relaciona os coeficientes do campo de espalhamento(não conhecido) e o campo incidente(conhecido), calculando a amplitude do espalhamento. A validade desta aproximação depende do parâmetro do tamanho de espalhamento, que depende do comprimento de onda e do diâmetro equivalente de uma esfera. Para radares de alta frequência, o T-matrix leva em conta os efeitos da inclinação dos hidrometeoros.

$$
\left[\begin{array}{c}
\text { Campo de } \\
\text { Espalhamento }
\end{array}\right]=[\mathbf{T}]\left[\begin{array}{c}
\text { Campo } \\
\text { Incidente }
\end{array}\right]
$$

\subsubsection{Mueller-matrix}

A Mueller-matrix é definida como a matriz que contém como elementos independentes as variáveis observáveis do radar, tais como a refletividade, refletividade diferencial, razão de depolarização linear e o coeficiente de correlação. Basicamente relaciona os vetores de Stokes dos campos incidente e de espalhamento e considera que o campo incidente está completamente polarizado e o campo de espalhamento está parcialmente polarizado(Bringi [2001]).

Além disso, a Mueller-matrix também pode ser usada quando assume-se que a onda espalhada está polarizada, nesse caso a polarização da onda espalhada pode ser deduzida usando a polarização da antena transmissora(de Oliveira Andrade et al. [2017]).

Esta matriz pode ser formada a partir da matriz espalhamento para uma orientação dada e para um dado especifico, os quais são as médias da distribuição de uma orientação 
especifica. Os efeitos do ângulo de elevação são obtidos a partir de cálculos simples do T-matrix. Em geral estas soluções usam teoremas de descomposição que permitem considerar o conhecimento polarimétrico dos alvos com tamanhos e formas complexas como o comportamento polarimétrico associados aos alvos simples.

Por fim Vivekanandan et al. [1991] calculam Mueller-matrix para um caso monodisperso e concluíram que este método também pode ser usado para misturas de diferentes tipos de hidrometeoros. Os resultados podem ser obtidos a partir da superposição de matrizes. O uso deste método pode ser usado para ajudar a modelar precipitações mistas. 


\title{
CAPÍTULO 3
}

\section{SimulaÇÕES TEÓRICAS: EFEITOS DOS HIDROMETEOROS, DSD, TEMPERATURA}

\author{
E ELEVAÇÃO NAS VARIÁVEIS \\ POLARIMÉTRICAS.
}

Para fazer uma caracterização de hidrometeoros na vertical é necessário antes conhecer as diferentes características relacionadas com os efeitos do comprimento de onda dos radares, a atenuação da chuva e a refletividade do radar. Além disso, é importante analisar os efeitos da distribuição do tamanho das gotas nos cálculos das variáveis polarimétricas. A metodologia proposta por Dolan and Rutledge [2009], a qual permitem realizar simulações teóricas o modelo T-matrix e Mueller-matrix (Vivekanandan et al. [1991]) serão aplicados neste projeto para investigar os efeitos dos hidrometeoros.

Na tabela 3.1 apresenta-se os dados de entrada que foram usados para fazer as simulações e levam em conta as condições microfísicas dos hidrometeoros (tipo e tamanho da partícula) e as condições termodinâmicas (temperatura do ar). No caso do modelo T-matrix, além destas propriedades, utilizou-se diferentes comprimentos de onda para analisar o efeito da atenuação e do tipo de hidrometeoro.Uma vez calculados os coeficientes de extinção para os diferentes tipos de hidrometeoros, T-matrix, pode-se então calcular as variáveis polarimétricas a partir da combinação de diversos hidrometeoros e características do radar, usando o Nmueller. Para o segundo código, Nmueller, definiu-se os hidrometeoros a 
Simulações teóricas: efeitos dos hidrometeoros, DSD, temperatura e elevação nas variáveis polarimétricas.

calcular e a distribuição do tamanho da partícula, descrita por as funções Marshall and Palmer [1948] e a função gama (Ulbrich [1983]), onde é preciso descrever o parâmetro $N_{0}$ , que é o coeficiente de interceptação $\left(m^{-4}\right)$ e o diâmetro mediano para cada distribuição.

TABELA 3.1: Parâmetros termodinâmicos e microfísicos dos hidrometeoros

\begin{tabular}{|c|c|c|c|c|c|c|c|c|c|}
\hline \multirow{3}{*}{$\begin{array}{l}\text { Hidrome- } \\
\text { teoros }\end{array}$} & \multirow{3}{*}{$\begin{array}{l}\text { Tempera } \\
\text { tura }\left({ }^{\circ} \mathrm{C}\right)\end{array}$} & \multicolumn{4}{|c|}{ DSD-Marshall-Palmer } & \multicolumn{4}{|c|}{ DSD-Gama $(\mu=2)$} \\
\hline & & \multicolumn{2}{|c|}{$D_{0}(\mathrm{~cm})$} & \multicolumn{2}{|c|}{$N_{0}\left(m m^{-3} \mathrm{~cm}^{-1}\right)$} & \multicolumn{2}{|c|}{$D_{0}(\mathrm{~cm})$} & \multicolumn{2}{|c|}{$N_{0}\left(m m^{-3} \mathrm{~cm}^{-1}\right)$} \\
\hline & & Máx & Min & Máx & Min & Máx & Min & Máx & Min \\
\hline Chuva & 10 & 0.33 & 0.039 & $8 \exp 4$ & $8 \exp 4$ & 0.3 & 0.06 & $8 \exp 4$ & $8 \exp 4$ \\
\hline Graupel & -10 & 1.75 & 0.020 & $4 \mathrm{ex}$ & 3.9 & 0.46 & 0.028 & $1.2 \mathrm{ex}]$ & 496.7 \\
\hline Granizo & -10 & 1.75 & 0.020 & $4 \exp 7$ & 3.95 & 0.46 & 0.028 & $1.2 \exp 7$ & 496.7 \\
\hline
\end{tabular}

A seguir é investigado o efeito do comprimento de onda para diferentes tipos e hidrometeoros.

\subsection{Efeito de comprimento de onda e refletividade}

O comprimento de onda do radar é um parâmetro importante, definido como a distância entre dois pontos consecutivos de um mesmo sinal, e se relaciona com a frequência emitida. Na tabela 3.2, são listados vários tipos de radar, que são usadas nas simulações, com seu comprimento de onda e seu frequência.

TABela 3.2: Frequência e comprimentos de ondas dos radares.

\begin{tabular}{||c|c|c||}
\hline \hline Bandas & Frequûencia $(\mathrm{GHz})$ & $\lambda(\mathrm{cm})$ \\
\hline$S$ & 3 & 10 \\
\hline$C$ & 6 & 5 \\
\hline$X$ & 10 & 3 \\
\hline$K_{u}$ & 15 & 2 \\
\hline$K$ & 24 & 1.25 \\
\hline$K_{a}$ & 35 & 0.85 \\
\hline \hline
\end{tabular}


Simulações teóricas: efeitos dos hidrometeoros, DSD, temperatura e elevação nas variáveis polarimétricas.

Para analisar os efeitos do espalhamento Rayleigh e Mie, utiliza-se o comprimento de onda de $10 \mathrm{~cm}$, banda $\mathrm{S}$, como referência, uma vez que esta frequência apresenta efeitos de atenuação desprezíveis.

\subsubsection{Chuva}

Os efeitos da chuva estão resumidos na figura 3.1. Para esta simulação teórica foi usado a distribuição Marshall and Palmer [1948] e uma temperatura ambiente de $10^{\circ} \mathrm{C}$.

Na figura 3.1(a), apresenta-se a variação do fator de refletividade do radar, onde a refletividade do radar banda $S$ é definida como padrão e varia entre 0.07 e $62.04 \mathrm{dBZ}$. Para valores baixos de refletividade do radar, menor que $30 d B Z$, observa-se que as refletividades dos outros radares são similares, ou seja, não temos espalhamento Mie para gotas pequenas.

Quando as partículas começam a ser maiores, acima dos $30 \mathrm{dBZ}$, observam-se diferenças. Os radares banda $C$ (azul), banda $K_{u}$ (cyan) e banda $X$ (marrom) tem $Z$ maior que o banda $S$. Isto pode ser devido que nestes radares quando ocorre o retroespalhamento na presença de gotas grandes, pode retornar a mesma potência ao radar, ou seja não ocorre quase o efeito de absorção. Já para os radares $K b$ e $K a$, a partir dos $35 d B$ e $50 d B$ respectivamente, observa-se uma diminuição do fator de refletividade com respeito aos valores do radar banda $S$, isto pode ser devido ao fato de que o tamanho das partículas que são maiores que o comprimento de onda dos radares. Além disso, estes radares tem uma maior frequência, o que causa uma maior absorção e uma maior atenuação, o que pode indicar também a diminuição dos valores para estes radares.

No caso de $Z_{D R}$, figura 3.1(b), observa-se que quando $Z<20 \mathrm{dBZ}$, ou seja, quando as gotas são pequenas, os valores desta variável são similares. Os radares que tem um maior espalhamento $\left(X, C\right.$, e $\left.K_{u}\right)$, mostrada na figura 3.1(a), tem os maiores valores, o que indica que as gotas são grandes e oblatas, ou seja, que espalha mais na horizontal, o que provoca que $Z D R$ seja maior para estes radares. Os valores máximos são observados para o banda $C$, perto a valores entre $2-2.5 \mathrm{~dB}$. Os radares que tem mais efeitos da atenuação pode causar uma diminuição nos valores de $Z_{D R}$ 
Simulações teóricas: efeitos dos hidrometeoros, DSD, temperatura e elevação nas variáveis polarimétricas.

Quando o fator de refletividade do radar é menor de $35 d B Z, K_{D P}$ (figura 3.1(c)) é zero, ou seja, as partículas são pequenas e esféricas, não tem efeito de atenuação. Para valores maiores de $35 \mathrm{dBZ}$ observam-se diferenças entre os radares. Os valores positivos indicam um maior atraso na horizontal, ou seja, a orientação das partículas é maior na horizontal, sofre mais atenuação nesta orientação, com valores máximos para o caso o radar banda $C$ de $40^{\circ} / \mathrm{km}$, correspondendo com o observado na figura 3.1(b). O valor negativo é observado no radar banda de $K a$, o que indica um atraso na vertical, sofrendo nesta orientação uma maior atenuação quando as gotas são grandes.

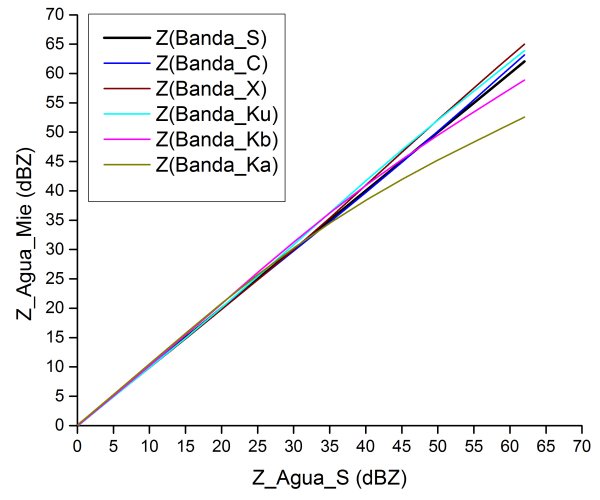

(a)

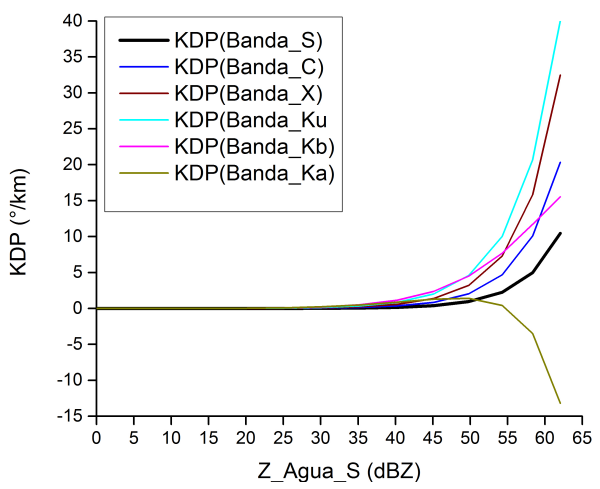

(c)

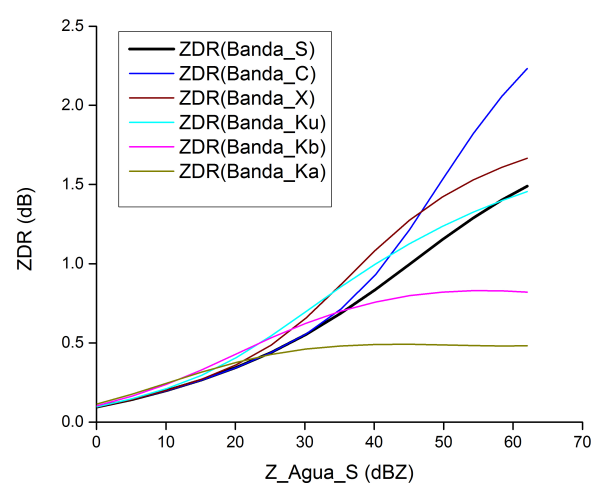

(b)

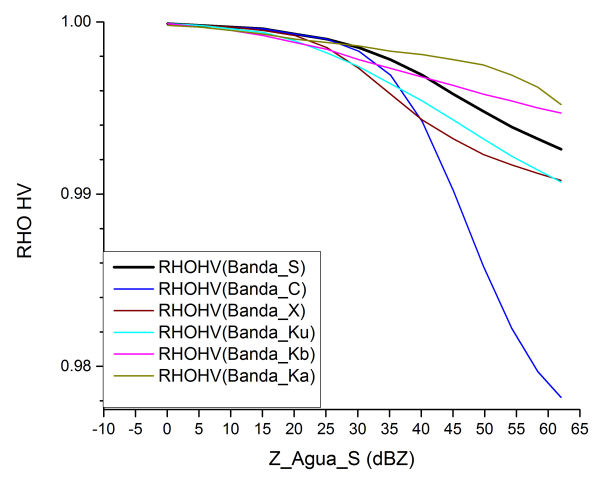

(d)

Figura 3.1: Simulações teóricas para a água para diferentes radares. (a)Fator de refletividade do radar $(Z)$; (b) Refletividade diferencial $\left(Z_{D R}\right)$; (c) Fase diferencial específica $\left(K_{D P}\right) ;(d)$ Coeficiente de correlação $\left(\rho_{H V}\right)$.

Na figura 3.1(d) quando o valor de refletividade do radar menor que $20 d B Z$, observase que o coeficiente de correlação é 1 para os radares, o que pode indicar a presença de gotas pequenas e esféricas e não apresentam efeitos de atenuação. Para o valores de refletividade do radar maior que $20 \mathrm{dBZ}$ observa-se maior diferença entre os radares, com 
valores mínimos para o radar banda $C$, o que indica uma maior orientação da gota, que não tem uma forma homogênea, ou seja, espalha mais na horizontal. Para o caso dos radares banda $K b$ e $K a$ o coeficiente de correlação é máximo, perto de 1, o que pode indicar um menor espalhamento e uma maior atenuação.

\subsubsection{Graupel}

As variáveis polarimétricas para o caso do graupel, são mostradas na figura 3.2. Para este caso a temperatura ambiente usada foi de $-15^{\circ} \mathrm{C}$, a densidade do graupel de $0.4 \mathrm{~g} / \mathrm{m}^{3} \mathrm{e}$ a excentricidade $a / b=0.75$.

O fator de refletividade do radar, figura 3.2(a), variam entre -7.14 e $30.10 \mathrm{dBZ}$. Os radares banda $S, C$, e $X$ não tem diferenças entre eles. Entretanto para $Z$ maior de $20 d B Z$ nota-se diferenças para radares que tem comprimento de onda pequeno. Este efeito está associado ao regime de espalhamento Mie e um pequeno efeito da atenuação, o que pode ser complementado quando analise-se $K_{D P}$.

Analisando a refletividade diferencial $\left(Z_{D R}\right)$ figura 3.2(b), levando em conta a excentricidade do graupel usada para fazer a simulação teórica, observa-se que a maior variação para está variável polarimétrica esta presente nos radares banda $K_{a}, K$ e $K_{u}$, indicando maior espalhamento na horizontal que na vertical. Já para os radares de maior comprimento de onda, a diferença entre a orientação horizontal e vertical é menor, os quais consideram as partículas de maior tamanho quase esféricas. Os valores estão entre 0.7 e $1.2 \mathrm{dBZ}$.

Para o caso da variável $K_{D P}$ não tem muita variação, $(<0.30)$, devido aos pequenos efeitos da atenuação. Com o aumento do fator de refletividade, observa-se um aumento dos valores e logo uma diminuição, devido que as partículas grandes são quase esféricas. Para a simulacão, foi considerado o graupel seco, ou seja não foi visto um derretimento do hidrometeoro. 


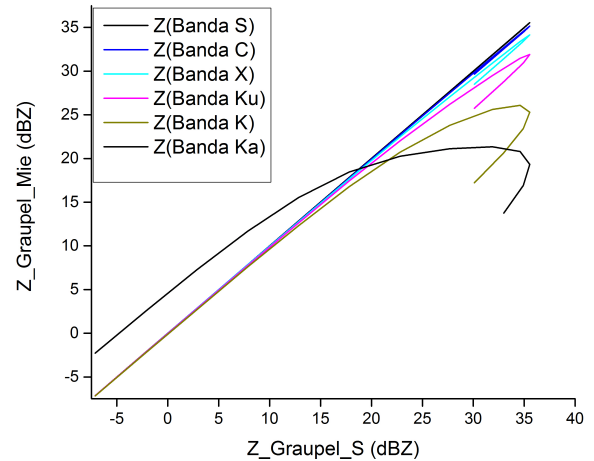

(a)

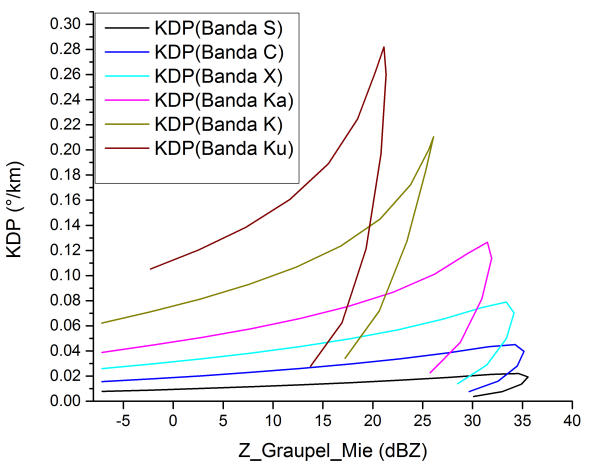

(c)

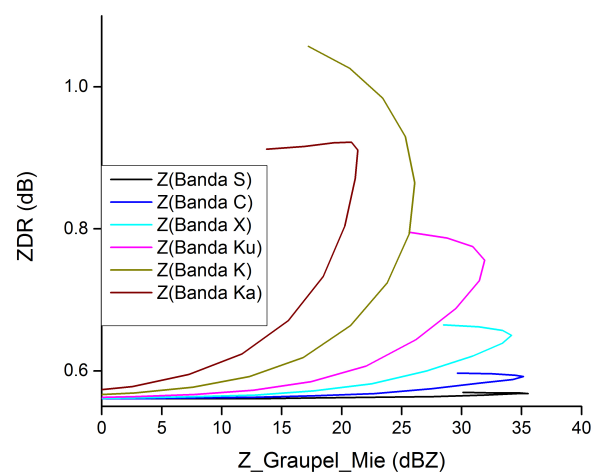

(b)

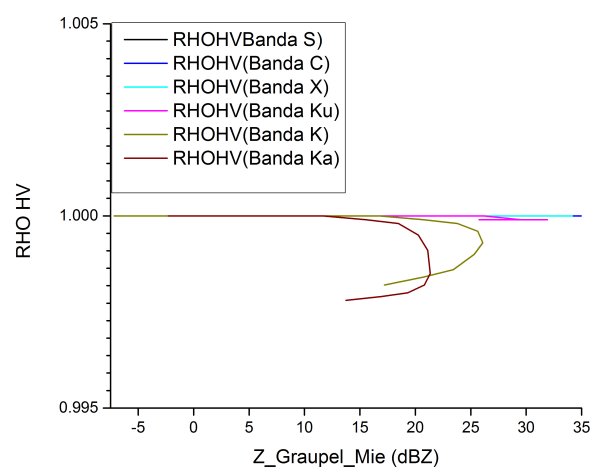

(d)

Figura 3.2: Simulações teóricas para o graupel para diferentes radares. (a)Fator de refletividade do radar $(Z)$; (b) Refletividade diferencial $\left(Z_{D R}\right)$; (c) Fase diferencial especifica $\left(K_{D P}\right) ;(d)$ Coeficiente de correlação $\left(\rho_{H V}\right)$.

Quando se analisa o coeficiente de correlação para este hidrometeoro, pode-se observar na figura 3.2(d), que não tem uma mudança nos valores desta variável, ou seja, com o aumento do tamanho o hidrometeoro segue sendo quase esférico. Só na variação pequena nos radares banda $K$ e $K a$.

\subsubsection{Granizo}

O comportamento do granizo, $\rho=0.917 \mathrm{~g} / \mathrm{m}^{-3}$, foi feito para uma excentricidade $(a / b)$ de 0.99 e uma temperatura de $-20^{\circ} \mathrm{C}$; figura 3.3

Na figura 3.3 é apresentado o comportamento do fator de refletividade do radar para os diferentes comprimentos de onda. $Z$ varia desde $-25 d B Z$ até um máximo de refletividade 
Simulações teóricas: efeitos dos hidrometeoros, DSD, temperatura e elevação nas variáveis polarimétricas.

do radar de $50 \mathrm{dBZ}$. Os radares mantém valores semelhantes até aproximadamente $20 \mathrm{dBZ}$ e depois é possível observar diferenças, em especial para os banda $K_{u}, K, K_{a}$ Os radares banda $X$ e $C$ atinge os valores similares. As maiores diferenças são observadas para os radares de menor comprimento de onda, logo podem ter espalhamento Mie e atenuação.

Uma vez que o granizo é mais esférico, os valores obtidos da refletividade diferencial neste caso, $Z_{D R}$, figura 3.3(b), são perto de zero. A refletividade diferencial pode ser reduzida, devido à orientação aleatória, associada com a queda e a baixa constante dielétrica do granizo. Para o caso dos radares banda $K$ e $K a$ tem valores negativos porque as partículas espalham mais na vertical do que horizontal, ou seja $Z_{v}>Z_{h}$.

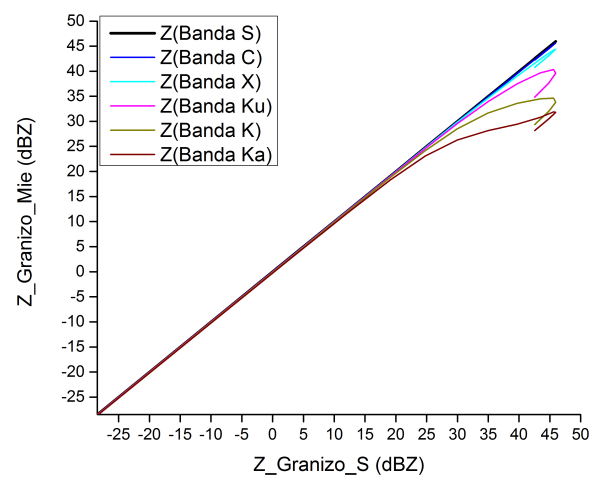

(a)

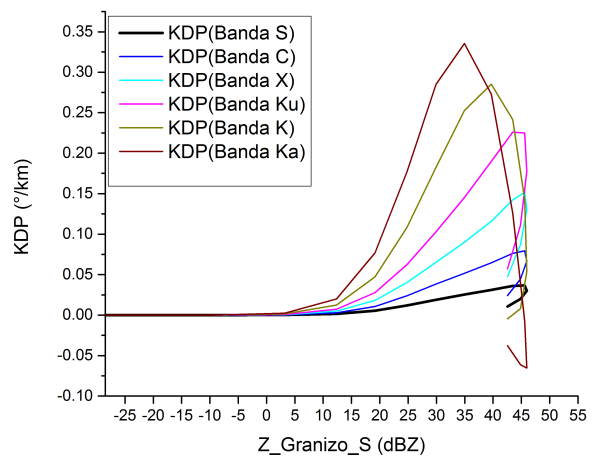

(c)

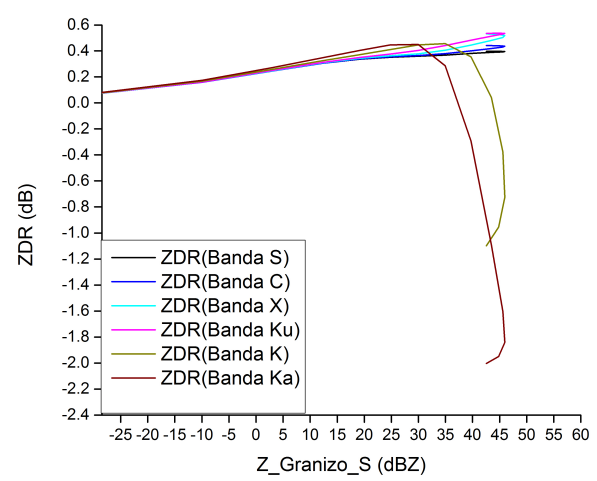

(b)

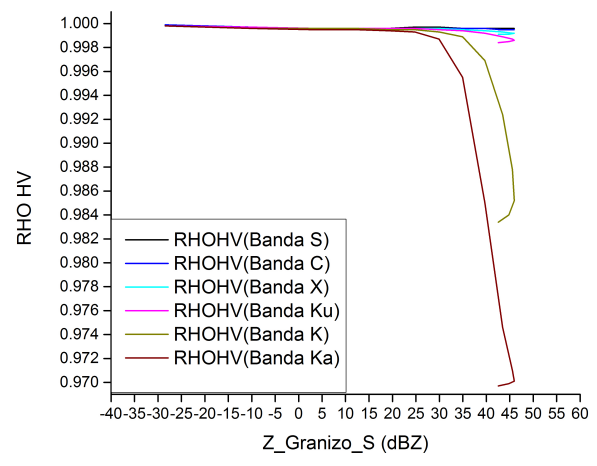

(d)

Figura 3.3: Simulações teóricas para o granizo para diferentes radares. (a)Fator de refletividade do radar $(Z)$; (b) Refletividade diferencial $\left(Z_{D R}\right)$; (c) Fase diferencial especifica $\left(K_{D P}\right) ;(d)$ Coeficiente de correlação $\left(\rho_{H V}\right)$.

Para a refletividade diferencial específica(figura 3.2(d)), os valores são baixos, ou seja, as partículas são esféricas. A análise foi feita considerando o granizo seco, portanto os 
valores desta variável são baixos porque não se leva em conta o derretimento. Os valores máximos são para o banda $K a$, devido ao efeito da atenuação, com respeito aos radares com maior comprimento de onda que apresentam menos efeitos da atenuação, como o mostrado para o radar banda $S$ que tem os valores mínimas de $K_{D P}$.

O coeficiente de correlação, figura 3.3(d), varia entre 0.97 e 1 e o coeficiente de correlação é 1 quando o fator de refletividade é menor que $20 \mathrm{dBZ}$. Para valores maiores temos que para comprimentos de onda pequenos o efeito do tamanho implica uma redução do coeficiente de correlação.

\subsection{Efeitos para diferentes temperaturas.}

Para o caso da temperatura, as simulações foram feitas para diferentes temperaturas. Na continuação serão mostradas somente os resultados das simulações teóricas para o caso da distribuição gama para chuva, graupel e granizo.

\section{Chuva}

Na figura 3.4 mostra-se que levando em conta as variáveis polarimétricas segundo as simulações, o comportamento para diferentes temperaturas tem pouca diferença, ou seja, não existe muita dependência com a variação da temperatura.

Não obstante a figura 3.4(b) nota-se que em relação à refletividade específica mostra-se uma pequena diferença do valor de esta variável é $>1 d B$ com a diminuição da temperatura quando $Z=65 \mathrm{dBZ}$. Para o caso de $K_{D P}$ (figura 3.4(c)) o comportamento é similar valores altos de esta variável e de $Z$.

Para o caso do $\rho_{H V}$, figura 3.4(d) para valores baixos de $Z$, ou seja, quando as partículas são pequenas, mostra que o valor o coeficiente é 1 , o que indica que as partículas são esféricas. Já com o aumento do $Z$ nota-se uma variação maior do $\rho_{H V}$ o que indica que com o crescimento das gotas estão se tornando mais oblatas. 
Simulações teóricas: efeitos dos hidrometeoros, DSD, temperatura e elevação nas variáveis polarimétricas.

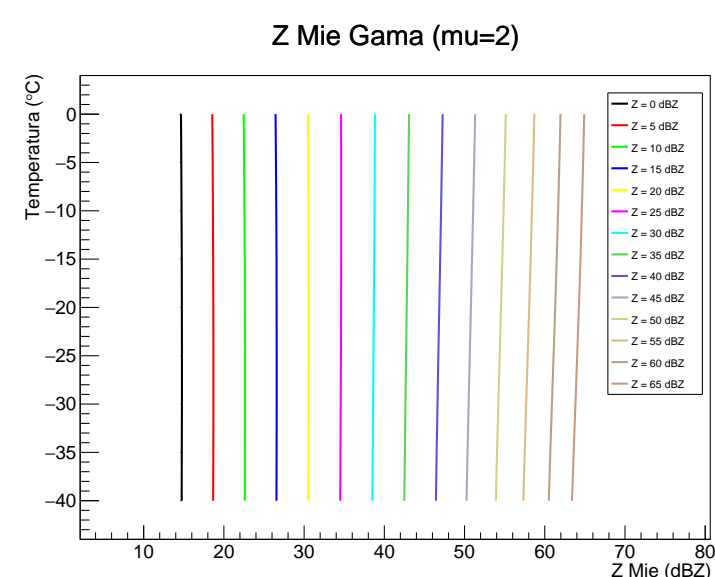

(a)

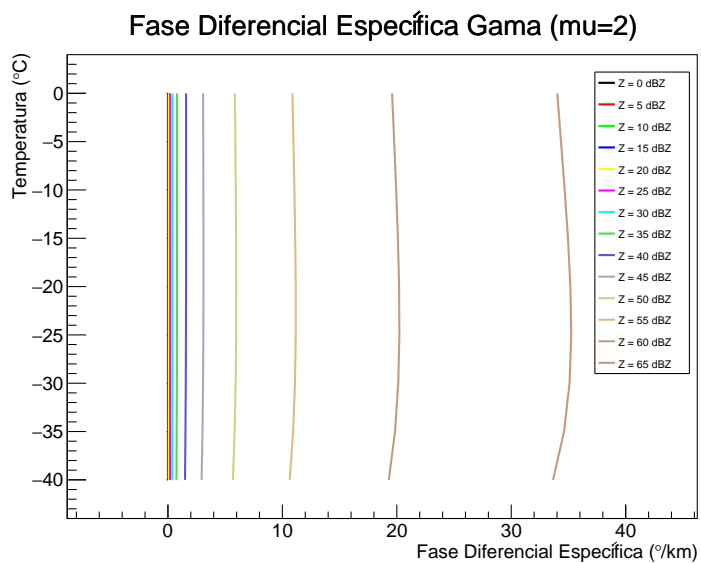

(c)
Reflectividade Diferencial Gama (mu=2)

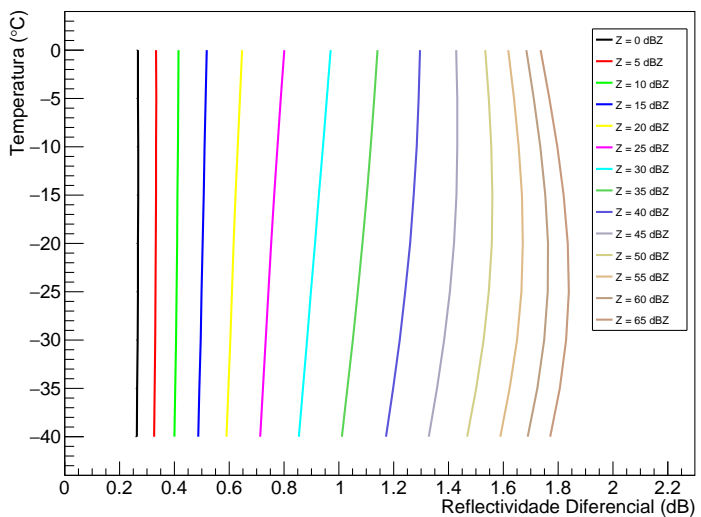

(b)

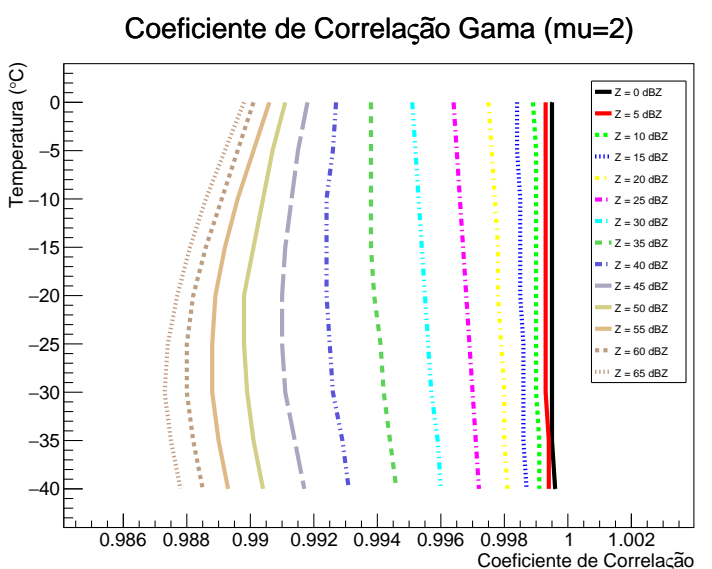

(d)

Figura 3.4: Simulações teóricas para chuva para diferentes temperaturas. (a)Fator de refletividade do radar $(Z)$; (b) Refletividade diferencial $\left(Z_{D R}\right)$; (c) Fase diferencial especifica $\left(K_{D P}\right) ;(d)$ Coeficiente de correlação $\left(\rho_{H V}\right)$.

\section{Graupel}

Para o caso do graupel, figura 3.5, os resultados das simulações teóricas das variáveis polarimétricas não mostram diferenças significativas com a variação da temperatura. $\mathrm{O}$ graupel mantém sua forma com o aumento do se tamanho. As variáveis $Z_{D R}$ e $K_{D P}$, figuras 3.5(b) e 3.5(c) tem valores maiores com o aumento da refletividade. No caso de $\rho_{H V}=1$ em toda a variação da temperatura. 
Simulações teóricas: efeitos dos hidrometeoros, DSD, temperatura e elevação nas variáveis polarimétricas.

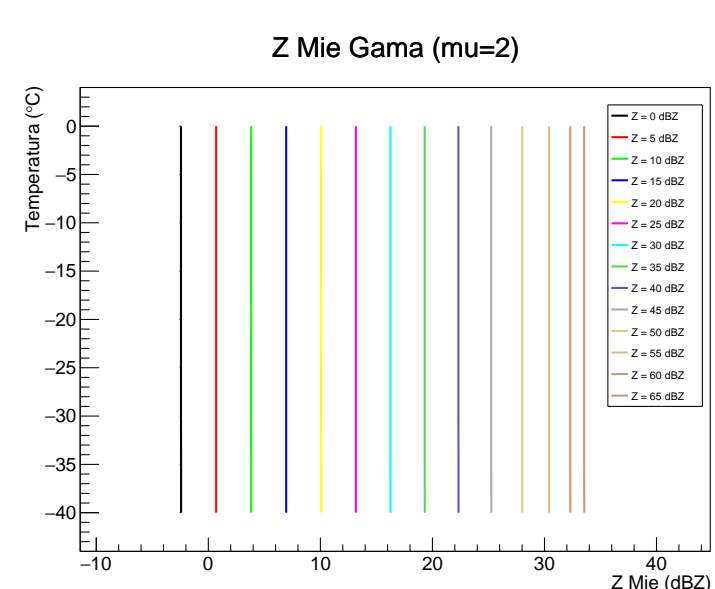

(a)

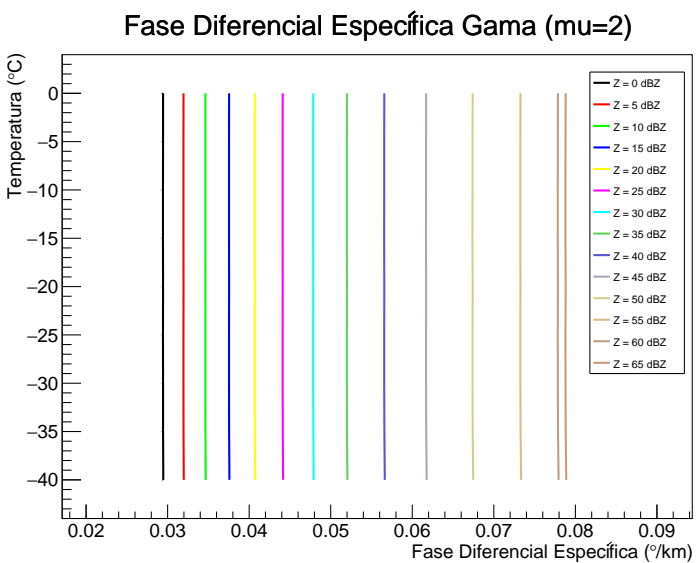

(c)
Reflectividade Diferencial Gama (mu=2)

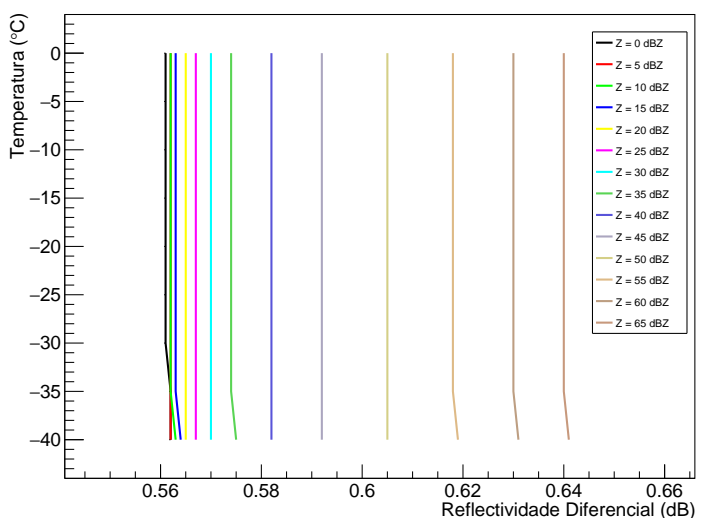

(b)

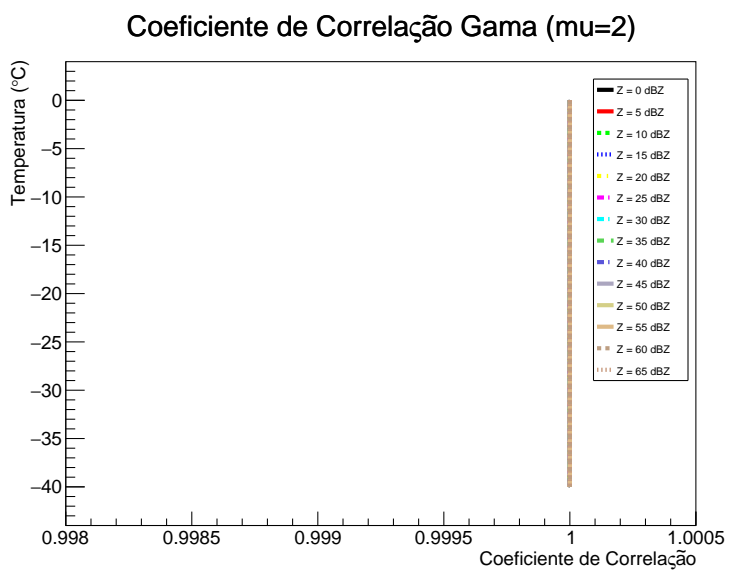

(d)

Figura 3.5: Simulações teóricas para graupel para diferentes temperaturas. (a)Fator de refletividade do radar $(Z)$; (b) Refletividade diferencial $\left(Z_{D R}\right)$; (c) Fase diferencial especifica $\left(K_{D P}\right) ;(d)$ Coeficiente de correlação $\left(\rho_{H V}\right)$.

\section{Granizo}

O granizo, figura 3.6, para as simulações teóricas foi considerado seco e tem similar comportamento com a variação da temperatura que o graupel. No caso de $\rho_{H V}$ o valor é perto 1, ou seja, não tem uma configuração esférica completamente. 
Simulações teóricas: efeitos dos hidrometeoros, DSD, temperatura e elevação nas variáveis polarimétricas.

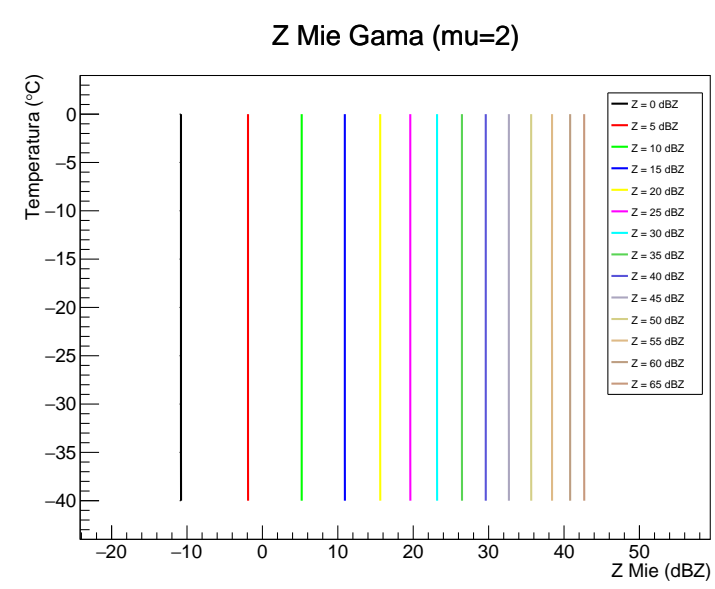

(a)

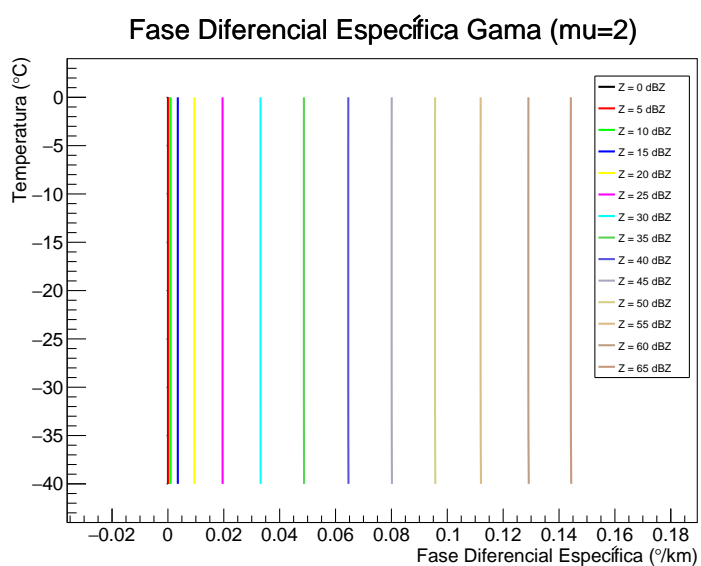

(c)
Reflectividade Diferencial Gama $(\mathrm{mu}=2)$

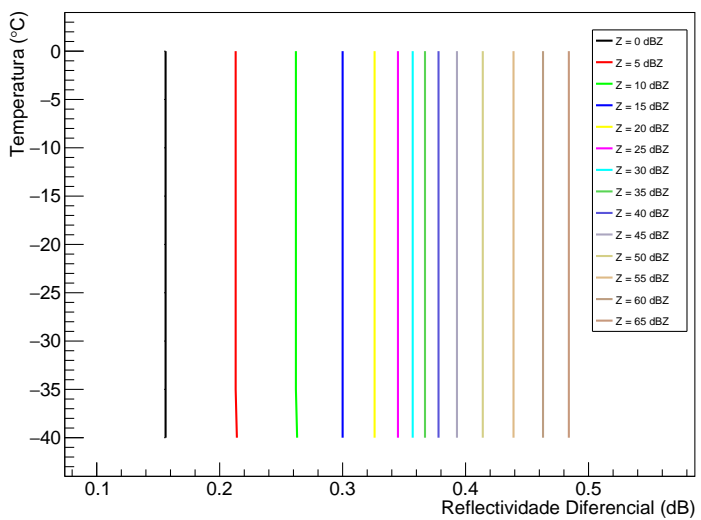

(b)

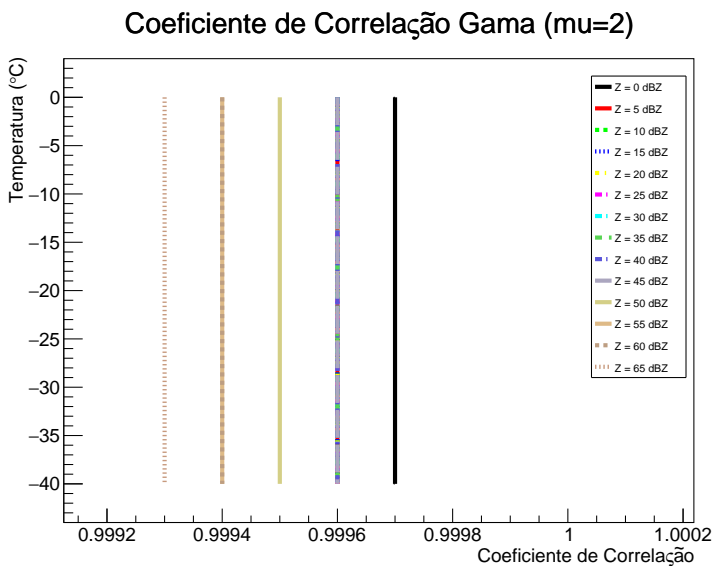

(d)

Figura 3.6: Simulações teóricas para granizo para diferentes temperaturas. (a)Fator de refletividade do radar $(Z)$; (b) Refletividade diferencial $\left(Z_{D R}\right)$; (c) Fase diferencial especifica $\left(K_{D P}\right) ;(d)$ Coeficiente de correlação $\left(\rho_{H V}\right)$.

\section{3 Ângulos de elevação.}

Os efeitos na variação do ângulo de elevação tem relação com a forma e orientação do hidrometeoro e com a sinal do radar que chega. Em alguns casos tem-se maior retroespalhamento quanto maior seja o ângulo de elevação se o alvo encontrado é oblato.

Para analisar o efeito dos ângulos de elevação $\left(O^{\circ}, 1 O^{\circ}, 2 O^{\circ}, 3 O^{\circ}, 4 O^{\circ}, 50^{\circ}, 60^{\circ}, 7 O^{\circ}\right.$, $80^{\circ}$ ) calcularam-se os parâmetros polarimétricos para as distribuição gama. 
Simulações teóricas: efeitos dos hidrometeoros, DSD, temperatura e elevação nas variáveis polarimétricas.

Chuva

Na figura 3.7 mostram-se os resultados das simulações teóricas para o caso da chuva. Note-se que para o caso de $Z$, tem pouca variação com a variação ângulo de elevação. Não obstante, ao analisar $Z_{D R}$ e $K_{D P}$ observa-se que o valor destas variáveis diminui com o aumento de ângulo de elevação. Para refletividades baixas, quando a partícula é quase esférica os valores são perto de 0 , quando $Z$ aumenta a partícula é maior, o valor diminui, até atingir quase 0, a simulação para o radar para ângulos grandes considera a secção transversal da partícula como uma esfera, figuras 3.7(b) e 3.7(c).

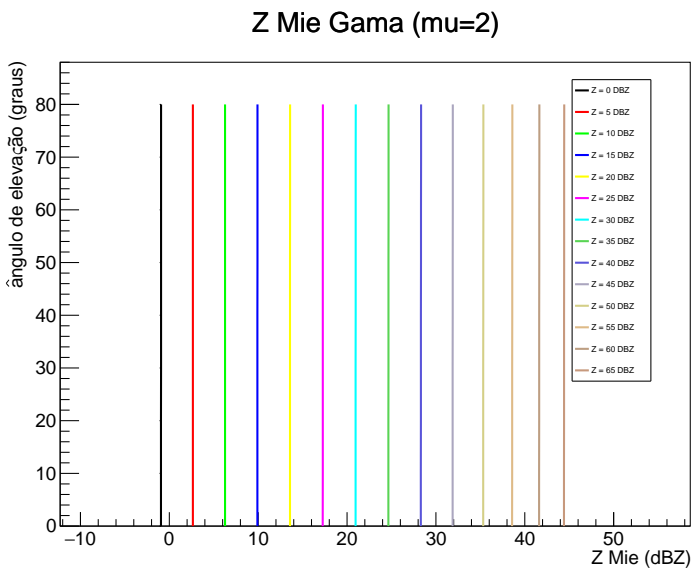

(a)

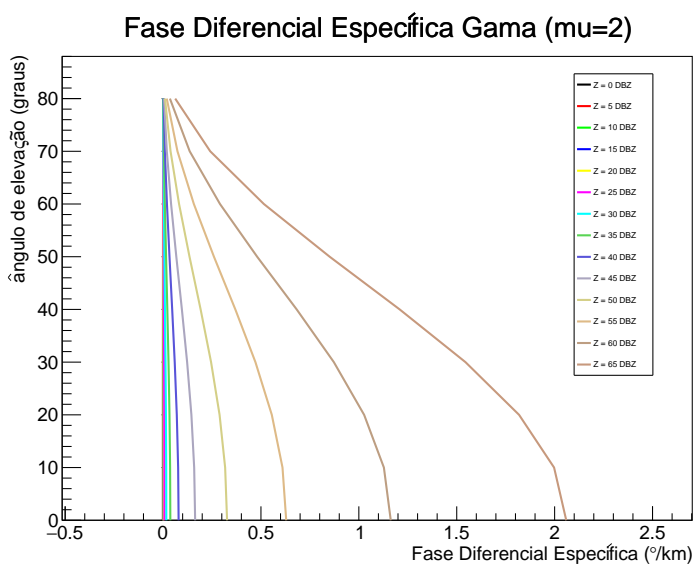

(c)

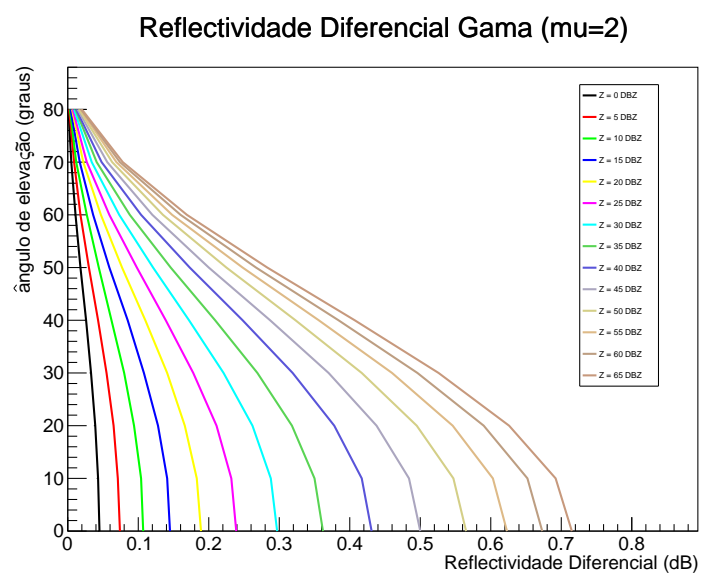

(b)

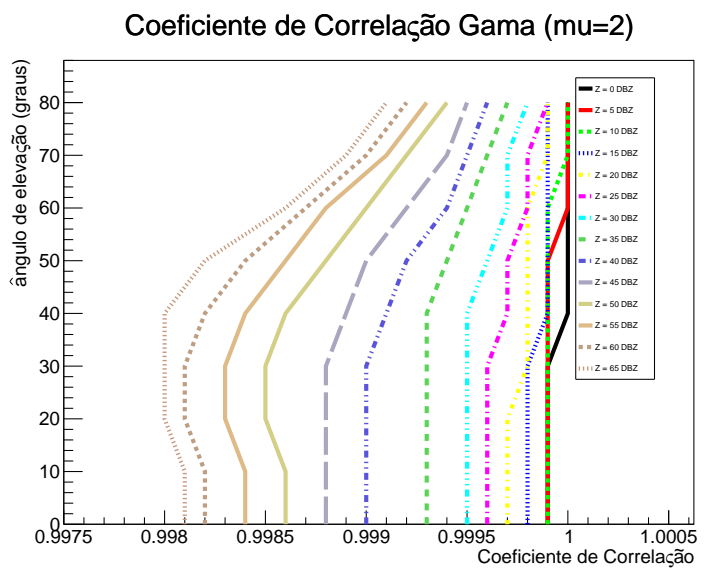

(d)

Figura 3.7: Simulações teóricas para chuva para diferentes ângulos de elevação. (a)Fator de refletividade do radar $(Z)$; (b) Refletividade diferencial $\left(Z_{D R}\right)$; (c) Fase diferencial específica $\left(K_{D P}\right)$; (d) Coeficiente de correlação $\left(\rho_{H V}\right)$. 
Simulações teóricas: efeitos dos hidrometeoros, DSD, temperatura e elevação nas variáveis polarimétricas.

Para o caso de $\rho_{H V}$, de acordo com o analisado nas variáveis anteriores, para valores baixos de refletividade o coeficiente de correlação esta perto de 1, e para valores altos é menor. A medida que o ângulo de elevação aumenta os valores para cada refletividade estão mais perto de 1, como é possível observar na figura 3.7(d).

\section{Graupel}

Para o caso das simulações para o graupel, figura 3.8, tem similar comportamento com respeito a água.

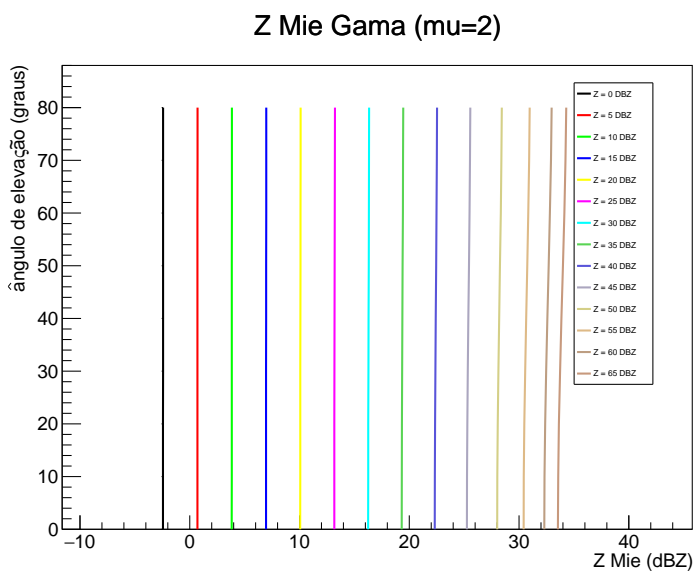

(a)

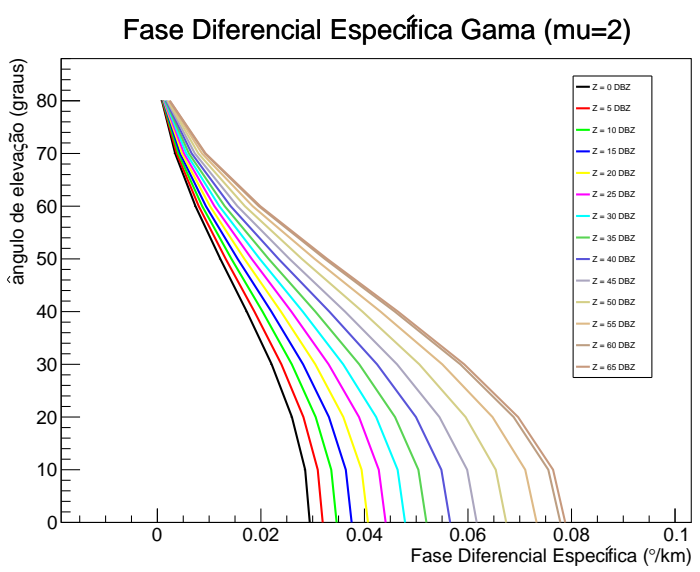

(c)

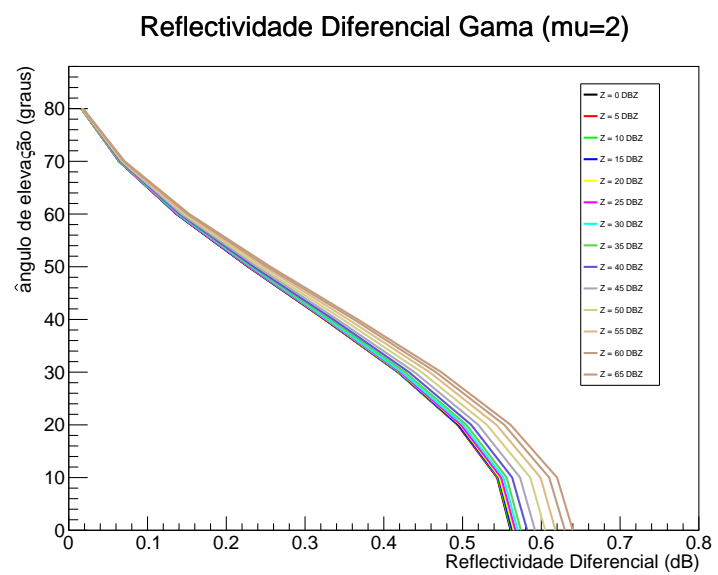

(b)

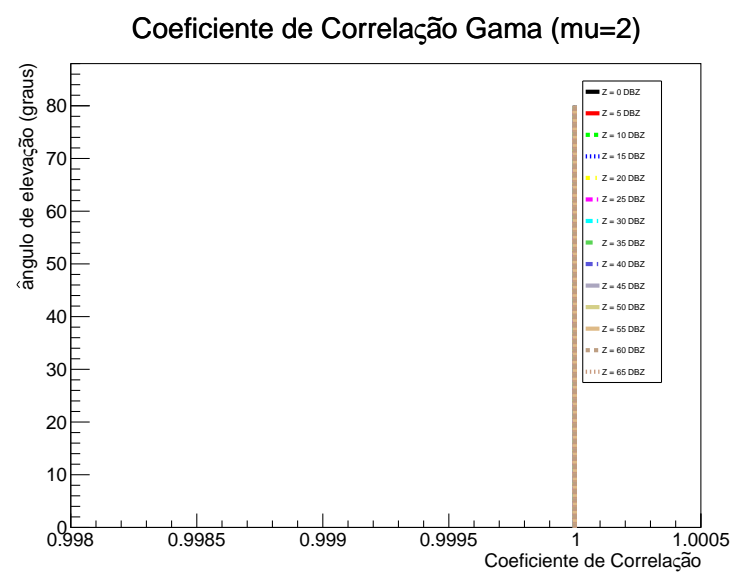

(d)

FiguRA 3.8: Simulações teóricas para graupel para diferentes ângulos de elevação. (a)Fator de refletividade do radar $(Z)$; (b) Refletividade diferencial $\left(Z_{D R}\right)$; (c) Fase diferencial específica $\left(K_{D P}\right)$; (d) Coeficiente de correlação $\left(\rho_{H V}\right)$. 
Simulações teóricas: efeitos dos hidrometeoros, DSD, temperatura e elevação nas variáveis polarimétricas.

Para o caso das variáveis $Z_{D R}$ e $K_{D P}$, embora as variações são pequenas, figuras 3.8(b) e 3.8(c) note-se que o valor destas diminui com o ângulo de elevação, para cada valor de $Z$. No caso do $\rho_{H V}$, como as variações anteriores são muito pequenas se valor mantém-se perto de 1 , ou seja, as simulações teóricas consideram este hidrometeoro como quase uma esfera em todo o crescimento.

\section{Granizo}

Na figura 3.9 note-se que o granizo também está em concordância com o analisado para os anteriores hidrometeoros.

A simulações teóricas para este hidrometeoro mostram que para o caso das variáveis $Z_{D R}$ e $K_{D P}$ as variações com o aumento do ângulo de elevação para diferentes $Z$ diminui, embora a variação com respeito ao graupel é um pouco maior, figuras 3.9(b) e 3.9(c).

Uma maior diferença para os distintos valores de $Z$ observa-se na figura 3.9(d), no caso de $\rho_{H V}$, mas com o aumento do ângulo de elevação os valores estão perto da unidade. 
Simulações teóricas: efeitos dos hidrometeoros, DSD, temperatura e elevação nas variáveis polarimétricas.

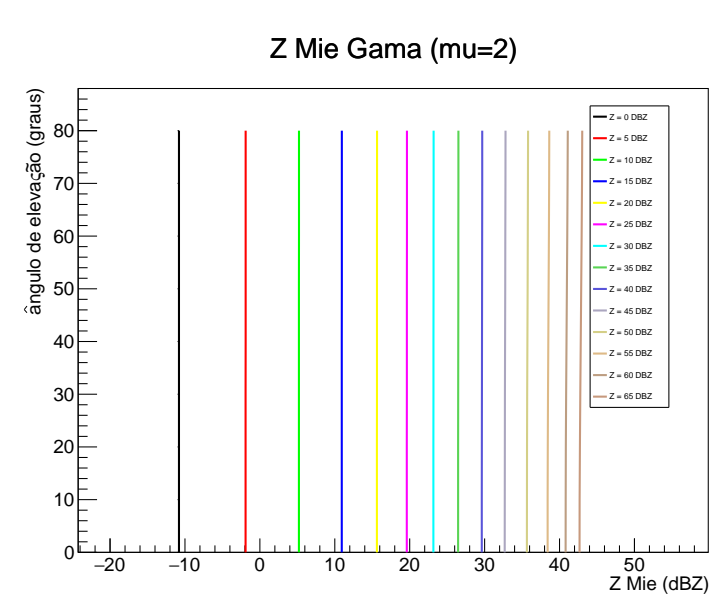

(a)

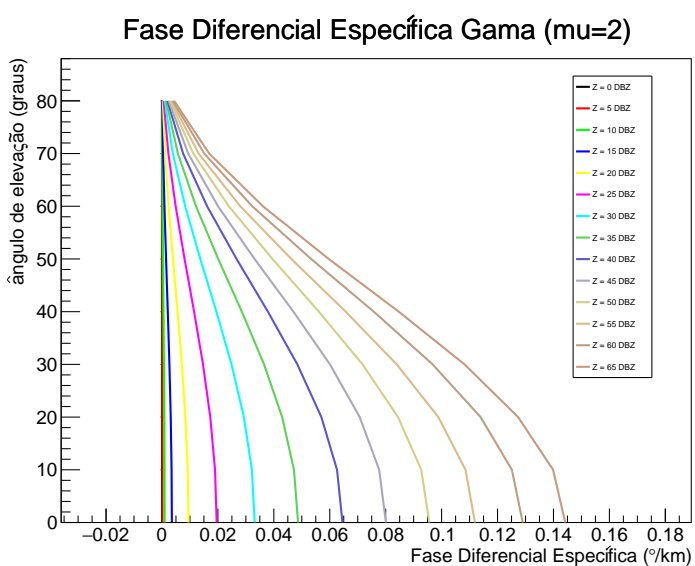

(c)
Reflectividade Diferencial Gama (mu=2)

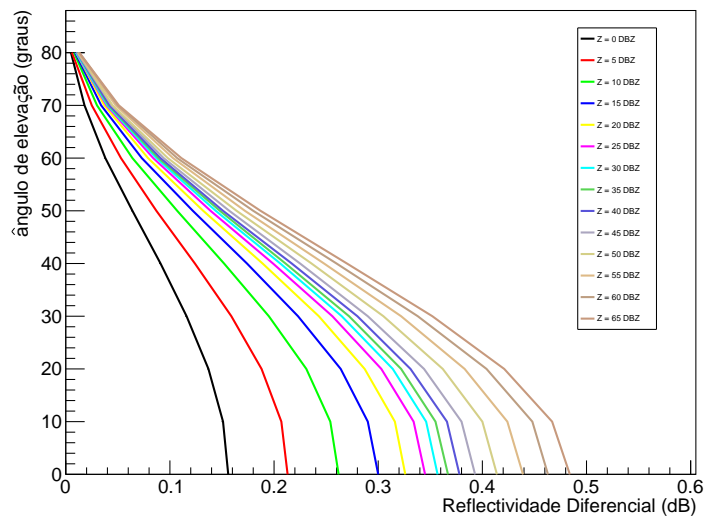

(b)

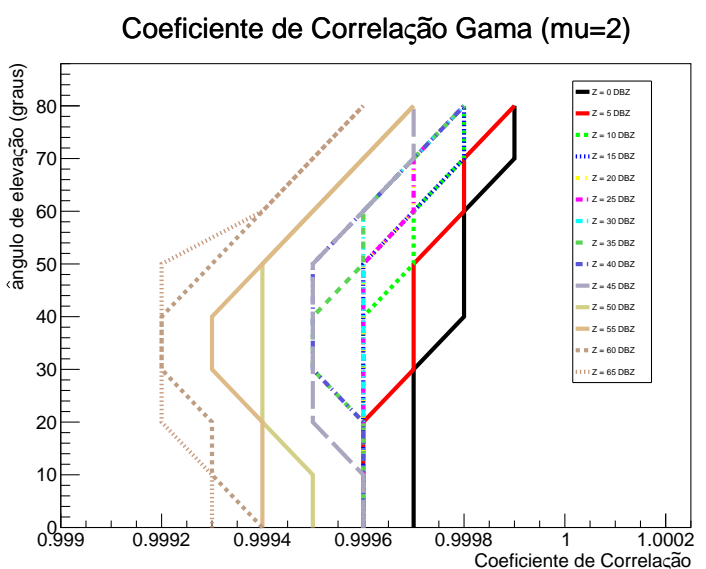

(d)

Figura 3.9: Simulações teóricas para granizo para diferentes ângulos de elevação.. (a)Fator de refletividade do radar $(Z)$; (b) Refletividade diferencial $\left(Z_{D R}\right)$; (c) Fase diferencial específica $\left(K_{D P}\right) ;(d)$ Coeficiente de correlação $\left(\rho_{H V}\right)$.

\subsection{Efeito da distribuição de tamanho de gotas.}

Além dos efeitos do tipo de hidrometeoro, a distribuição do tamanho de gotas também influência o cálculo das variáveis polarimétricas(ver equações 2.5, 2.6, 2.7). Portanto, se uma região tem mais ou menos gotas maiores ou menores, é possível analisar em função da DSD. De uma forma geral, a DSD de tamanho de gota é comumente descrita por uma função exponencial e por uma função gama. 
As funções da distribuição do tamanho das gotas expressa a distribuição do número de gotas por volume por intervalos de classe do diâmetro. A concentração das gotas, sem importar a região de observação, diminui com o aumento do tamanho, ou seja, o diâmetro. A concentração depende do coeficiente linear $\left(N_{0}\right)$ e o coeficiente angular $(\Lambda)$.

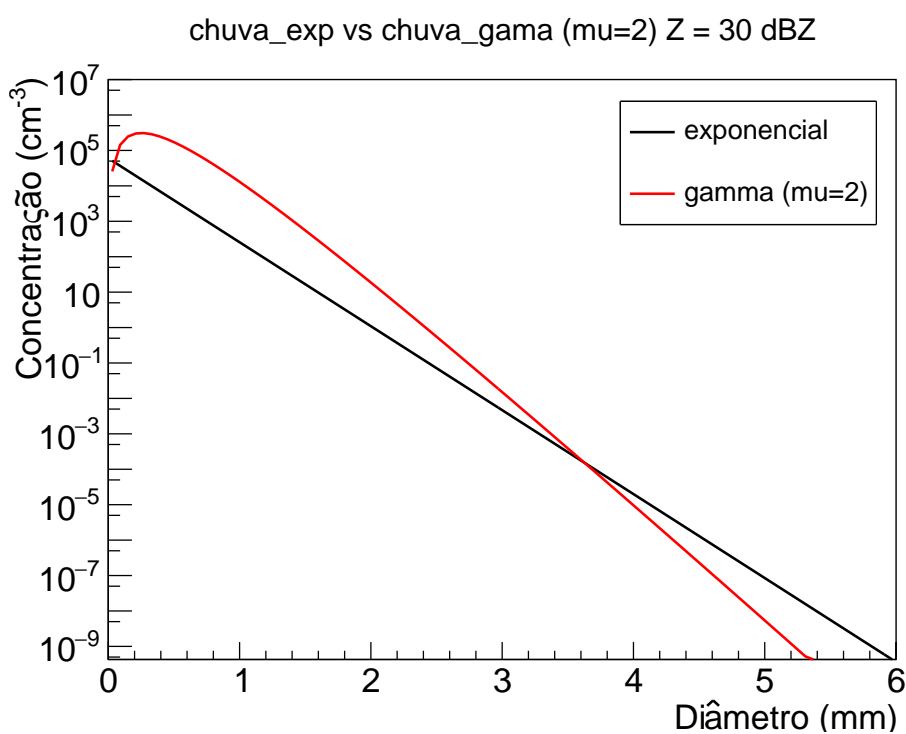

Figura 3.10: Diferenças das distribuições exponencial e gama da chuva para $Z=$ $30 d B Z$.

Por exemplo, a figura 3.10 mostra uma DSD exponencial e uma gama para $Z=30 \mathrm{dBZ}$. Note-se que a maior concentração de gotas está relacionada com os menores diâmetros e diminui a medida que o diâmetro das gotas aumenta. Quando as gotas são pequenas a diferença entre as distribuições é menor.

A comparação entre os espectro revela que a diferença entre os parámetros entre a distribuição gama e exponencial é devido à diferença na concentração das gotas maiores. A distribuição de tamanho de gota de chuva é fortemente controlada pela quantidade de gotas. Isto implica que as mudanças nas propriedades de distribuição de tamanho de gota de chuvas são causadas principalmente pelas variações nas concentrações de número de gota.

Para o caso do graupel e o granizo, figuras 3.11, note-se que tem uma mínima diferença as distribuições gama e exponencial no espectro de DSD. Observa-se que para uma maior concentração estes hidrometeoros a distribuição gama tem uma menor concentração que a exponencial para um mesmo diâmetro. 
Simulações teóricas: efeitos dos hidrometeoros, DSD, temperatura e elevação nas variáveis polarimétricas.

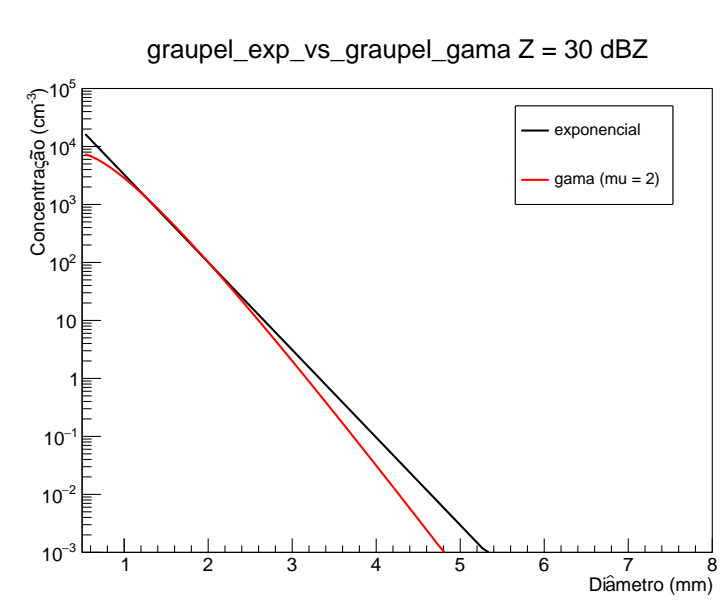

(a) granizo exp vs granizo gama $Z=30 \mathrm{dBZ}$

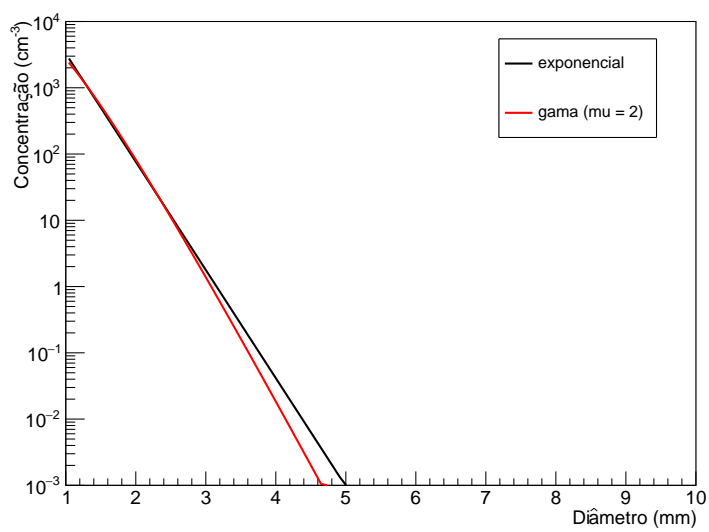

(b)

Figura 3.11: Distribuição de partículas exponencial e gama para a) graupel e b) granizo.

A continuação é apresentada na tabela(3.3) com as diferenças entre a refletividade para chuva das distribuições exponencial e gama. Neste caso a função gama é maior que a exponencial para gotas pequenas e tem uma maior concentração. As diferencia entre as duas distribuições diminui como o aumento do tamnho das gotas e a dimuição da concentração. Para as gotas grandes com menos concentração.

Para os três tipos de hidrometeoros, note-se que as diferencias, são maiores quando as partículas são pequenas. Para o caso da função exponencial as partículas diminuem sua concentração com o aumento do tamanho, e aumenta também sua refletividade. Para o caso da função gama, as partículas que podem variar a função são as partículas medianas que para refletividades médias tem uma maior concentração. No apêndice .2, mostra-se as diferenças para o caso do graupel e o granizo. 
Simulações teóricas: efeitos dos hidrometeoros, DSD, temperatura e elevação nas variáveis polarimétricas.

TABela 3.3: Diferenças entre as refletividades obtidas da simulação da chuva para a distribuição e a gama $Z_{\text {exp }}-Z_{\text {gama }}$, levando em conta o ângulo de elevação.

\begin{tabular}{|c|c|c|c|c|c|c|c|c|c||}
\hline \hline $\begin{array}{c}|c| \\
\text { Theta }\end{array}$ & 0 & 10 & 20 & 30 & 40 & 50 & 60 & 70 & 80 \\
\hline \hline 0 & $-7,8$ & $-7,8$ & $-7,8$ & $-7,8$ & $-7,8$ & $-7,8$ & $-7,8$ & $-7,8$ & $-7,8$ \\
\hline 5 & $-6,1$ & $-6,1$ & $-6,1$ & $-6,1$ & $-6,1$ & $-6,1$ & $-6,1$ & $-6,1$ & $-6,1$ \\
\hline 10 & $-4,5$ & $-4,5$ & $-4,5$ & $-4,5$ & $-4,5$ & $-4,5$ & $-4,5$ & $-4,5$ & $-4,5$ \\
\hline 15 & $-3,0$ & $-3,0$ & $-3,0$ & $-3,0$ & $-3,0$ & $-2,9$ & $-2,9$ & $-2,9$ & $-2,9$ \\
\hline 20 & $-1,4$ & $-1,4$ & $-1,4$ & $-1,4$ & $-1,4$ & $-1,4$ & $-1,4$ & $-1,4$ & $-1,4$ \\
\hline 25 & 0,1 & 0,1 & 0,1 & 0,1 & 0,1 & 0,1 & 0,1 & 0,1 & 0,1 \\
\hline 30 & 1,7 & 1,7 & 1,7 & 1,7 & 1,7 & 1,7 & 1,7 & 1,7 & 1,7 \\
\hline 35 & 3,5 & 3,5 & 3,5 & 3,5 & 3,5 & 3,5 & 3,5 & 3,5 & 3,5 \\
\hline 40 & 5,5 & 5,4 & 5,4 & 5,4 & 5,4 & 5,4 & 5,4 & 5,4 & 5,4 \\
\hline 45 & 7,3 & 7,3 & 7,3 & 7,3 & 7,3 & 7,3 & 7,2 & 7,2 & 7,2 \\
\hline 50 & 8,9 & 8,9 & 8,9 & 8,9 & 8,9 & 8,9 & 8,8 & 8,8 & 8,8 \\
\hline 55 & 10,1 & 10,1 & 10,1 & 10,1 & 10,1 & 10,0 & 10,0 & 10,0 & 10,0 \\
\hline 60 & 10,8 & 10,8 & 10,7 & 10,7 & 10,7 & 10,7 & 10,7 & 10,7 & 10,7 \\
\hline 65 & 10,9 & 10,9 & 10,9 & 10,9 & 10,9 & 10,9 & 11,0 & 11,0 & 11,0 \\
\hline
\end{tabular}

\subsection{Resultados das simulações com dois hidrometeoros}

Uma vez que pode existir mais de um tipo de hidrometeoro, foram feitas simulações teóricas para a presença de pelo menos 2 tipos de hidrometeoros(agua - graupel e aguagranizo). Os códigos T-matrix e o Mueller-matrix foram modificados para levar em conta as condições microfísicas, as constantes dielétricas para cada tipo de hidrometeoro. Nas simulações as fracões são calculadas em função da refletividade do radar de cada tipo de hidrometeoro. Sendo que a distribuição de tamanho de gotas o exponente de Marshall and Palmer [1948], com diferente tipo de espécie, variando entre 0 a $65 d B Z$ e depois é feito a combinação entre elas. 
Simulações teóricas: efeitos dos hidrometeoros, DSD, temperatura e elevação nas variáveis polarimétricas.

\subsubsection{Mistura água-graupel}

Na figura 3.12 são apresentadas as simulações para a mistura de água-graupel, sendo que pode-se observar os seguintes resultados:

Na figura 3.12(a) observa-se que para valores de fator de refletividade baixos onde predomina o graupel com respeito às gotas de agua presentes. A partir de $30 d B Z$ para água começa a ser predominante, devido ao aumento da concentração das gotas de água ou o aumento de seu tamanho que refletem mais que o graupel.

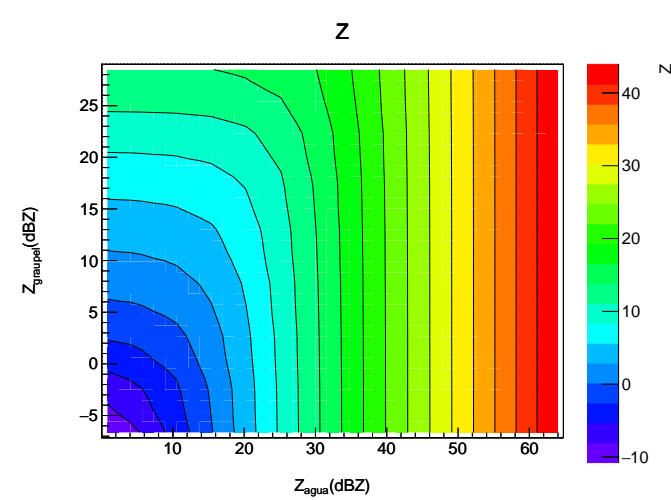

(a)

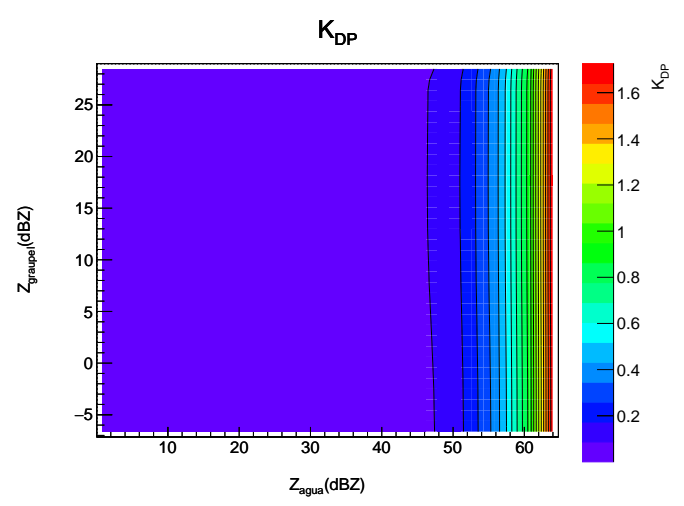

(c)

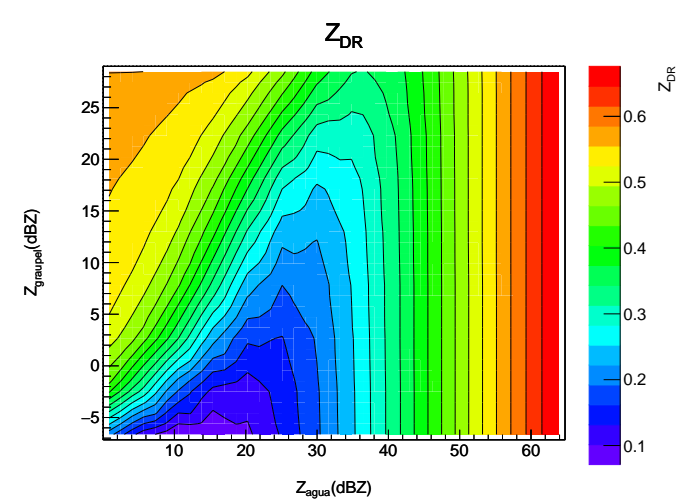

(b)

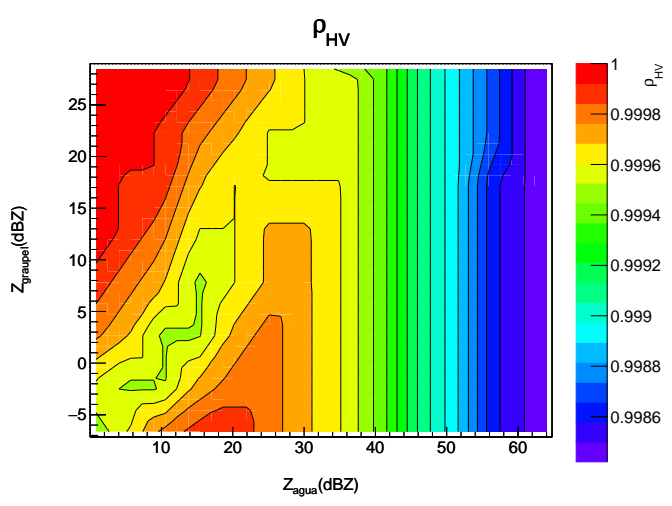

(d)

FigURA 3.12: Simulações teóricas para mistura entre água e graupel: (a) Fator de refletividade do radar $(Z)$; (b) Refletividade diferencial $\left(Z_{D R}\right)$; (c) Fase diferencial especifica $\left(K_{D P}\right) ;(d)$ Coeficiente de correlação $\left(\rho_{H V}\right)$.

Ao analisar o $Z_{D R}$, figura 3.12(b), enquanto os valores de refletividades de chuva são baixos, menor de $30 \mathrm{dBZ}$ para altos valores de refletividade do graupel, o $Z_{D R}$ apresenta valores baixos perto de zero devido ao tamanho do graupel com respeito à gota de chuva. 
Simulações teóricas: efeitos dos hidrometeoros, DSD, temperatura e elevação nas variáveis polarimétricas.

Quando a gota de chuva começa a aumentar seu tamanho e o valor de refletividade é superior a $35 \mathrm{dBZ}$, os valores de $Z_{D R}$ aumentam e predomina em relação ao graupel.

Quando os hidrometeoros são pequenos e quase esféricos, a figura 3.12(c) mostra que estes mantém-se isotrópicos até que a refletividade da água tenha valores maiores e começa a a variar dependendo da mudança de fase presente na mistura. Para o caso da correlação, mostra concordância com o dito anteriormente, os dois hidrometeoros são esféricos para valores baixos de refletividade, não sendo desse jeito quando a refletividade aumenta.

\subsubsection{Mistura água-granizo}

Dos resultados da simulação da mistura água-granizo, figura figura 3.13 pode-se observar que no caso da refletividade para estes hidrometeoros, partir dos $40 \mathrm{dBZ}$ predomina água, dado por aumento de gotas de água e por seu tamanho, então as gotículas de água refletem mais que o granizo, figura 3.13(a).

Ao analisar a figura 3.13(b), $Z_{D R}$, esta indica que para valores baixos de refletividade o valor de $Z_{D R}$ é perto de zero, devido ao tamanho do granizo com respeito à gota de água. Com o crescimento do tamanho dos hidrometeoros $(Z>40 \mathrm{dBZ})$ aumenta também o valor de $Z_{D R}$, predominando os valores das gotas de chuva em relação ao granizo.

Para o caso da $K_{D P}$, figura $3.13(\mathrm{c})$, observa-se que os hidrometeoros só se mantém esféricos quando as refletividades são baixas e existe predomínio do graupel em relação a água, quando são pequenos ambos hidrometeoros. Quando tem mudança de fase, com o crescimento dos hidrometeoros, o valor de $K_{D P}$ varia e predomina com respeito ao valor de $K_{D P}$ da água, para refletividades $>40 \mathrm{dBZ}$.

Os valores da correlação, figura 3.13(d) se aproximam de 1, e as diferenças entre os valores são pequenas, com predomínio do granizo quando as partículas são pequenas e esféricas. Quando começa a variar sua geometria com o aumento do tamanho, e o aumento da refletividade diminui o valor do coeficiente ce correlação, predominando água para valores $>30 \mathrm{dBZ}$. 
Simulações teóricas: efeitos dos hidrometeoros, DSD, temperatura e elevação nas variáveis polarimétricas.

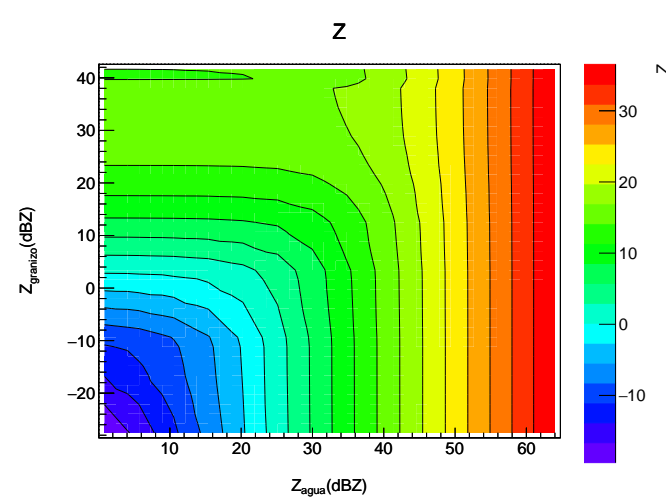

(a)

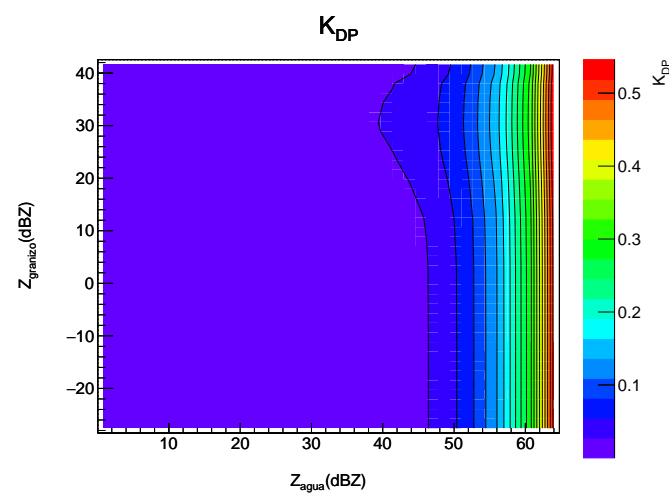

(c)

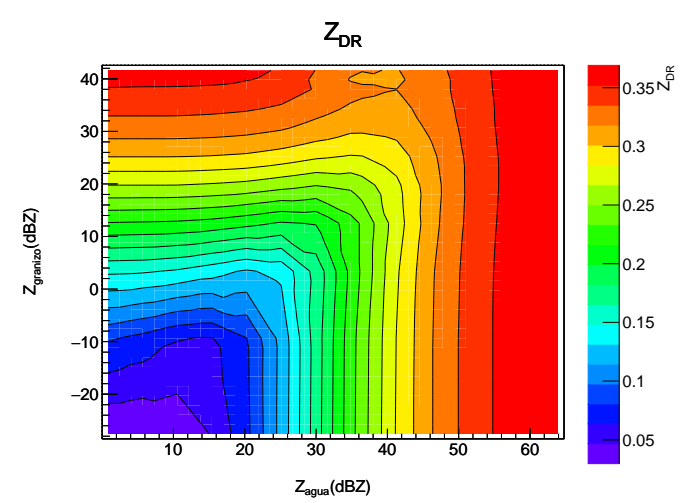

(b)

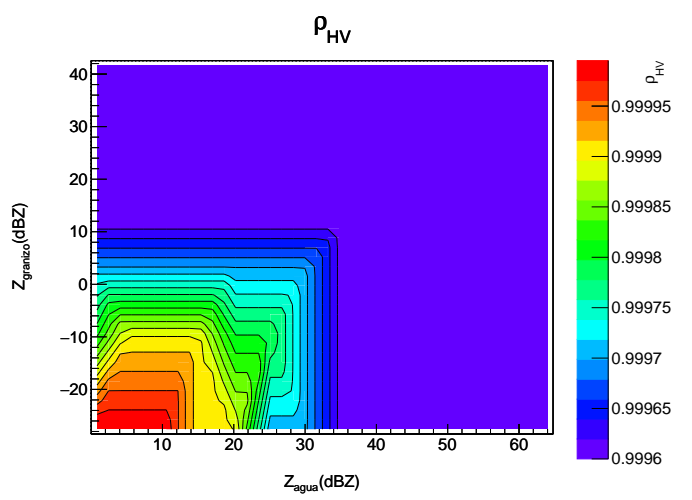

(d)

Figura 3.13: Simulações teóricas para mistura entre água e granizo: (a) Fator de refletividade do radar $(Z)$; (b) Refletividade diferencial $\left(Z_{D R}\right)$; (c) Fase diferencial especifica $\left(K_{D P}\right) ;(d)$ Coeficiente de correlação $\left(\rho_{H V}\right)$. 


\section{CAPÍTULO 4}

\section{ClassifiCAÇÃO DE HidROMETEOROS: ESTUDO DE CASOS.}

\subsection{Experimento CHUVA.}

Para entender os processos das nuvens e validar as estimativas de precipitação do TRMM e GPM, foram realizadas diversas campanhas experimentais durante os anos 2010-2014, dentro do projeto CHUVA (do inglês "Cloud Processes of the Main Precipitation Systems in Brazil: A Contribution to Cloud Resolving Modeling and to the Global Precipitation Measurement",Machado, L. A. et al. [2014]).

No período compreendido entre 1 de novembro de 2011 e 31 de março de 2012 foi realizada a campanha de maior duração correspondente ao Projeto CHUVA no Vale do Paraíba. Nesta campanha, o principal instrumento usado para medir as assinaturas polarimétricas dos hidrometeoros o radar Doppler banda X de dupla polarização (XPOL 9.3 GHz), modelo Meteor 50DX fabricado por Selex Gemanotrik, (Mattos et al. [2016]). O radar foi instalado na Universidade do Vale do Paraíba, figura 4.1, a $650 \mathrm{~m}$ acima do nível do mar e tinha uma cobertura de $100 \mathrm{~km}$ de distância, logo monitoramento o Vale do Paraíba e a cidade de São Paulo. Durante estes experimento o radar foi configurado para realizar diversas varreduras volumétricas de 13 elevações e seç̧ões transversais (RHI) ao longo de dois lugares instrumentados conforme detalhado na tabela 4.1 a cada 6 minutos. 


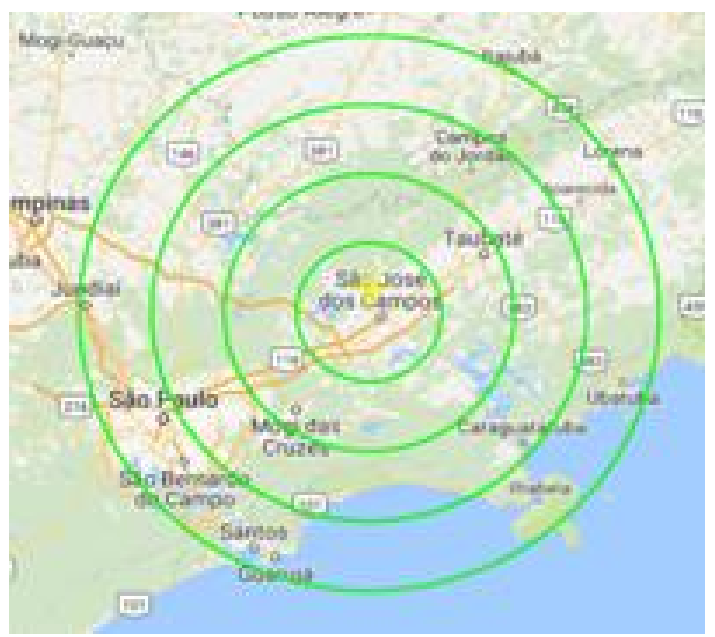

Figura 4.1: Localização do radar Doppler banda X de dupla polarização durante o experimento de campo no Vale do Paraíba.

O radar coletava $Z_{H}, Z_{D R}, \phi_{D P}, \rho_{H V}, V_{\text {rad }}$ e $W_{\text {rad }}$. Incluiu como parte da estratégia de varredura do radar, uma varredura volumétrica, duas varreduras de indicadores de altura e uma varredura de feixe vertical (Mattos et al. [2016]).

TABela 4.1: Parâmetros operacionais do radar XPOL durante a Campanha do Vale do Paraíba. (Fonte: Mattos et al. [2016])

\begin{tabular}{|c|c||}
\hline \hline Parâmetros & Características \\
\hline Frequência de operação & $9.375 \mathrm{GHz}$ \\
\hline Potência do transmissor & $35 \mathrm{~kW}$ (magnetron, valor por canal de transmissão) \\
\hline Polarização & Transmissão simultânea na horizontal e na vertical \\
\hline Frequência de repetição do pulso & $1500 / 1200 \mathrm{~Hz}$ (todas as elevações) \\
\hline Largura do feixe da antena & $1.3^{\circ}$ \\
\hline Diâmetro da antena & $1.8 \mathrm{~m}$ \\
\hline Altitude do radar & $650 \mathrm{~m}$ \\
\hline Número de Elevações & $13(1.0,1.7,2.6,3.6,4.8,6.2,7.8,9.7,11.9,14.5$, \\
\hline Resolução do gate & $17.5,20.9,25.0)^{\circ}$ \\
\hline \hline
\end{tabular}


Uma vez que o estudo está centrado na distribuição vertical dos hidrometeoros, somente as varreduras em elevação com azimute constante, ou seja, RHI serão utilizados neste estudo. As varreduras de RHI estavam configuradas com um gate de $125 \mathrm{~m}$ e 190 elevações entre 0 e $60^{\circ}$ de elevação.

Para evitar os efeitos da atenuação da chuva nesta frequência e radoma molhada (Schneebeli et al. [2012]), já que podem comprometer a classificação dos hidrometeoros, as análises ficaram restritas a casos onde não estava chovendo sobre o radar e que tinham pouca atenuação ao longo do caminho de propagação do feixe do radar, ou seja, 2 dois casos: 8 de Fevereiro e 22 de Março de 2012.

Além deste controle, foi aplicado uma correção de atenuação específica aos dados observados conforme a metodologia descrita por Testud et al. [2000]. De uma forma resumida, a correção é baseada na equação 4.2 que relaciona a fase diferencial específica e a atenuação específica através de uma relação de potência.

$$
A(r)=\alpha K_{D P}(r)
$$

onde $\alpha$ é um coeficiente que depende da temperatura e da frequência e o valor usado foi $\alpha=0.233$, logo a refletividade corrigida foi calculada pela seguinte equação:

$$
Z^{\prime}(r)=Z(r) e^{-0.46 \int_{0}^{r} A(r) d r}
$$

Sabendo que:

$$
\begin{aligned}
\int_{0}^{r} A(r) d r & =\alpha \int_{0}^{r} K_{D P}(r) d r \\
& =\frac{\alpha}{2} \int_{0}^{r} 2 K_{D P}(r) d r \\
& =\frac{\alpha}{2}\left[\Phi_{D P}(r)-\Phi_{D P}(0)\right]
\end{aligned}
$$

Substituindo 4.3 em 4.2:

$$
Z^{\prime}(r)=Z(r) e^{-0.23\left[\Phi_{D P}(r)-\Phi_{D P}(0)\right.} \quad Z\left[\mathrm{~mm}^{6} / \mathrm{m}^{-3}\right]
$$


Além disso para $Z_{D R}$ fizeram-se correções baseadas na análise de Sakuragi and Biscaro [2012], onde demonstram que houve um aumento do viés e é necessária a correção de viés para melhorar a classificação dos hidrometeoros, equação 4.5.

$$
Z_{D R D}=Z_{D R}+0.5
$$

\subsection{Classificação de hidrometeoros: estudo de casos.}

Para inferir a distribuição vertical dos hidrometeoros foi utilizado o algoritmo proposto por Dolan and Rutledge [2009] além das simulações teóricas feitas com os algoritmos Tmatrix e Nmueller (Capitulo 3), pois podem existir mais de um tipo de hidrometeoro dentro do volume iluminado pelo radar.

\subsubsection{Caso de estudo: 8 de fevereiro de 2012}

Durante o dia 8 de Fevereiro de 2012, o estado de São Paulo apresentava aumento da temperatura e a elevada umidade relativa que favoreceram a formação de temporais associados a rajadas de vento e precipitação na forma de granizo em várias cidades do estado.

Para este caso, figura 4.2, foi observado uma célula de tempestade isolada ao longo do azimute que é feito o RHI durante às 19 : 54 GMT. De acordo com os registros do Projeto CHUVA, esta tempestade provocou chuva forte na região.

Na figura 4.3 é apresentado o $R H I$ do fator de refletividade do $\operatorname{radar}(Z)$, refletividade diferencial $\left(Z_{D R}\right)$, fase diferencial específica $\left(K_{D P}\right)$, o coeficiente de correlação $\left(\rho_{H V}\right)$, velocidade Doppler $(v)$ além da classificação dos hidrometeoros segundo a metodologia de Dolan and Rutledge [2009]. 


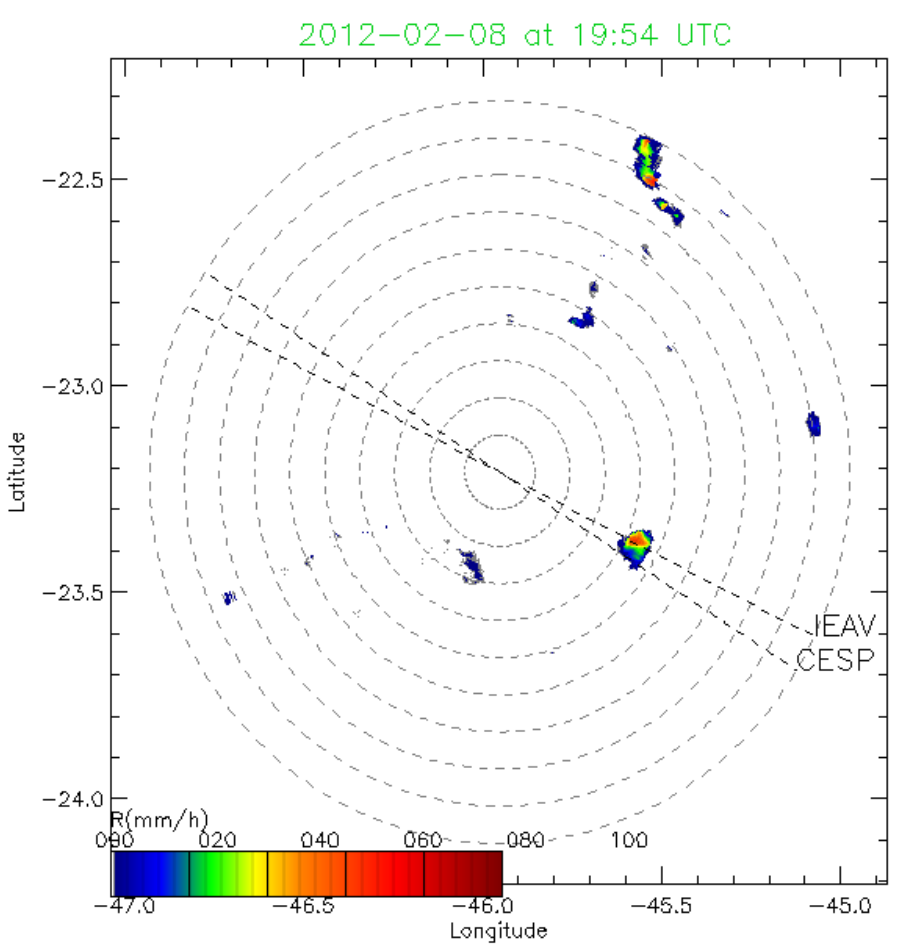

Figura 4.2: PPI da chuva observada no dia 02/08/2012 as 19 : 54 GMT.

\subsubsection{Variáveis polarimétricas}

A figura 4.3(a) ilustra a refletividade do radar a qual varia entre 10 e $70 \mathrm{dBZ}$. Nota-se que a uma distância aproximada de $45 \mathrm{~km}$ do radar, entre $1 \mathrm{~km}$ e $5 \mathrm{~km}$ de altura observa-se $Z>55 d B$ o que pode indicar a presença de granizo ou gotas de chuva grandes. Perto da superfície, o valor de refletividade do radar varia entre 15 e $50 \mathrm{dBZ}$ o qual indica regiões de garoa e chuva forte. Aproximadamente entre $30 \mathrm{~km}$ e $35 \mathrm{~km}$ do radar, e entre $1 \mathrm{~km}$ e $4 \mathrm{~km}$ de altura, observa-se uma área com um fator de refletividade do radar entre os 20 e $35 \mathrm{dBZ}$, que está associado com chuva fraca. Logo, de acordo com a variação dos valores observados acima dos $5 \mathrm{~km}$ de altura nesta tempestade podemos ter presença de granizo, graupel, gotas congeladas e cristais de gelo, acima da isoterma de $0^{\circ} \mathrm{C}$.

Na figura 4.3(b) temos valores de $Z_{D R}$ variando entre $-1,5 e>3 d B$. Na região onde os valores de $Z$ apresentam um máximo, ou seja, $45 \mathrm{dBZ}, Z_{D R}$ oscila entre 0.5 e $>3 \mathrm{~dB}$, o que indica a presença de chuva forte próximo da superfície e acima de $5 \mathrm{~km}$ de altura a presença de granizo pequeno ou graupel. Entre a superfície e os $4 \mathrm{~km}$ de altura, a $35 \mathrm{~km}$ 


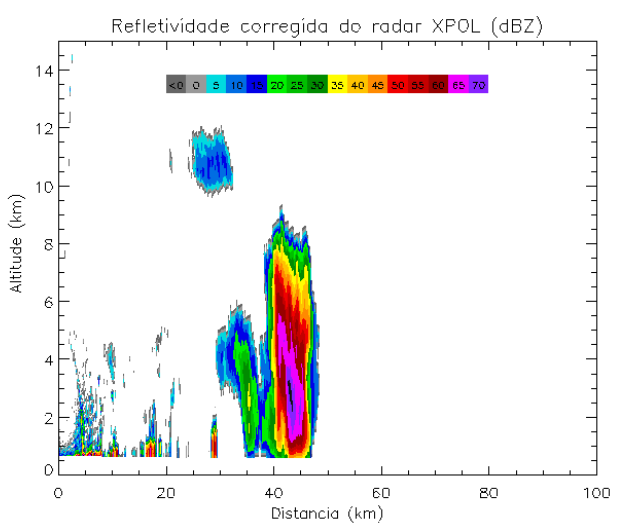

(a)

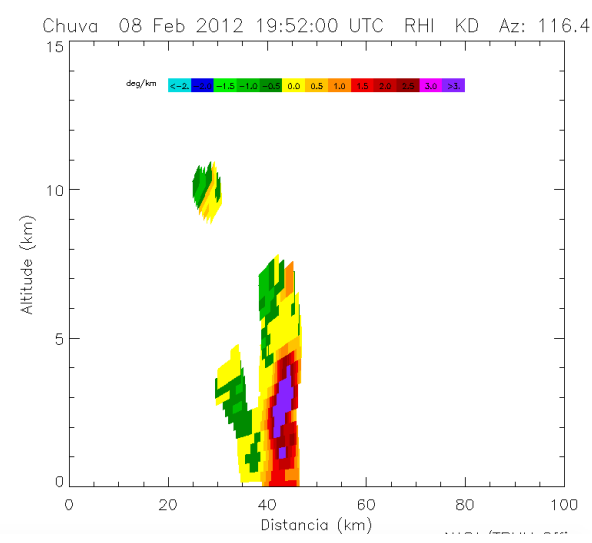

(c)

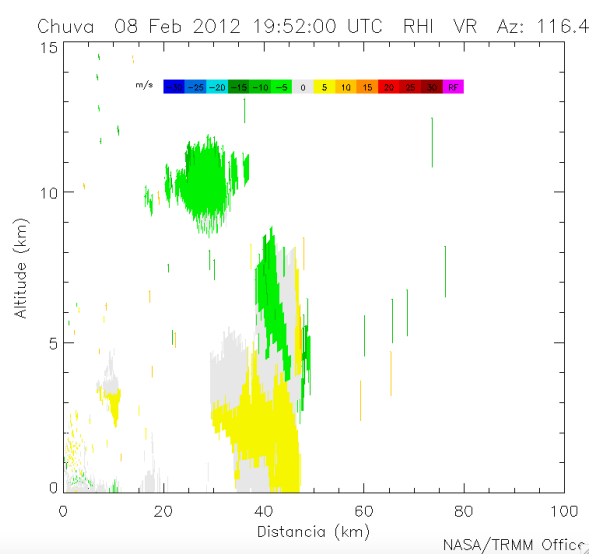

(e)

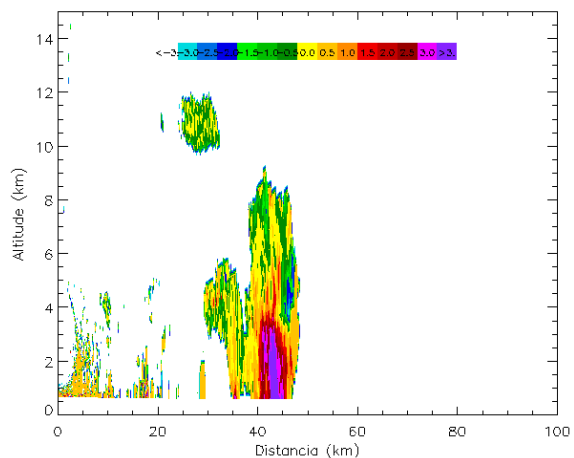

(b)

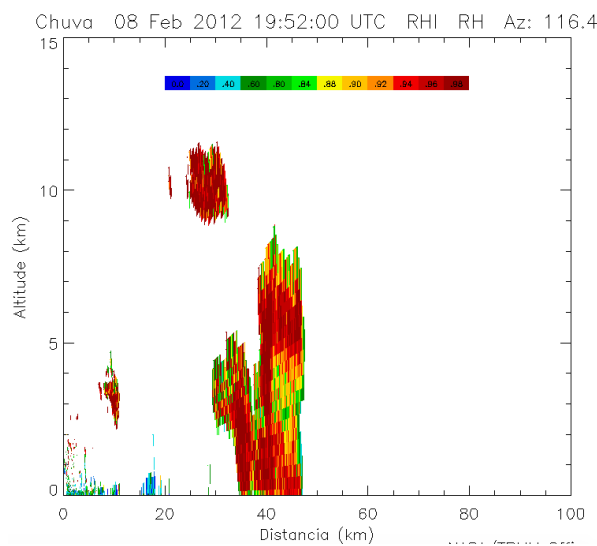

(d)

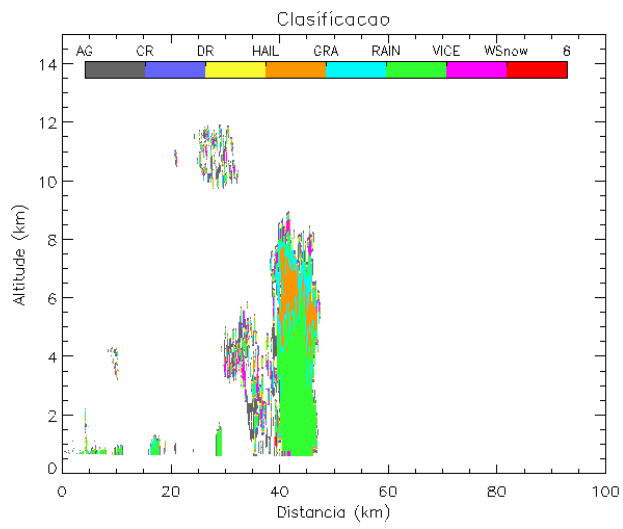

(f)

Figura 4.3: Imagens $\boldsymbol{R H I}$ das variáveis polarimétricas e classificação de hidrometeoros: (a) Fator de refletividade do radar $(Z)$; (b) Refletividade diferencial $\left(Z_{D R}\right)$; (c) Fase diferencial especifica $\left(K_{D P}\right)$; (d) Coeficiente de correlação $\left(\rho_{H V}\right)$; (e) Velocidade Doppler (v); (f) Classificação dos hidrometeoros(Dolan and Rutledge [2009]) (v) para a chuva observada em 02/08/2012 as 19 : 52 GMT. 
do radar o valor de $Z_{D R}$ está aproximadamente entre -0.5 e $0 \mathrm{~dB}$, indicando a presença de graupel derretendo e chuva fraca.

Acima da isoterma de $0^{\circ} \mathrm{C}$ aproximadamente a $45 \mathrm{~km}$ predominam valores negativos, com $Z_{D R}-2 e-0.5 d B$, o que pode ser atribuído aos efeitos da elevação da antena o a presença de cristais de gelo ou graupel.

Na figura 4.3(c), os valores de $K_{D P}$ oscilam entre $-1.5 e>3^{\circ} / \mathrm{km}$. A região de máximo é $K_{D P}$ coincidente com o máximo de $Z$, indicando que nesta área os hidrometeoros não são esféricos, são oblatos ou achatados. Este valor indica que temos temos presença de chuva forte. Perto da superfície, a $40 \mathrm{~km}$ do radar observa-se valores de $1.5^{\circ} / \mathrm{km}$ o que indica gotas de chuva ou a presença de graupel ou granizo derretendo. No resto da tempestade, predominam valores de $0^{\circ} / \mathrm{km}$ o que indica a presença de hidrometeoros isotrópicos, que podem ser gotas pequenas se congelando que tem pouca atenuação. Observa-se também uma área com predomínio de valores entre $-1.5 e-0.5^{\circ} / \mathrm{km}$ indicando hidrometeoros com orientação vertical e podendo ser cristais de gelo ou graupel.

Na figura 4.3(d) verifica-se que os valores do coeficiente de correlação $\rho_{H V}$ são altos (> 0,98), o que significa que os hidrometeoros que predominam são esféricos. A zona onde o coeficiente de correlação é menor (valores entre 0.84 e 0.88 ), corresponde com a região atrás da área com máxima refletividade do radar, denotando a presença de hidrometeoros orientados aleatoriamente, ou seja, granizo, agregados, neve ou critais de gelo molhado. Abaixo dos $2 \mathrm{~km}$ predominam os valores entre 0.96 e 0.98 o que representa chuva. Entre os $8 \mathrm{~km}$ e $10 \mathrm{~km}$ de altura tem-se valores de aproximadamente 0.84 o que pode indicar existência de agregados de gelo e neve molhada.

Os campos de velocidade Doppler caracterizam os movimentos de deslocamento dos hidrometeoros em relação ao radar (figura 4.3(e)). Abaixo de $5 \mathrm{~km}$ de altura predominam velocidades de $5 \mathrm{~m} / \mathrm{s}$, o que significa que os hidrometeoros estão se afastando do radar e precipitando Já acima dos $5 \mathrm{~km}$ de altura, as velocidades são negativas, logo os hidrometeoros estão-se aproximando do radar e estão sendo carregados por uma corrente ascendente.

Finalmente, na figura 4.3(f) é apresentada a classificação dos hidrometeoros conforme a metodologia de Dolan and Rutledge [2009]. É possível observar dentro desta nuvem de tempestade o predomínio de gotas de chuva até uma altura de $5 \mathrm{~km}$, coincidindo com a região de máxima refletividade. Acima dos $5 \mathrm{~km}$ de altura, observam-se áreas definidas 
por chuva, granizo, e cristais de gelo. Aproximadamente aos $35 \mathrm{~km}$ do radar e uma altura entre os 2 e $4 \mathrm{~km}$ nota-se uma região pequena com graupel.

\subsubsection{Caso de estudo: 22 de Março de 2012}

Na figura 4.4 são mostrados PPIs de taxa de precipitação de uma linha de instabilidade que se formou no dia 22 de março de 2012 durante as 19 : 36 GMT e 20 : 18 GMT na região do experimento de campo.

É possível observar a formação de uma célula isolada às 19 : 36 GMT (figura 4.4(a)) que se mantém na região por 24 minutos. Depois das 20 : 00 GMT, figura 4.4(e), várias células ficam alinhadas e se unem, de forma a criar uma linha de instabilidade. Às $20: 06$ GMT, figura 4.4(f), é observada a máxima refletividade do radar, ou seja, mais que $60 \mathrm{dBZ}$.

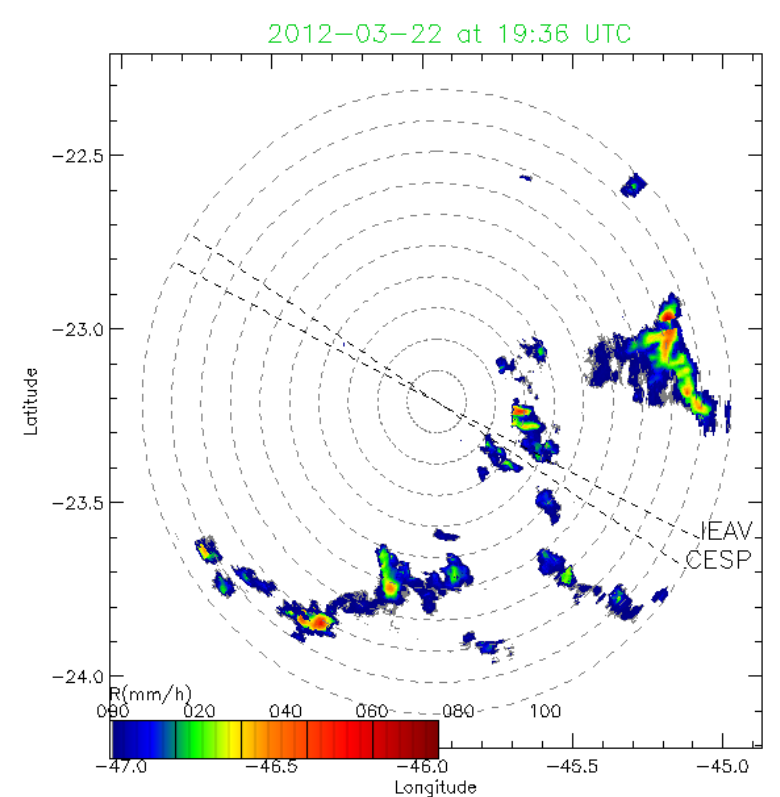

(a) 19:36 GMT

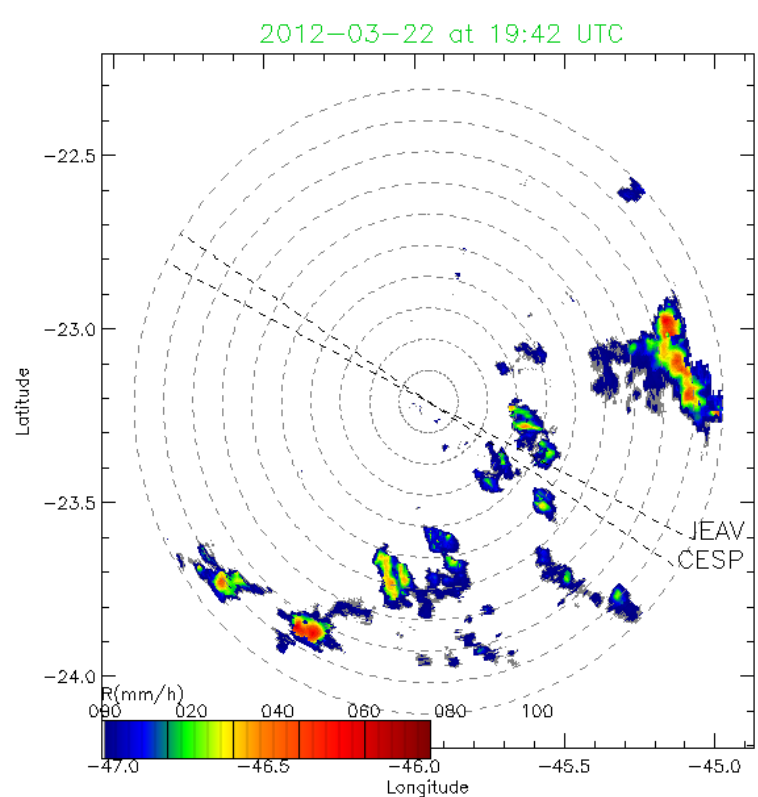

(b) 19:42 GMT 


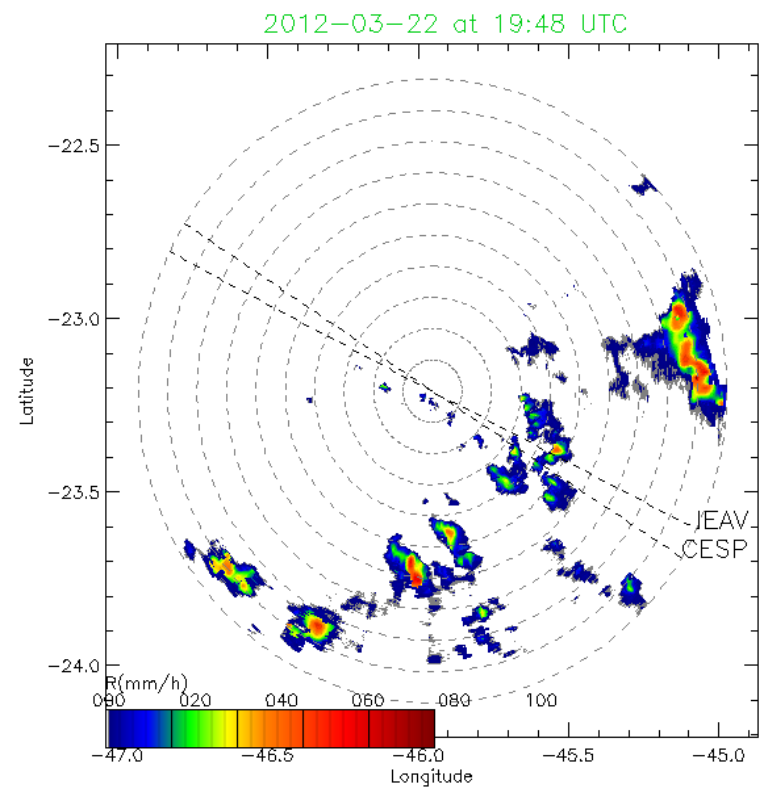

(c) 19:48 GMT

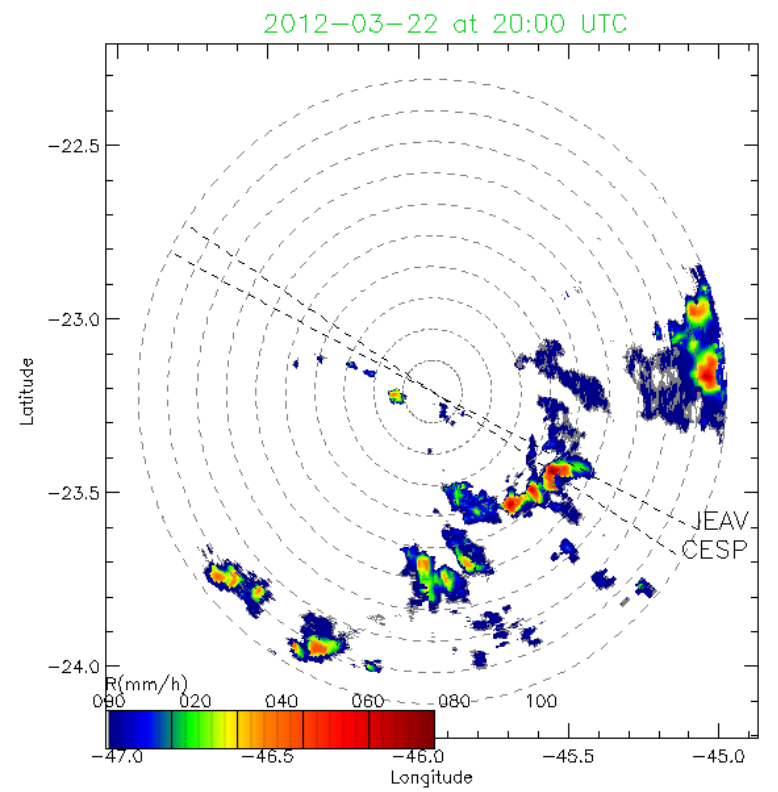

(e) 20:00 GMT

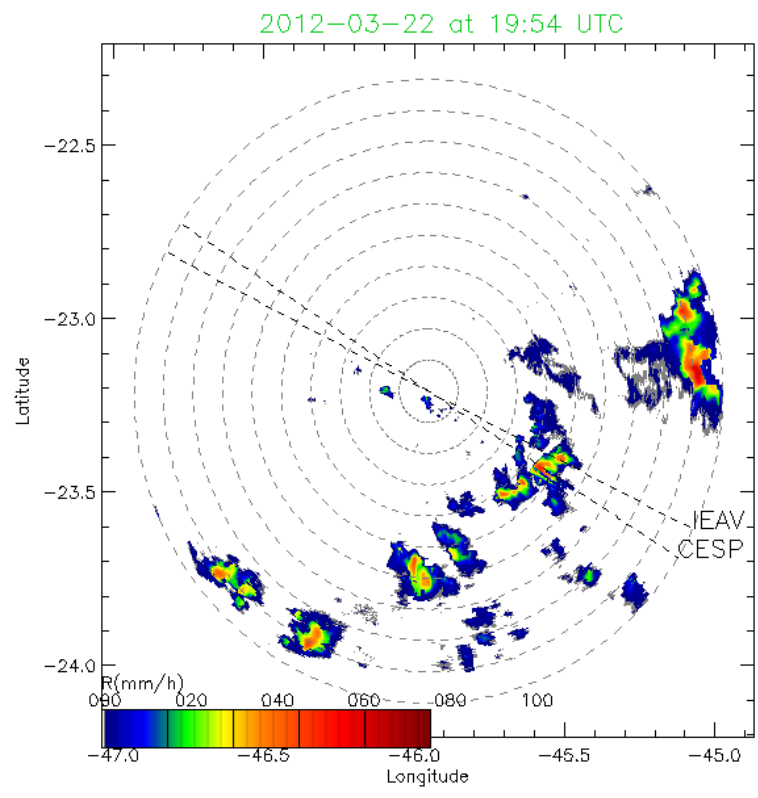

(d) 19:54 GMT

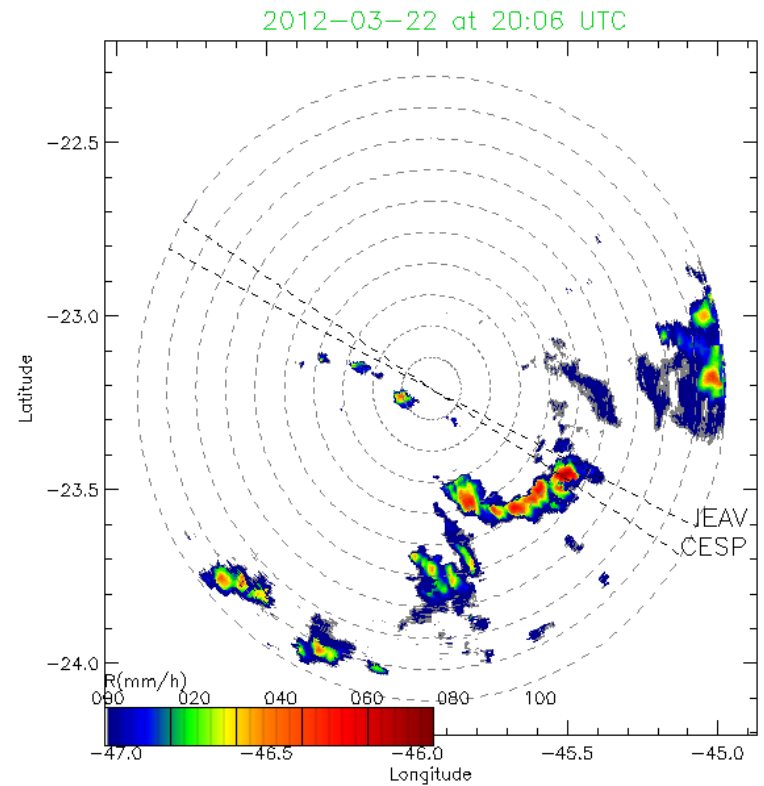

(f) 20:06 GMT 


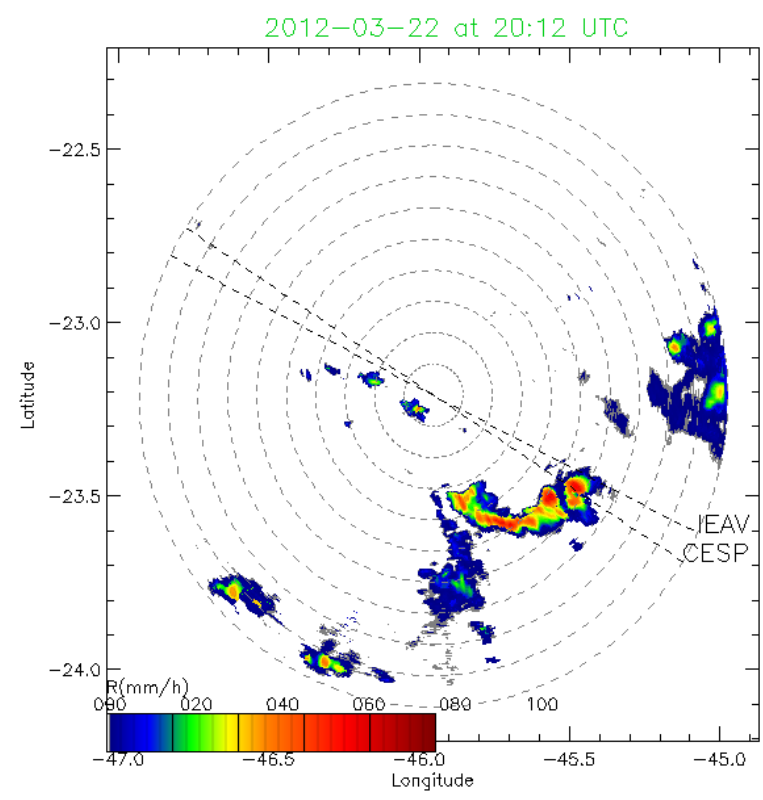

(g) 20:12 GMT

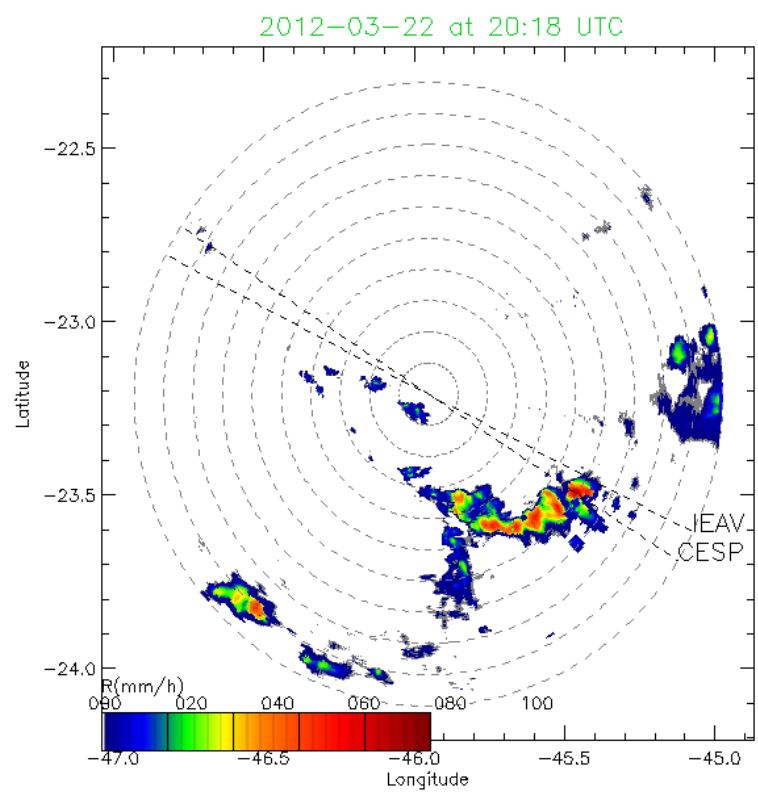

(h) 20:18 GMT

Figura 4.4: Imagens PPI do radar meteorológico Banda X Polarimétrico do dia 22 de março de 2012 para o intervalo entre às $19: 34$ e 20 : 16 GMT.

\subsubsection{Variáveis polarimétricas}

A seguir são analisados individualmente todas as variáveis polarimétricas $\left(Z, Z_{D R}, K_{D P}\right.$ e $\left.\rho_{H V}\right)$ e depois é apresentada a classificação dos hidrometeoros conforme a metodologia de Dolan and Rutledge [2009] para cada RHI. Dessa forma, é possível entender como foi a evolução temporal dos hidrometeoros.

\section{a) Fator de Refletividade (Z)}

Na figura 4.5 são apresentados os RHIs do fator de refletividade do radar para período entre 19 : 34 GMT e $20: 16$ GMT. Na figura 4.5(a), $19: 34$ GMT, nota-se que entre $30 \mathrm{~km}$ e $35 \mathrm{~km}$ existe uma coluna que se estende desde a superfície até os $4 \mathrm{~km}$ de altura com refletividade maior que $50 \mathrm{dBZ}$, além disso, observa-se regiões que atingem mais que $65 \mathrm{dBZ}$. Nestas regiões, pode ter presença de chuva forte e granizo. Entre $4 \mathrm{~km}$ e $6 \mathrm{~km}$ de altura observam-se $\mathrm{Z}$ variando entre 35 e $45 \mathrm{dBZ}$, indicando à presença de graupel e granizo perto da isoterma de $0^{\circ} \mathrm{C}$. Acima dos $6 \mathrm{~km}$ os valores são menores que $30 \mathrm{dBZ}$, o 
que pode estar associado a existência de graupel e ou cristais de gelo. Na parte traseira da célula, abaixo da isoterma de $0^{\circ} \mathrm{C}$, observam-se refletividades entre 25 e $30 \mathrm{dBZ}$ indicando garoa ou chuva fraca.

Às 19: 40 GMT, figura 4.5(b), observa-se que a célula aumenta de área e desloca-se a $40 \mathrm{~km}$ do radar. Entre entre os 2 e $3 \mathrm{~km}$ de altura é observado uma região com $65 \mathrm{dBZ}$, o que pode estar associado gotas grandes de chuva e pedras de granizo. A $45 \mathrm{~km}$ do radar tem-se uma coluna com valor aproximado de $55 \mathrm{dBZ}$ que se estende entre 1.5 e $5 \mathrm{~km}$ de altura indicando a presença de granizo e chuva forte. Já em $30 \mathrm{~km}$ do radar, desde a superfície até $5 \mathrm{~km}, \mathrm{Z}$ varia entre $35 \mathrm{dBZ}$ e $40 \mathrm{dBZ}$, indicando a presença de chuva e graupel. Acima dos $5 \mathrm{~km}$, Z varia entre 10 e $30 \mathrm{dBZ}$ o que pode estar associado com a presença de graupel e cristais de gelo.

Às 19 : 46 GMT, figura 4.5(c), a coluna de refletividade do radar máxima deslocouse a $45 \mathrm{~km}$ do radar, e se estendeu da superfície até $7 \mathrm{~km}$. Entre 2 e $4 \mathrm{~km}$ de altura nota-se valores de $\mathrm{Z}$ maiores que $65 \mathrm{dBZ}$, indicando a presença de granizo derretendo. A presença deste granizo provocou espalhamentos secundários que foram observados a $50 \mathrm{~km}$ de distância acima de 2,5 km (Zrnic [1987]). Acima dos $8 \mathrm{~km}$, os valores de refletividade variam entre 10 e $25 \mathrm{dBZ}$ devido à presença de cristais de gelo e agregados.

Na figura 4.5(d), às 19:52 GMT, a célula esta visivelmente divida porém existe predomínio de chuva forte próxima a superfície. O núcleo de máxima intensidade está a $45 \mathrm{~km}$ do radar e entre 3 e $6 \mathrm{~km}$ temos refletividades do radar acima de $65 \mathrm{dBZ}$, indicando a presença de uma camada de granizo acima. Tal qual no caso anterior, é observado os espalhamento secundário de gelo após $50 \mathrm{~km}$ e acima de $5 \mathrm{~km}$ de altura.

Na varredura correspondente às 19 : 58 GMT, figura 4.5(e), observa-se que entre 35 e $55 \mathrm{~km}$ do radar próximo da superfície a refletividade do radar varia entre 40 e $55 \mathrm{dBZ}$, o que representa chuva forte. Nesta fase a célula alcança uma altura aproximada de $15 \mathrm{~km}$. Já a coluna de máxima refletividade do radar estende-se de 2 a $6 \mathrm{~km}$ com valores maiores de $50 \mathrm{dBZ}$ e com um núcleo com mais de $65 \mathrm{dBZ}$. Estes valores indicam presença de chuva forte, granizo, granizo molhado e chuva com granizo molhado. Note que acima de $8 \mathrm{~km}$ de altura após $50 \mathrm{~km}$ do radar, temos a assinatura de espalhamento secundário de granizo. Nas demais regiões da tempestade, temos a presença de granizo e cristais de gelo acima da isoterma de $0^{\circ} \mathrm{C}$. 
Nos minutos seguintes, a tempestade se desenvolve verticalmente e atinge alturas superiores a $15 \mathrm{~km}$, deslocando-se do radar, figura 4.5(h). Neste horário, observa-se uma diminuição do fator de refletividade principalmente na parte traseira e dianteira da célula, indicando a presença de garoa ou chuva fraca. Entre 55 e $65 \mathrm{~km}$ do radar observa-se um máximo de $50 \mathrm{dBZ}$ indicando nesta região presença de gotas grandes. Esta sequência, apesar de mostrar um desenvolvimento vertical, mostra que a tempestade começa a dissipar pois a refletividade máxima do radar é da ordem de $55 \mathrm{dBZ}$, mas ainda tem granizo em níveis mais altos.

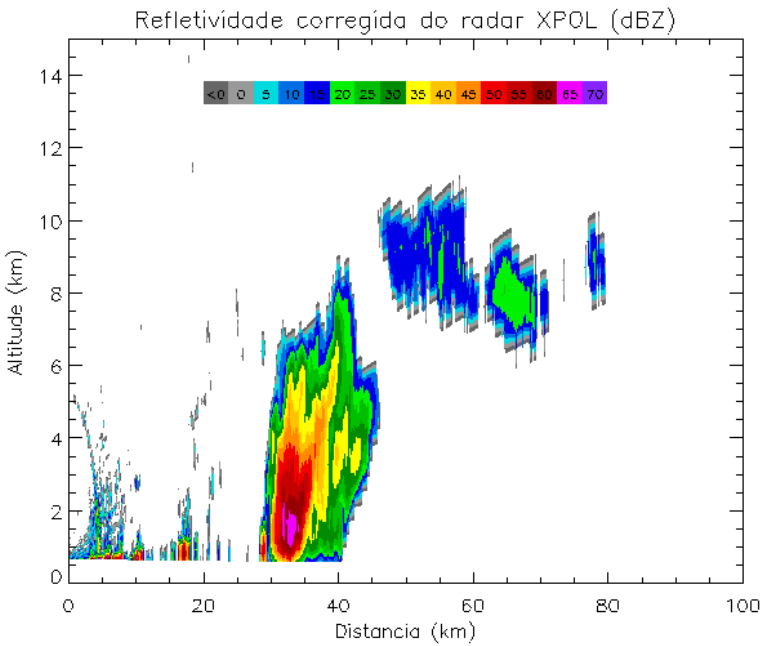

(a) 19:34 GMT

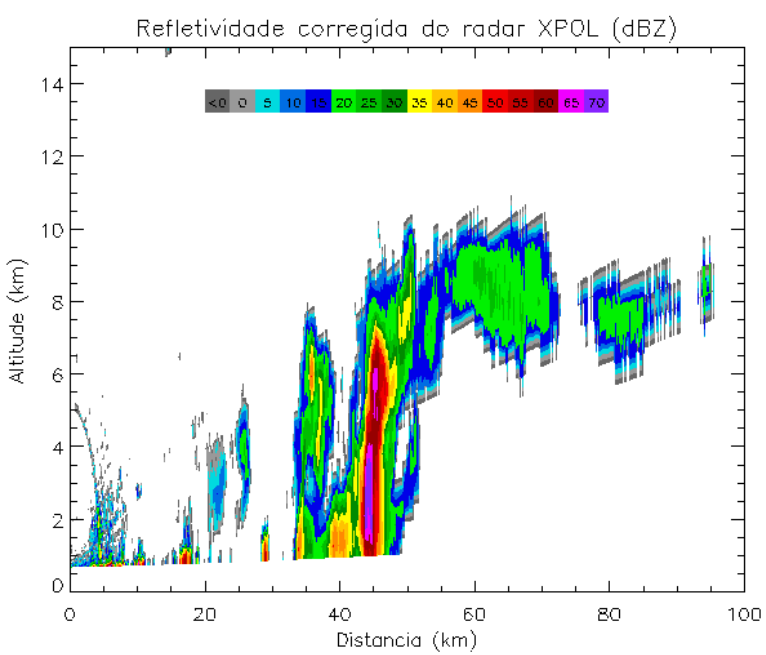

(c) 19:46 GMT

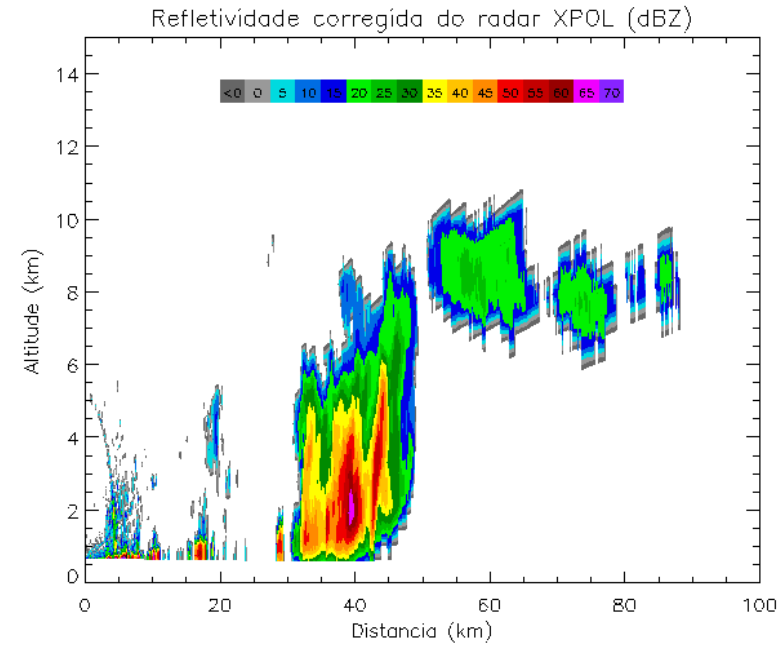

(b) 19:40 GMT

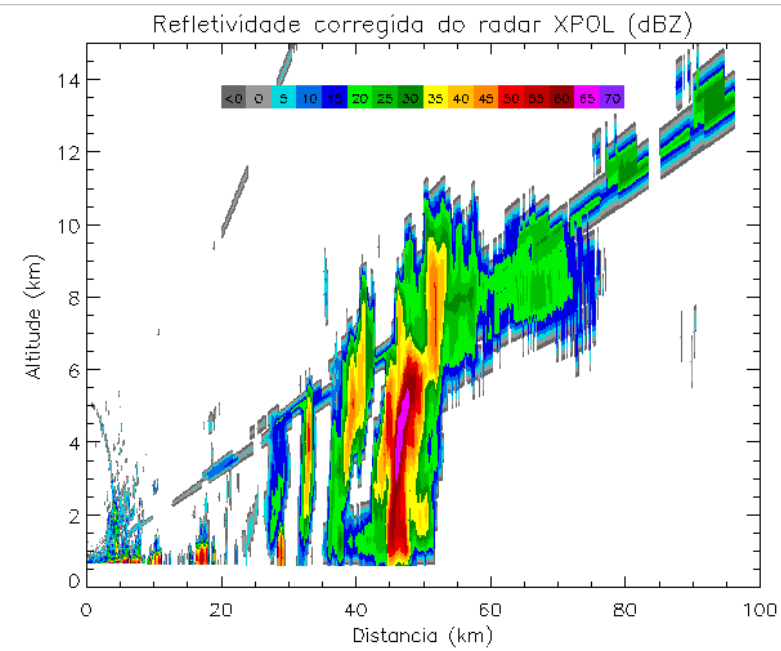

(d) 19:52 GMT GMT 


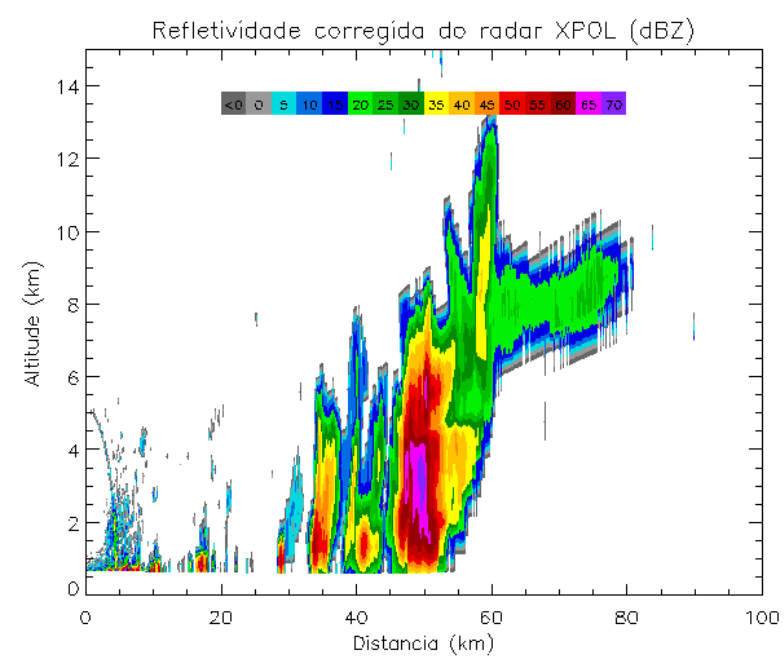

(e) 19:58 GMT

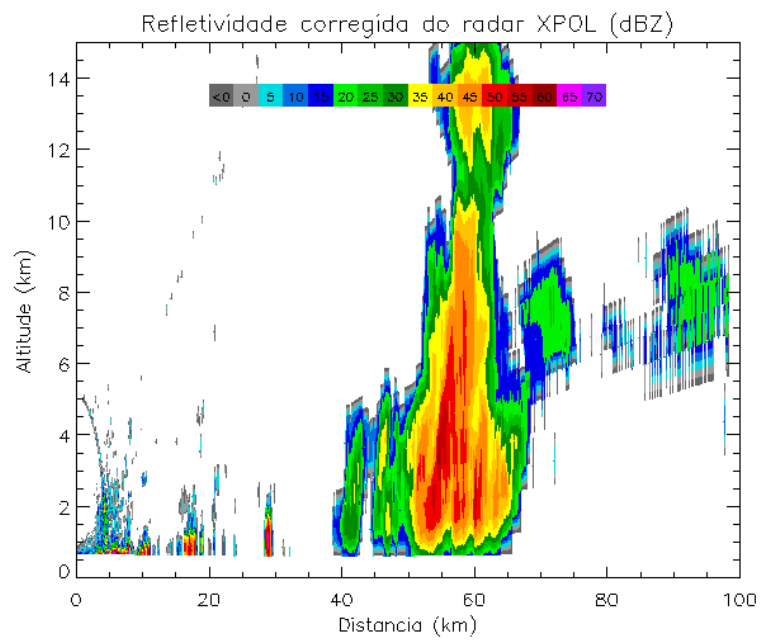

(g) 20:10 GMT

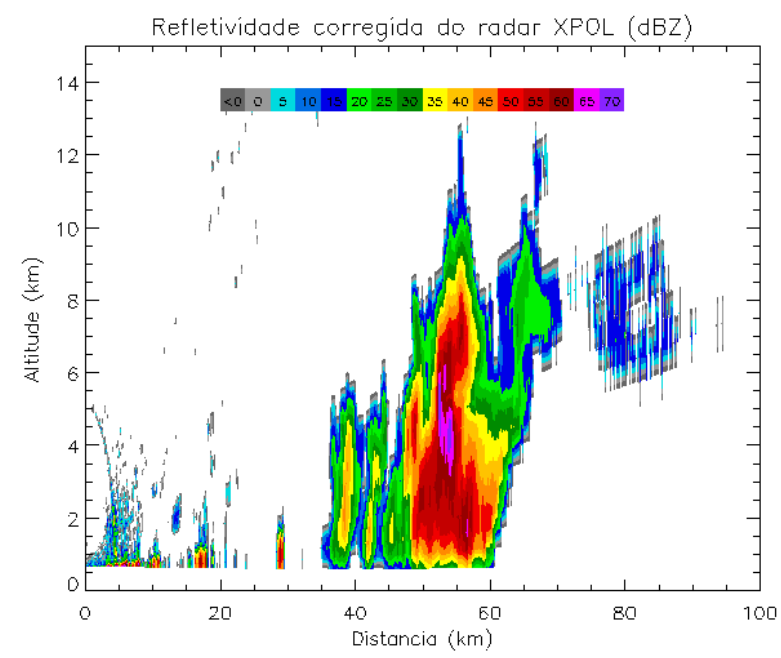

(f) 20:04 GMT

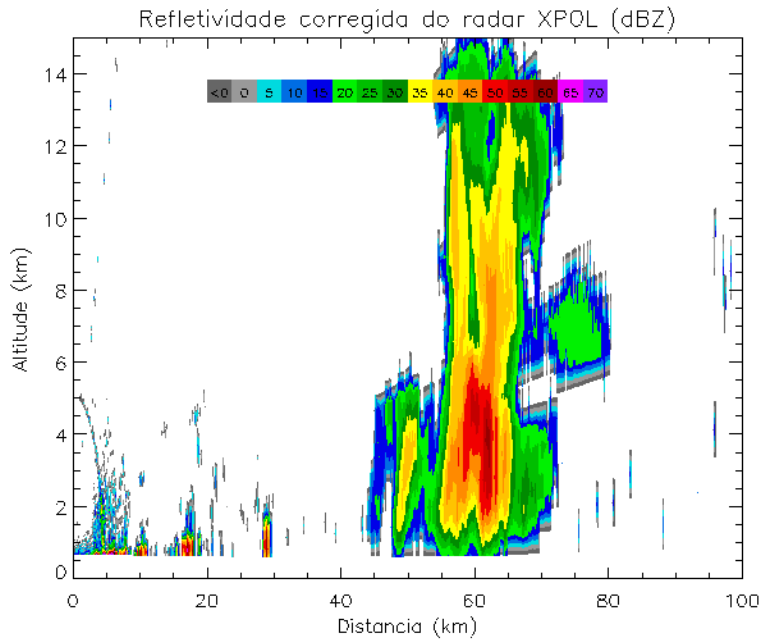

(h) 20:16 GMT

FigurA 4.5: Imagens $\boldsymbol{R H I}$ do fator de refletividade medido pelo radar desde 19 : 34 até $20: 16$ GMT.

\section{b) Refletividade Diferencial $\left(Z_{D R}\right)$}

Quando se analisa a refletividade diferencial $\left(Z_{D R}\right)$ na figura 4.6(a) às $19: 34 G M T$, notase que os valores abaixo da isoterma de $0^{\circ} \mathrm{C}$ os valores desta variável são maioritariamente positivos. Entre os 27 e $30 \mathrm{~km}$ do radar, observa-se uma coluna de maior $Z_{D R}$ que se estende da superfície até $3 \mathrm{~km}$ de altura, com valores de $2.5 \mathrm{~dB}$, coincidindo com a região de máximo $Z$, o que pode indicar presença de hidrometeoros oblatos grandes, neste 
caso podem ser, gotas grandes de chuva ou granizo derretendo. Na parte traseira do sistema, também abaixo da isoterma de $0^{\circ} \mathrm{C}$ existem áreas com valores perto de $0 \mathrm{dBZ}$ o que significa a presença de gotas pequenas quase esféricas. Já a partir dos $3 \mathrm{~km}$ de altura, predominam os valores negativos entre $-0.5 e-1.5 \mathrm{dBZ}$, que se estendem até os $11 \mathrm{~km}$. Acima do nível de congelamento estes valores indicam presença de granizo molhado, graupel e cristais verticais.

Ás 19 : 40 GMT, figura 4.6(b) os máximos estão entre os 40 e $45 \mathrm{~km}$ do radar desde a superfície até uma altura de $5 \mathrm{~km}$. Os valores acima da isoterma $0^{\circ} \mathrm{C}$ não tem variação com respeito à RHI, logo não houve modificação dos hidrometeoros.

Na figura 4.6(c), coincidindo com a coluna de $Z$ máxima, tem-se uma coluna $Z_{D R}$ variando entre 1.5 e $3 \mathrm{~dB}$ que se estende até os $7 \mathrm{~km}$ de altura, com um núcleo que tem um valor maior de $3 d B$. Este valor alto de $Z_{D R}$ pode indicar presença de gotas grandes nesta região, e acima do nível de congelamento podemos ter água superresfriada, cristais de gelo e granizo. Observa-se que na parte traseira do sistema há predomínio de valores negativos que oscilam entre $-0.5 e-1.0 \mathrm{~d} B$, o que sugere a presença de cristais de gelo com orientação vertical e graupel.

O sistema às 19 : 52 GMT, figura 4.6(d) tem valores positivos máximos aos $45 \mathrm{~km}$, e a coluna de máximos estende-se entre os 2 e $5 \mathrm{~km}$ com valores que oscilam entre $1.5 e>$ $3 d B$, ou seja, os hidrometeoros nesta região estão alinhados horizontalmente, indicando a presença de gotas grandes. Acima dos $7 \mathrm{~km}$ predominam valores negativos o que pode indicar de presença cristais de gelo alinhados verticalmente ou presença de graupel.

Na figura 4.6(e) verifica-se un comportamento similar ao observado anteriormente, mas neste caso observa-se na parte traseira do sistema uma região com valores bem negativos que diminuem até $-2.5 \mathrm{~dB}$ indicando a presença de granizo aos $55 \mathrm{~km}$ do radar ou uma atenuação da sinal entre 50 e $55 \mathrm{~km}$.

Nas figuras seguintes, figuras 4.6(f), 4.6(g) e 4.6(h) observa-se na superfície valores perto de $0 \mathrm{~dB}$ com algumas áreas com valores maiores que $1.5 \mathrm{~dB}$, o qual indica chuva fraca com gotas pequenas. Acima dos $5 \mathrm{~km}$ o sistema apresenta uma maior área de $Z_{D R}$ observa-se $Z_{D R}$ negativo o que pode indicar a presença de hidrometeoros alinhados verticalmente, ou seja, podemos ter predomínio de granizo e cristais de gelo. 


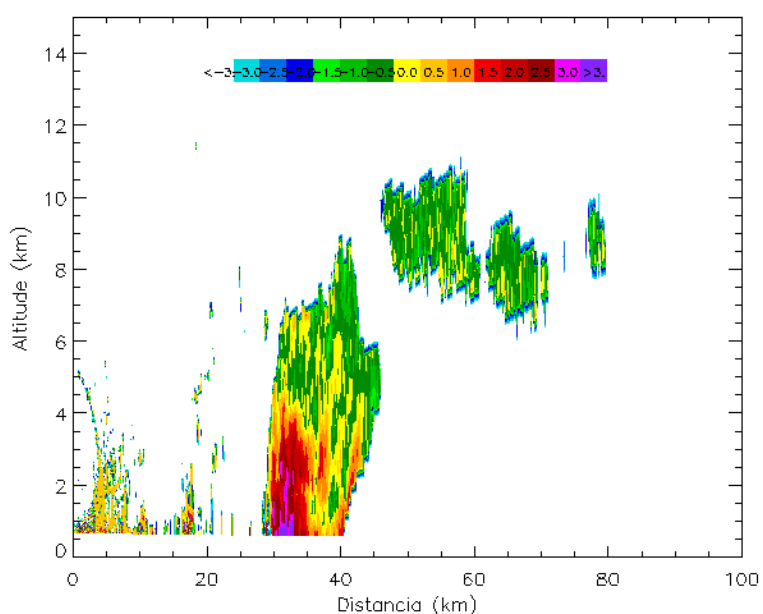

(a) 19:34 GMT

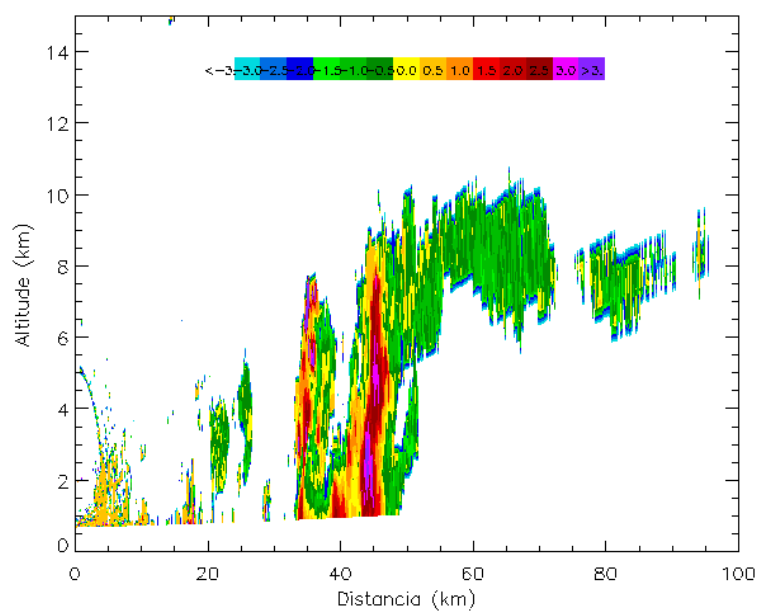

(c) 19:46 GMT

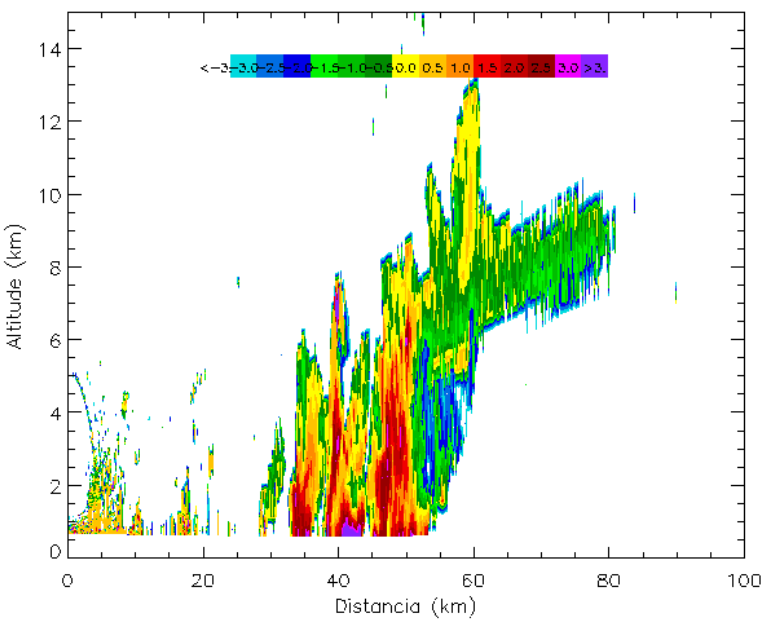

(e) 19:58 GMT

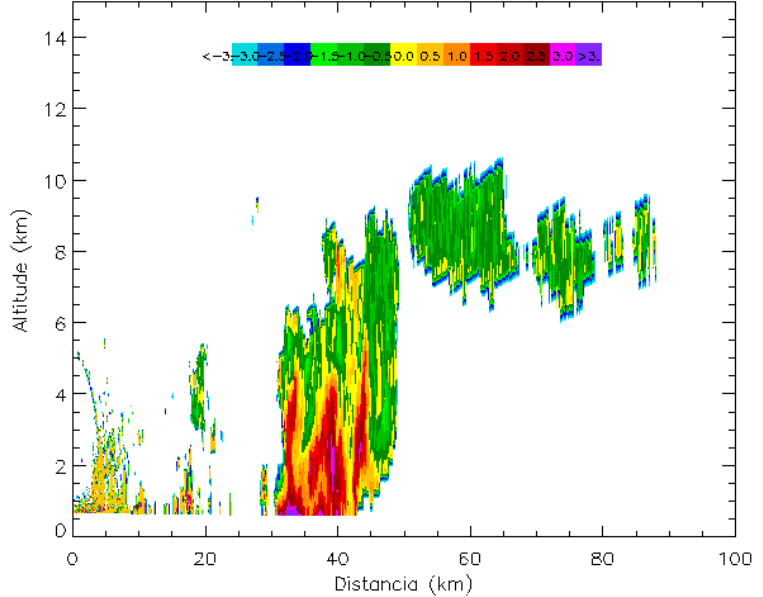

(b) 19:40 GMT

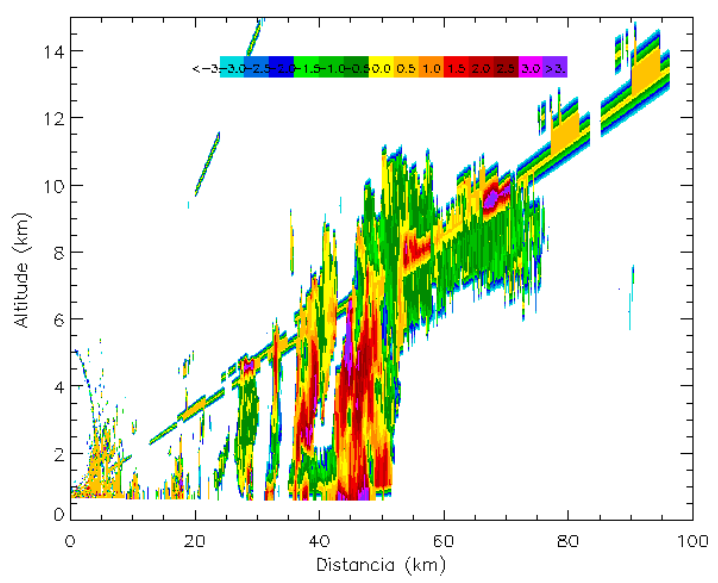

(d) 19:52 GMT GMT

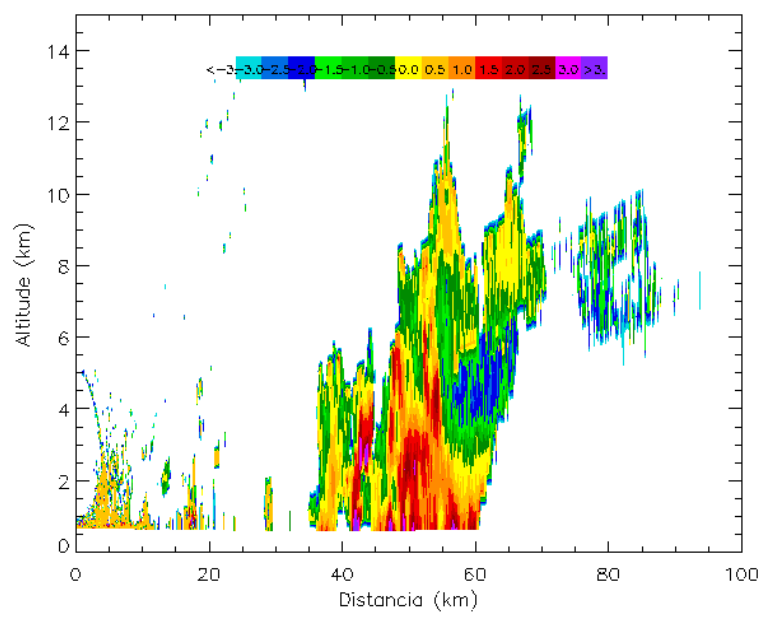

(f) 20:04 GMT 


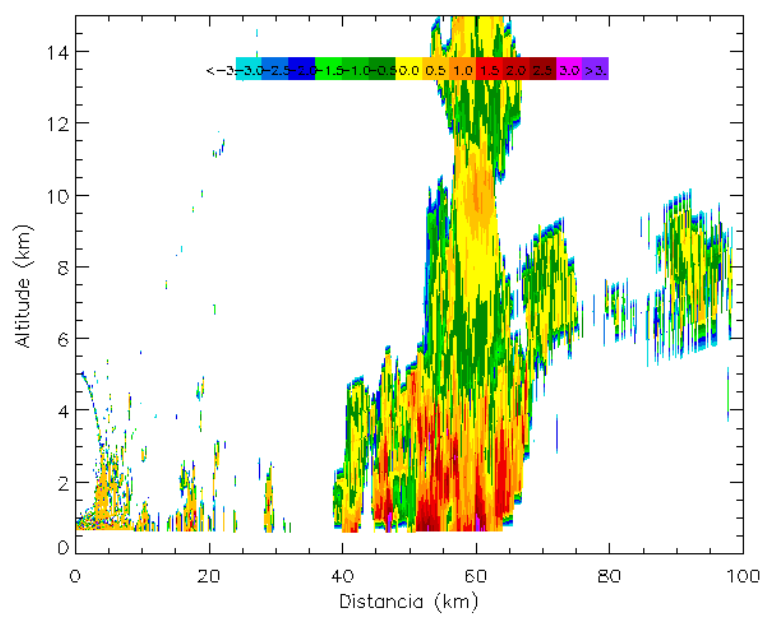

(g) 20:10 GMT

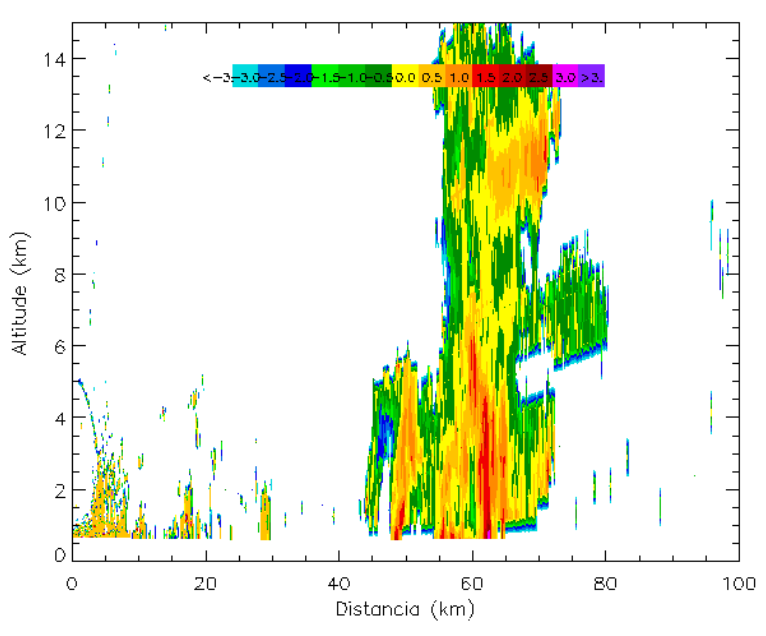

(h) 20:16 GMT

Figura 4.6: Imagens $\boldsymbol{R H I}$ do diferença de refletividade desde $19: 34$ at $20: 16$ GMT.

\section{c) Fase Diferencial Especifica $\left(K_{D P}\right)$.}

As figuras são correspondentes à fase diferencial específica para as nas figuras 4.7(a) e 4.7(b) são apresentados o RHIs da fase diferencial específica correspondente às varreduras das 19 : 34 GMT e 19:40 GMT, respectivamente. É possível observar que nas mesmas regiões onde existam os máximos de $Z$ e $Z_{D R}$, temos na coluna valores de $K_{D P}=2.0 d B$, indicando chuva nessa região.

Nas figuras 4.7(c) e 4.7(d), observam-se colunas com $K_{D P}>1,5^{\circ} / \mathrm{km}$ que coincidem com as variáveis anteriores. Os valores alcançam valores $>3 \% / \mathrm{km}$. Estas regiões com altos valores de $K_{D P}$ podem estar associadas a uma alta concentração de hidrometeoros na fase mista, ou seja, mistura de gotas de chuva grande e granizo.

Os valores negativos de $K_{D P}$ observados no topo da tempestades, ou seja, entre $-0.5 e-$ $1.5^{\circ} / \mathrm{km}$, podem indicar a presença de hidrometeoros orientados verticalmente ou a ocorrência de atenuação por chuva.

Às 19 : 58 GMT, figura 4.7(e), a tempestade apresenta uma coluna que atinge valores $>3 \% / \mathrm{km}$, se estendendo da superfície até os $5 \mathrm{~km}$ de altura, sugerindo a presença de água líquida misturada com partículas de gelo, o que pode ser, granizo, na maior parte da coluna. 
Nas varreduras seguintes, figuras 4.7(f), 4.7(g) e 4.7(h), é possível notar uma diminuição nos valores máximos de $K_{D P}$, coincidindo com o decaimento da tempestade, apesar do desenvolvimento vertical acentuado apresentado neste estágio. Nestes períodos observouse valores próximos de $0^{\circ} / \mathrm{km}$, logo a presença de pequenas partículas . 


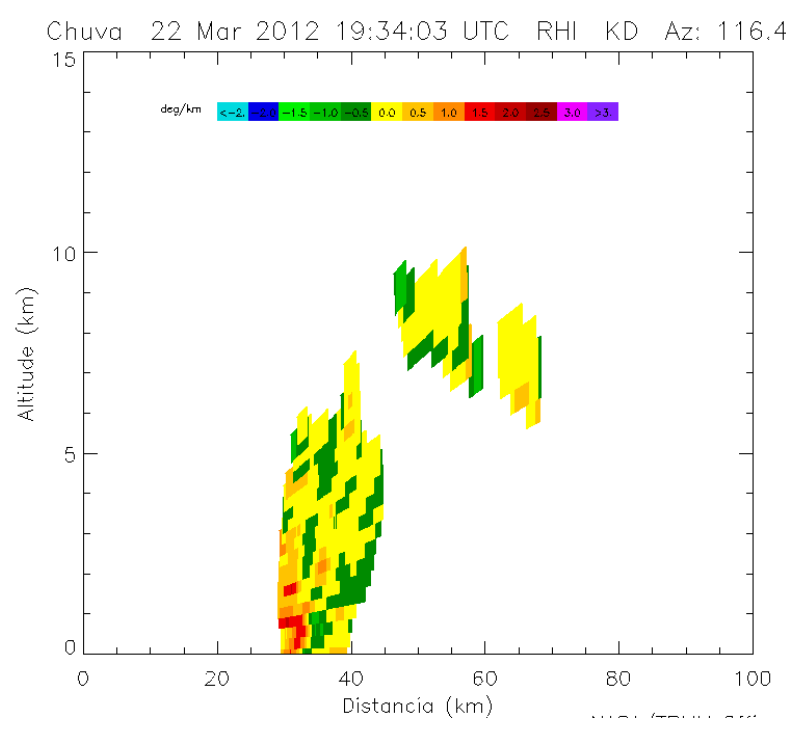

(a) 19:34 GMT

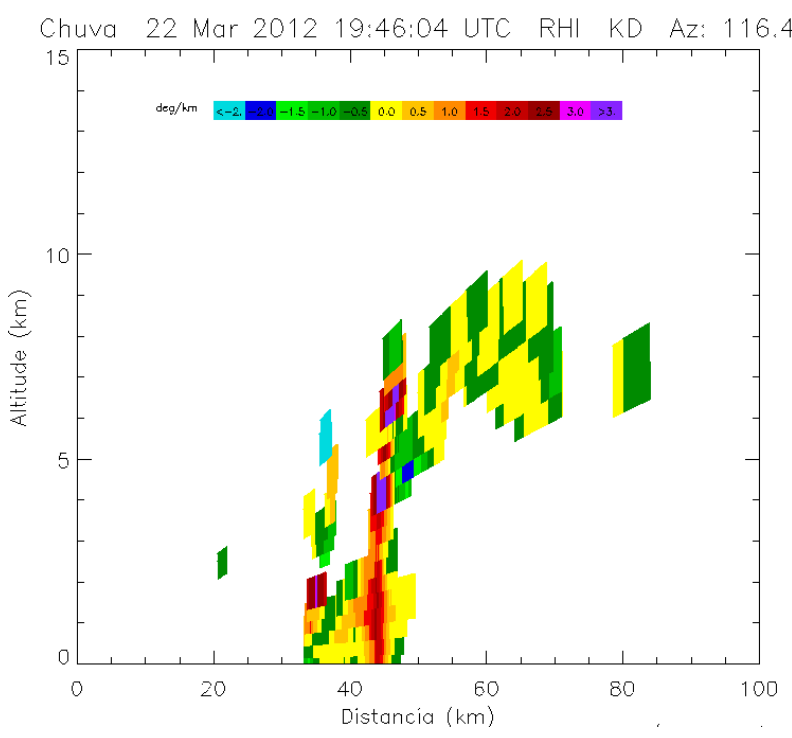

(c) 19:46 GMT

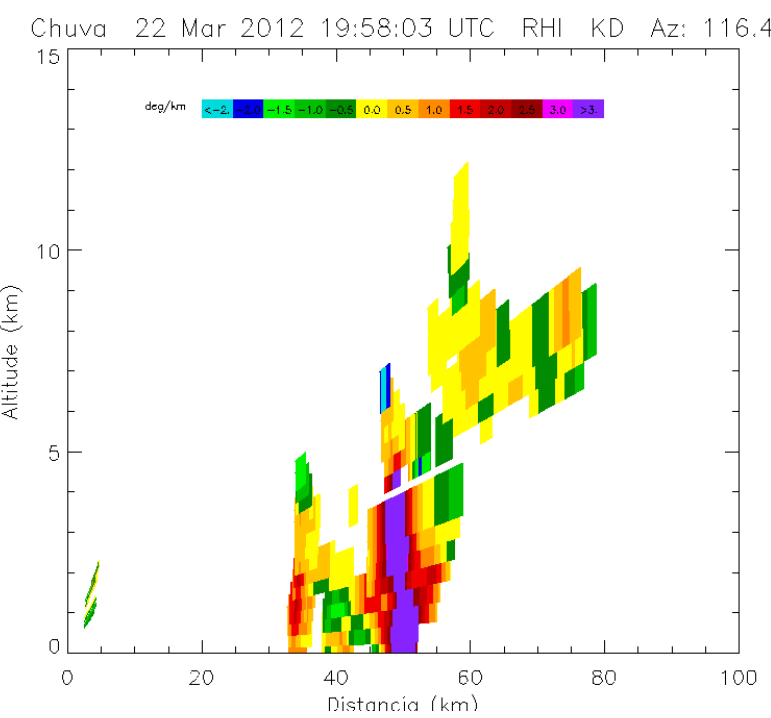

(e) 19:58 GMT

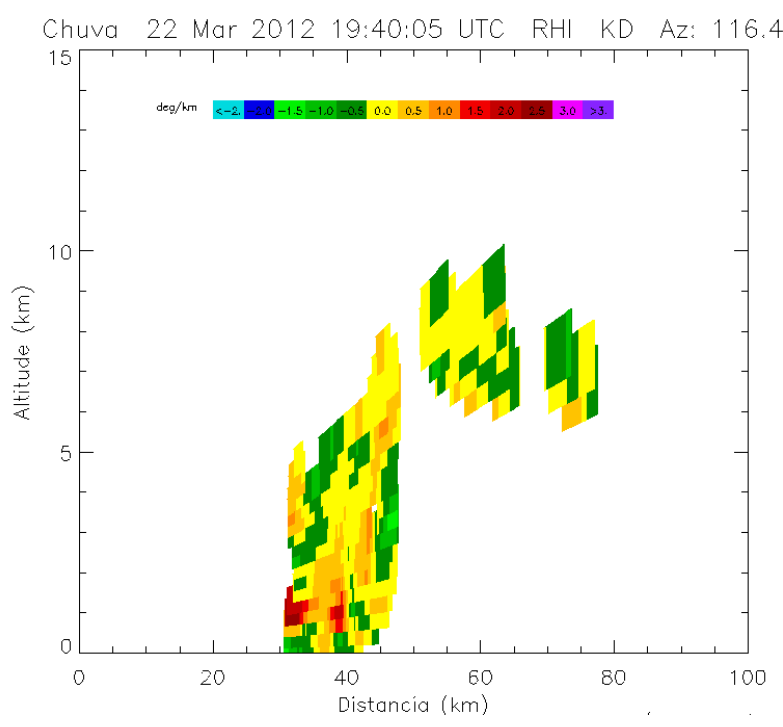

(b) 19:40 GMT

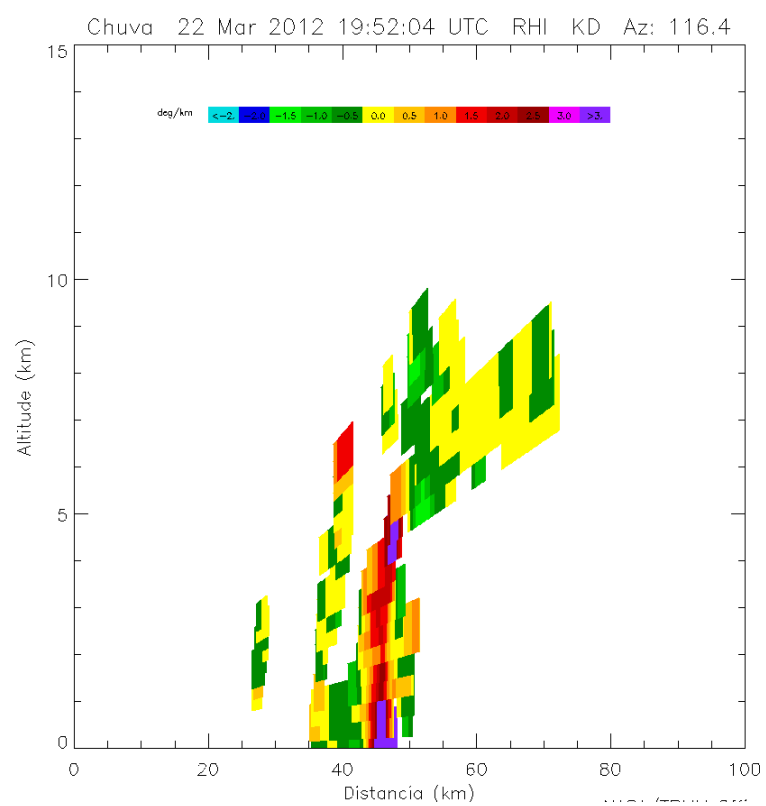

(d) 19:52 GMT

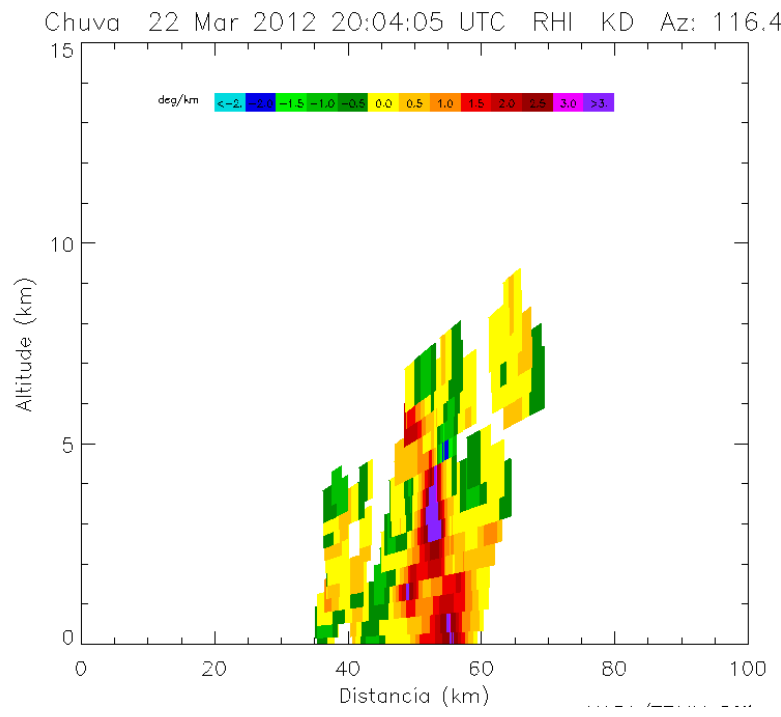

(f) 20:04 GMT 


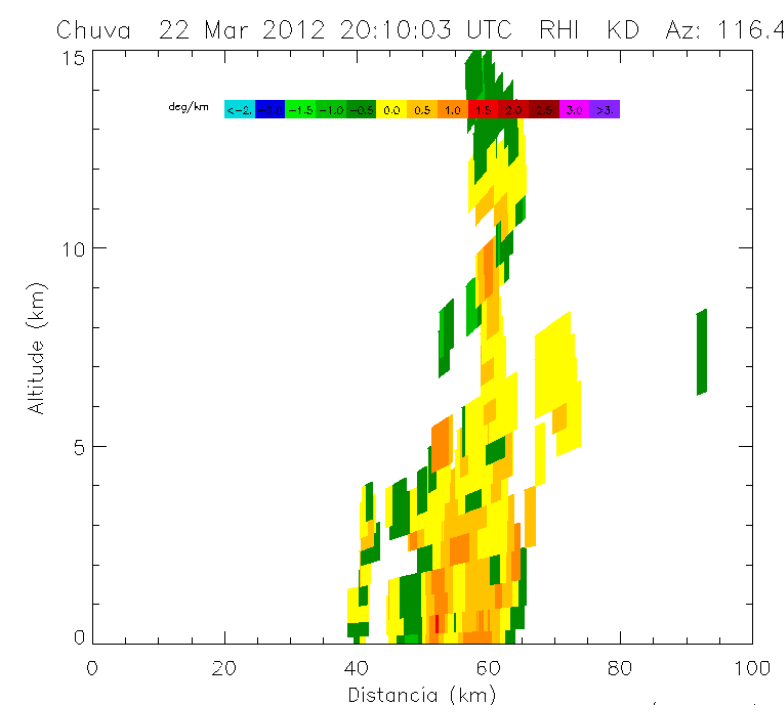

(g) 20:10 GMT

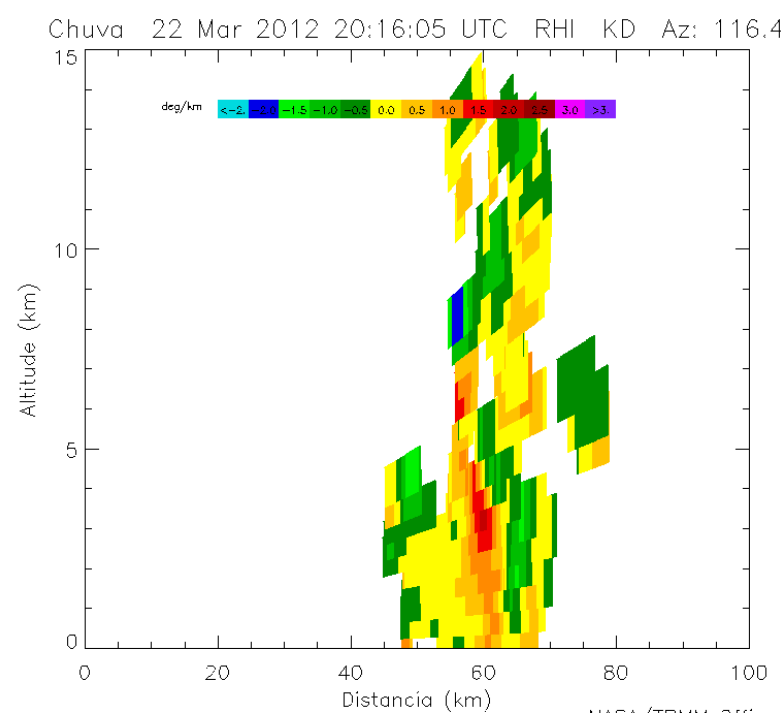

(h) 20:16 GMT

Figura 4.7: Imagens $\boldsymbol{R H I}$ da fase diferencial específica de $19: 34$ a $20: 16$ GMT.

\section{d) Coeficiente de Correlação $\left(\rho_{H V}\right)$.}

Ao analisar o coeficiente de correlação das primeiras varreduras, observa-se que os valores estão próximos de 1, figuras 4.8(a) e 4.8(b). Este resultado indica que há pouca variabilidade dos hidrometeoros, seja na forma, orientação e tipo.

Entretanto, nos seguintes minutos (19:46 GMT e 19 : 52 GMT), entre a superfície e os $7 \mathrm{~km}$, já é possível observar uma heterogeneidade, onde a correlação varia entre 0,8 e 0,92 que pode indicar a presença de chuva e gelo molhado (figuras 4.8(c) e 4.8(d)).

Na figura 4.8(e), correspondente à varredura das 19 : 58 GMT, observa-se na parte traseira do sistema, um área que se estende desde a superfície até os $6 \mathrm{~km}$ de altura, que tem valores de coeficiente de correlação entre 0.80 e 0.92, indicando que tem existência nessa área de uma mistura de hidrometeoros que diferem em forma e tamanho ou atenuação.

O sistema às 20 : 04 GMT, (figura 4.8(f)) apresenta um núcleo no seu interior com valores de $\rho_{H V}$ entre 0.60 e 0.92 , que se estende entre $3 \mathrm{~km}$ e $7 \mathrm{~km}$, que indica que os hidrometeoros são diversificados nesta região. No resto do sistema mantém-se a homogeneidade dos hidrometeoros, com valores próximos a 1 demonstrando que os hidrometeoros são quase esféricos. 
Nas figuras 4.8(g) e 4.8(h), nota-se que o sistema é quase homogêneo em toda sua extensão, ou seja, os hidrometeoros que tem en seu interior são quase esféricos. Abaixo da isoterma de $0^{\circ} \mathrm{C}$ os hidrometeoros podem ser pequenas gotas de chuva e acima do nível de congelamento podem ser granizos pequenos e graupel.

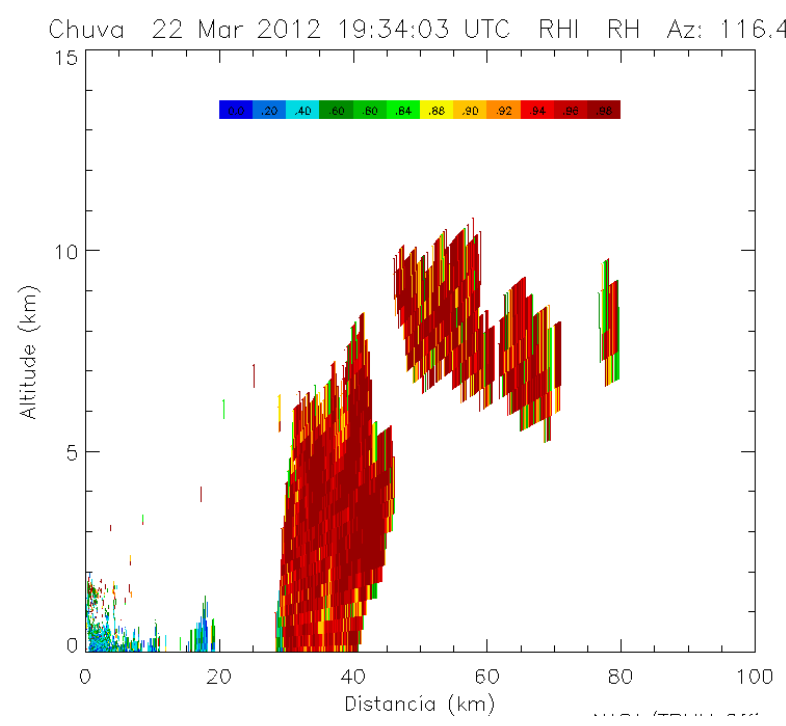

(a) 19:34 GMT

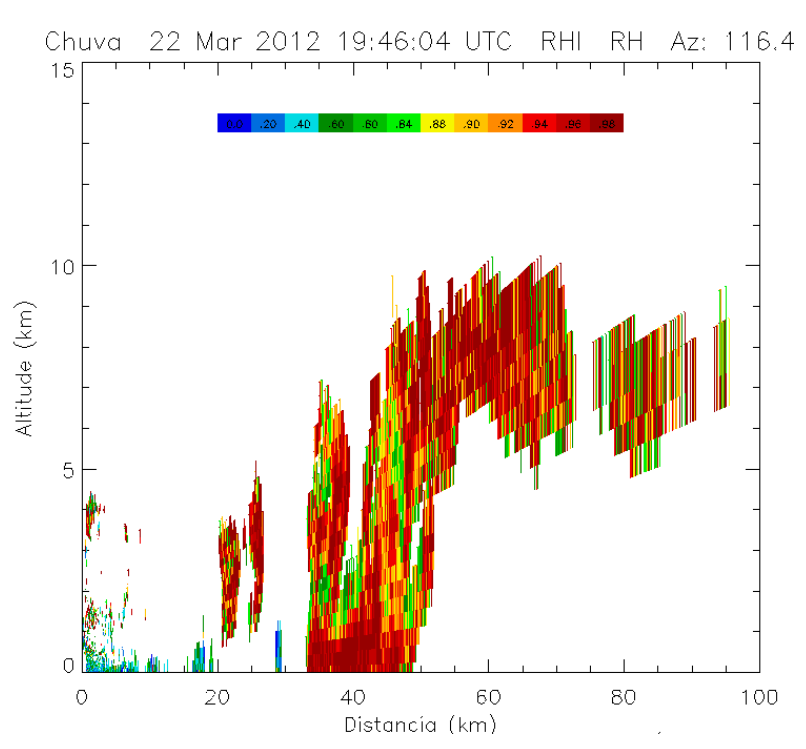

(c) 19:46 GMT

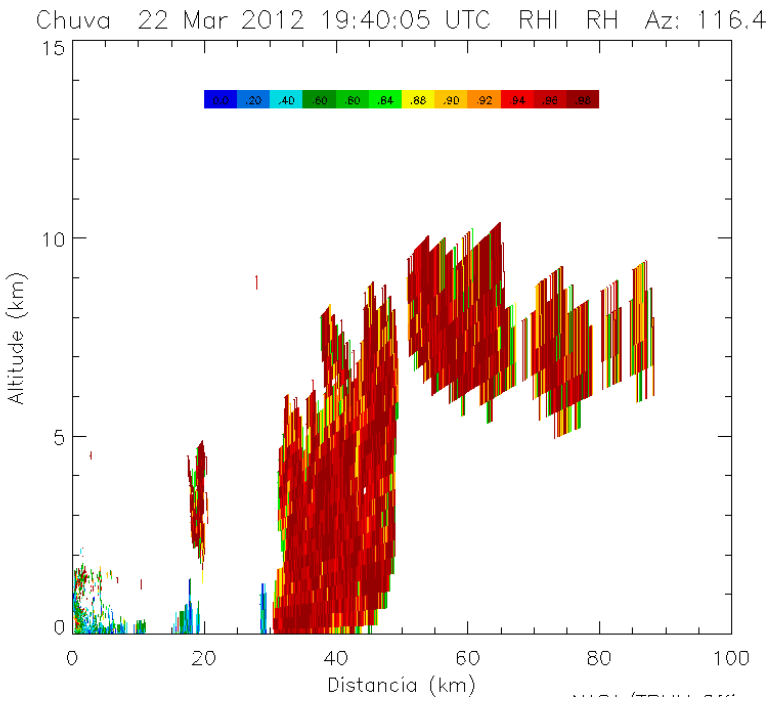

(b) 19:40 GMT

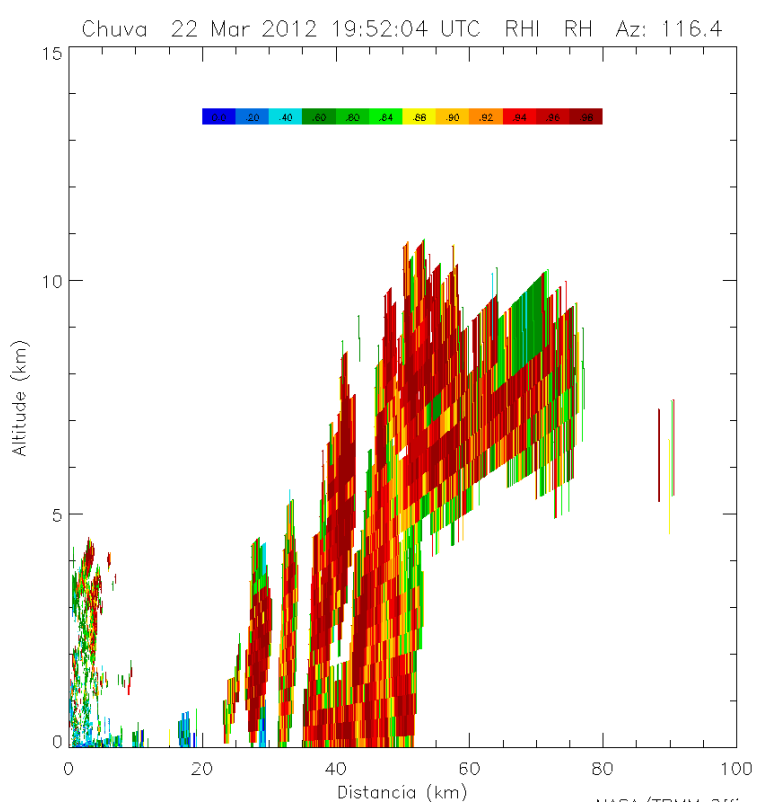

(d) 19:52 GMT 


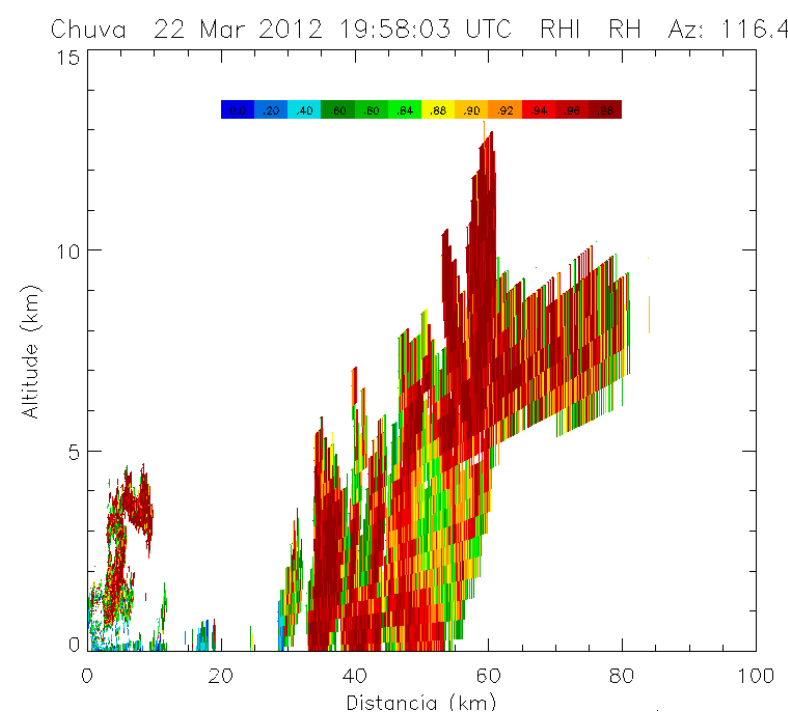

(e) 19:58 GMT

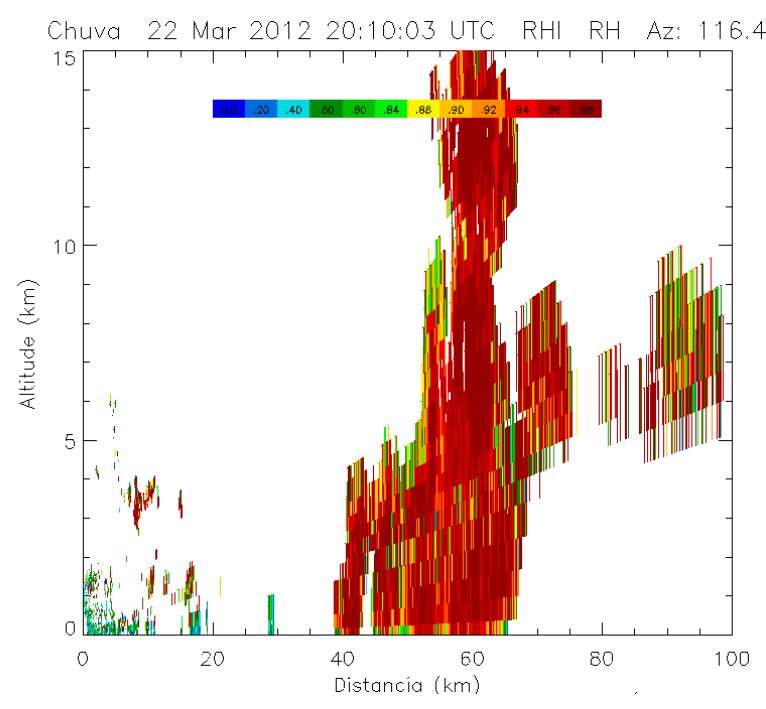

(g) 20:10 GMT

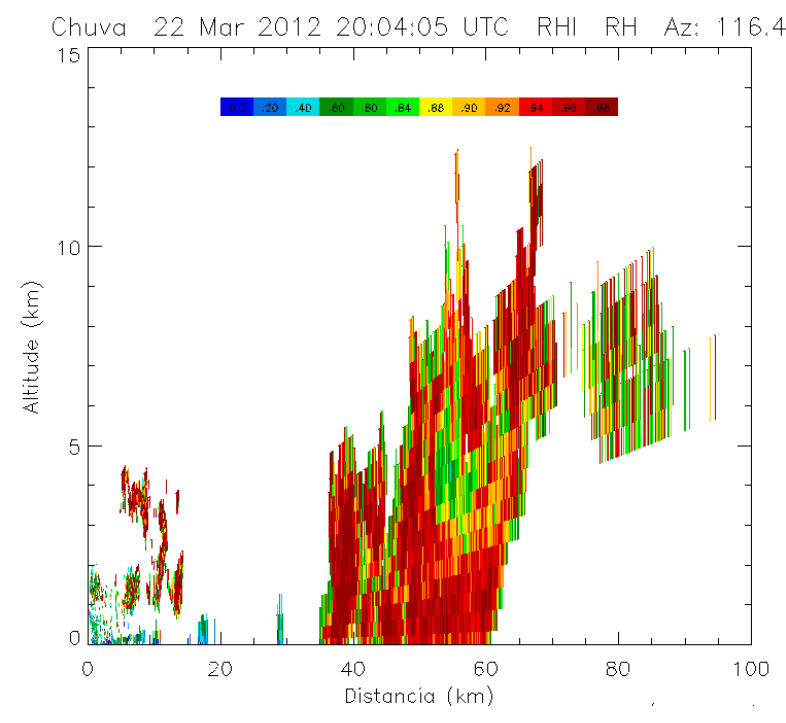

(f) 20:04 GMT

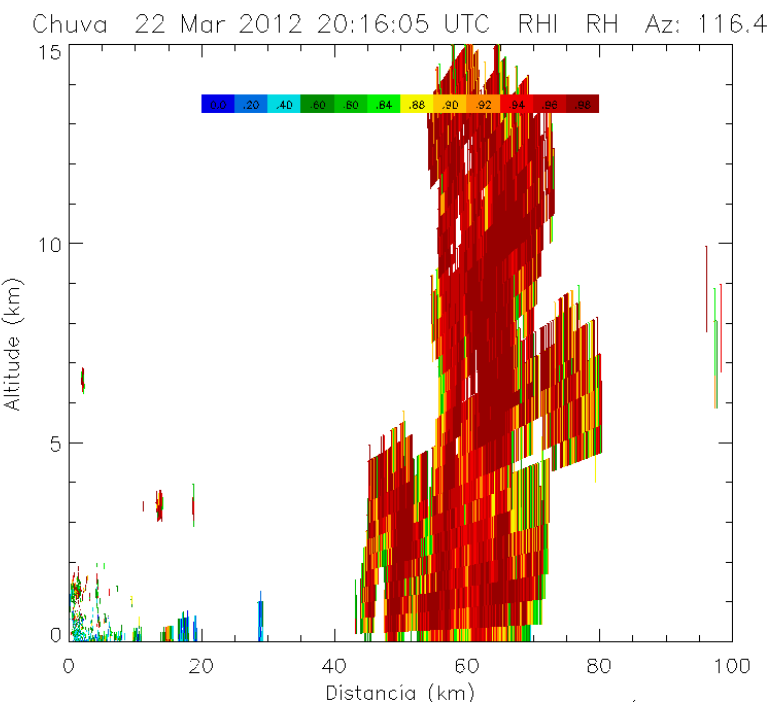

(h) 20:16 GMT

Figura 4.8: Imagens $\boldsymbol{R H I}$ do coeficiente de correlação desde 19 : 34 at 20 : 2016 GMT.

\section{d) Classificação dos hidrometeoros}

Nos diferentes gráficos da figura 4.9 são apresentados os resultados da classificação dos hidrometeoros, segundo a metodologia Dolan and Rutledge [2009], a partir dos RHIs das figuras 4.5 e 4.5 


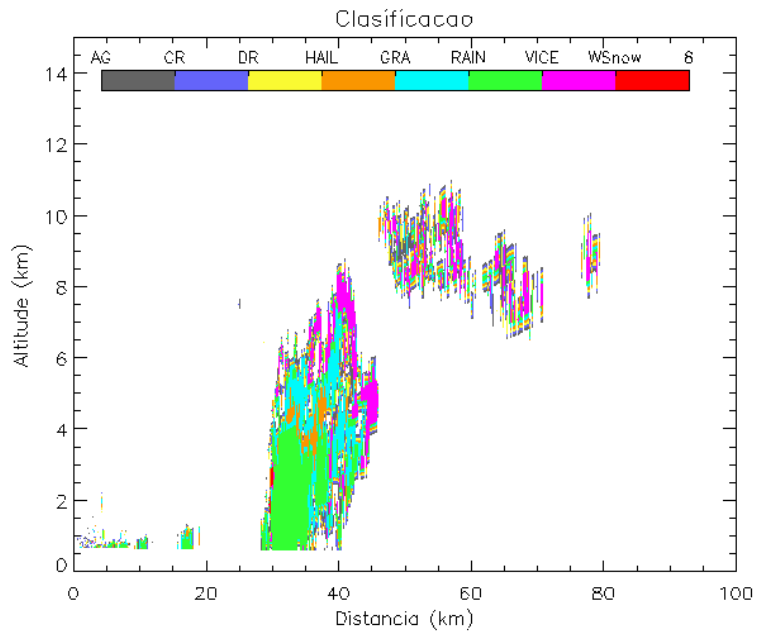

(a) 19:34 GMT

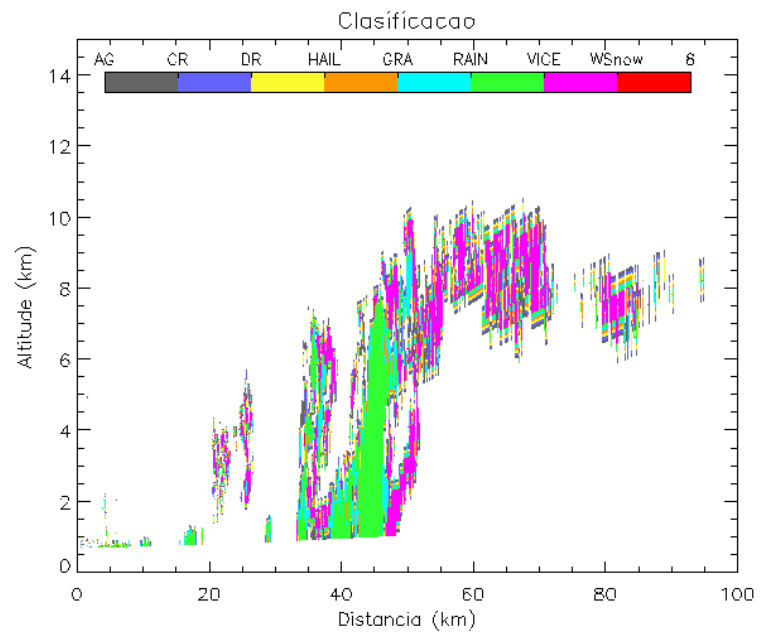

(c) 19:46 GMT

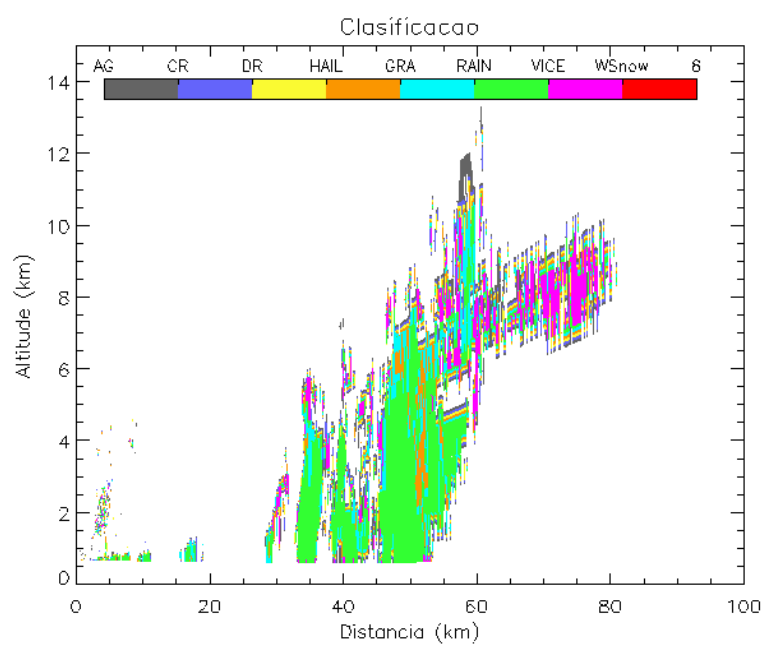

(e) 19:58 GMT

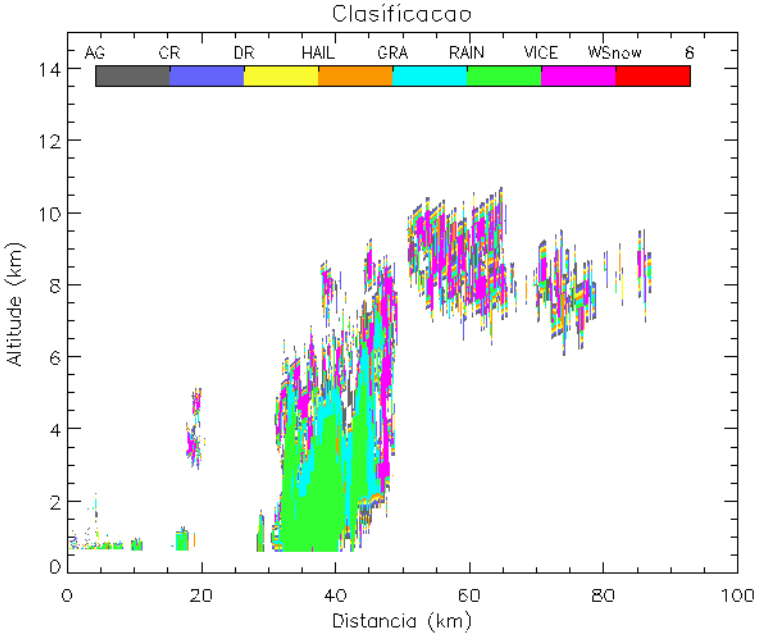

(b) 19:40 GMT

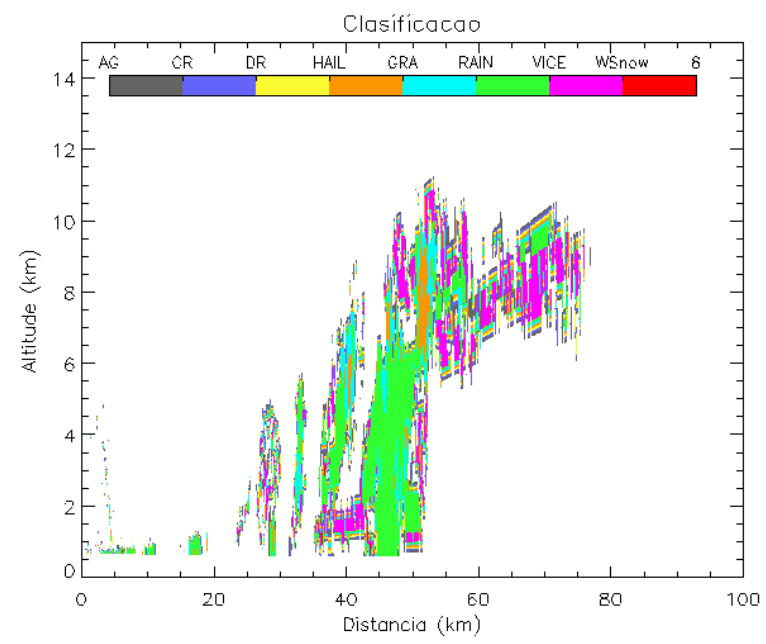

(d) 19:52 GMT

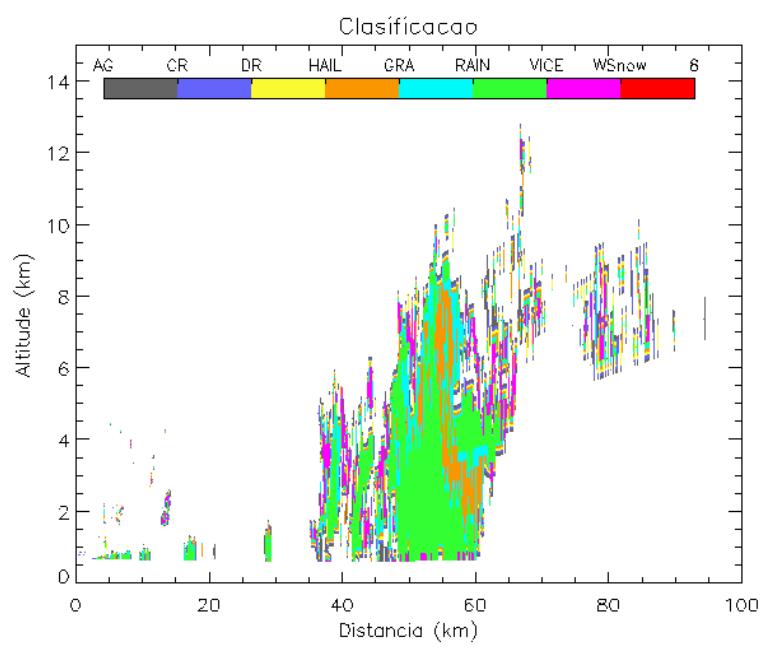

(f) 20:04 GMT 


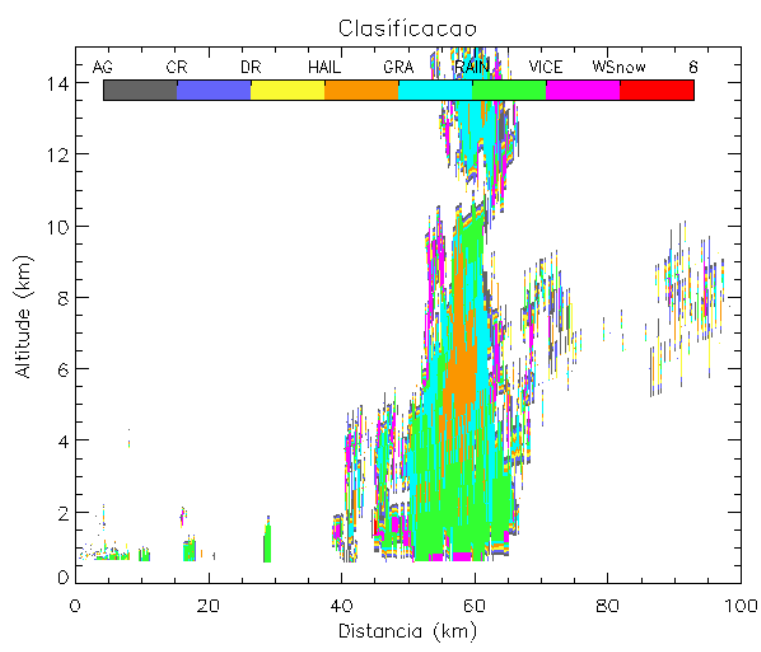

(g) 20:10 GMT

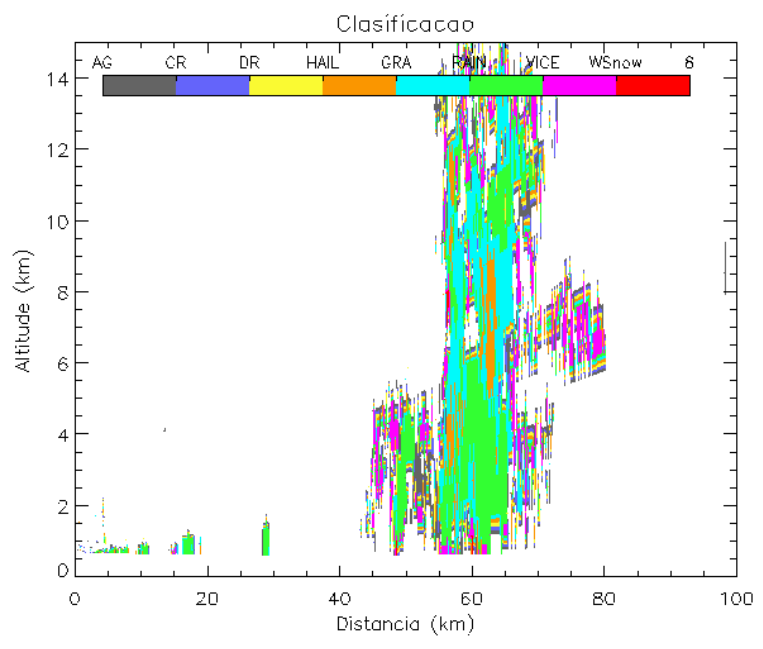

(h) 20:16 GMT

Figura 4.9: Classificação entre os hidrometeoros segundo Dolan and Rutledge [2009] de $19: 34$ a $20: 16$ GMT.

A figura 4.9(a) indica que na parte dianteira do sistema existe chuva que se estende até $5 \mathrm{~km}$, logo acima existe uma pequena camada de granizo. No resto da nuvem existe graupel acima da isoterma $0^{\circ} \mathrm{C}$ e cristais de gelo em níveis mais altos.

$\mathrm{Na}$ varreduras seguinte, figura 4.9(b), nota-se um aumento area de chuva e acima dos $4 \mathrm{~km}$ de altura existe uma região com granizo e cristais de gelo.

A classificação apresentada na figura 4.9(c) correspondente à varredura da 19 : 46 GMT e é possível observar que na região onde foi observado o máximo $Z$ e $Z_{D R}$ existe chuva até os $8 \mathrm{~km}$ de altura com pequenos núcleos de graupel e granizo. Acima dos $8 \mathrm{~km}$ temos a presença de cristais de gelo. Para as próximas varreduras, 19 : 52 GMT (figura 4.9(d)) e 19 : 58 GMT(figura 4.9(e)) não se observa nenhuma variação dos hidrometeoros.

Na figura 4.9(f), observa-se chuva na maior parte do sistema, mas após $60 \mathrm{~km}$ do radar existe uma região de granizo. Acima da isoterma $0^{\circ} \mathrm{C}$ há um predomínio de granizo, graupel e cristais de gelo.

Finalmente, na figura(4.9(g)) observa-se uma mistura de granizo, graupel e chuva abaixo da isoterma de $0^{\circ} \mathrm{C}$. Porém acima da isoterma de $0^{\circ} \mathrm{C}$ até $12 \mathrm{~km}$ de altura observa-se granizo e graupel. No topo da tempestade existem cristais de gelo orientados verticalmente. 
Nas figuras apresentadas, observa-se ao inicio do período a presença de uma coluna de chuva . Logo, nota-se um desenvolvimento vertical, e a coluna de chuva aumenta seu altura até atingir a níveis mais altos acima da isoterma de $0^{\circ} \mathrm{C}$ e congela até formar granizo, como foi observado nas figuras anteriores. Como continua o ascenso vertical pode-se ter aparecimento de cristais de gelo na altura.

\subsubsection{Diferenças entre as simulações teóricas e a classificação de Dolan and Rutledge [2009].}

Medições in situ observaram que em certas regiões e determinadas condições podem coexistir dois tipos de hidrometeoros diferentes (Stith et al. [2002], Black and Hallett [1986,1999]), daí a importância das simulações teóricas realizadas neste trabalho. Uma boa metodologia para avaliar a possibilidade de mistura de hidrometeoros usando as nossas simulações é a seguinte: tomar uma região pontual no espaço para o casos de estudo do dia 22/03/2012, nos horários 19 : 34 GMT e $20: 16$ GMT onde seguindo a classificação de Dolan and Rutledge [2009] tenhamos a predominância de algum hidrometeoro para usar os valores de $Z, Z_{D R}$ e $K_{D P}$ observados no radar. Logo, procurar nas simulações do hidrometeoro (T-Matrix e Mueller-Matrix) os valores de $Z_{D R}$ e $K_{D P}$ calculados para o $Z$ observado no radar.

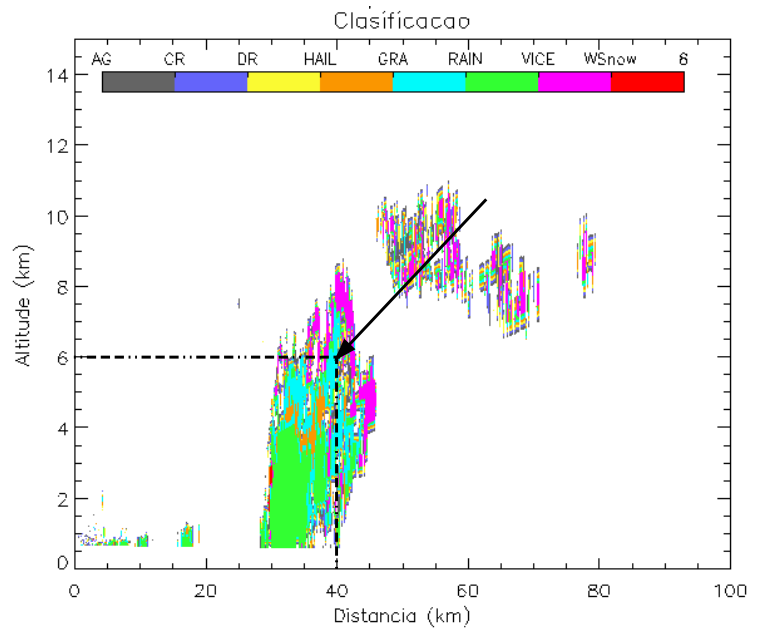

(a) Classificação Dolan and Rutledge [2009]

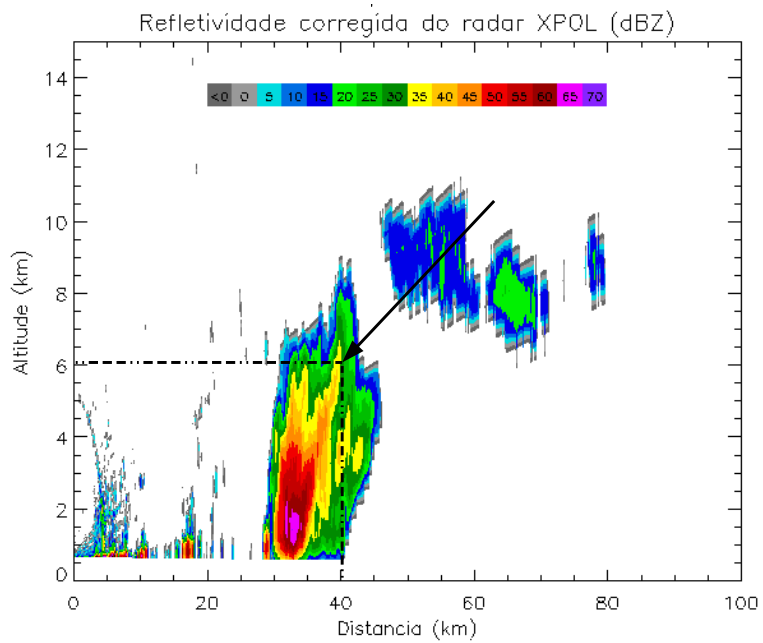

(b) $Z$ 


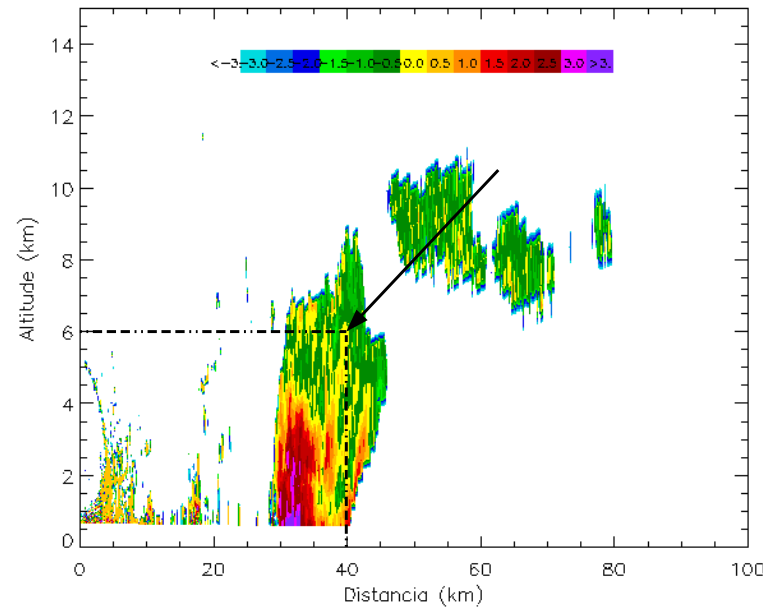

(c) $Z_{D R}$

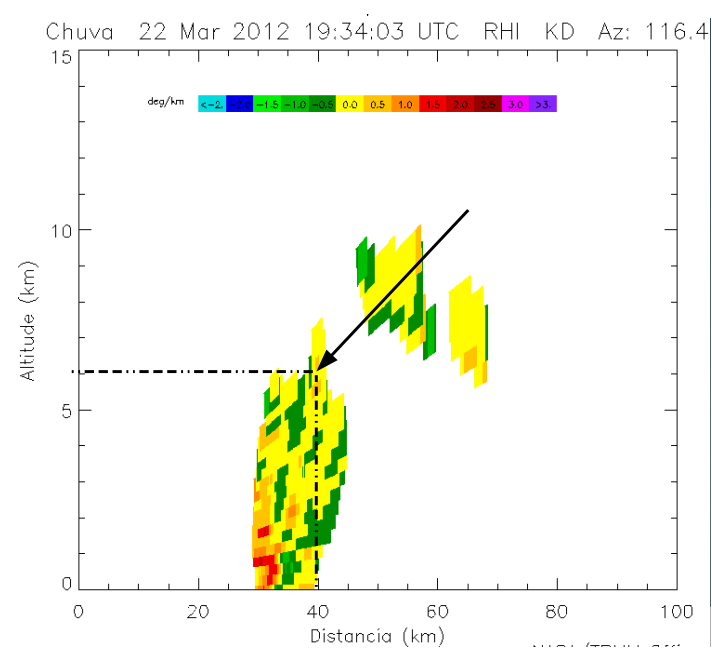

(d) $K_{D P}$

Figura 4.10: Caso de estudo do 22/03/2012 19:34 GMT. Medições radar XPOL a) Classificação do hidrometeoro segundo Dolan and Rutledge [2009], b) $Z$, c) $Z_{D R}$, d) $K_{D P}$

Para entender bem o caso anterior vamos tomar o primeiro caso de estudo $(22 / 03 / 2012$ 19:34 GMT), apresentado na figura $4.10 \mathrm{com}$ uma seta $(D=40 \mathrm{~km}, A=6 \mathrm{~km})$. Pode ser observado que na região selecionada temos presença de graupel segundo a metodologia de Dolan and Rutledge [2009] na figura 4.10(b). Tomaremos como valores de comparação de referência os valores medidos pelo radar das variáveis $Z, Z_{D R}, k_{D P}$ e $\rho_{H V}$. Logo para avaliar a existência de uma mistura os dados das variáveis medidas são comparados com os resultados das simulações teóricas feitas para àgua, graupel e a mistura deles.

Nas tabelas 4.2 e 4.3, pode-se observar que os valores das variáveis estão perto das medidas feitas por o radar, as diferenças observadas nestes valos estão dadas porque as simulações não levam em conta a atenuação. Além disso os valores negativos medidos de $Z_{D R}$ e $K_{D P}$, não concordam com os obtidos nas simulações porque as mesmas não consideram gelo irregular.

As simulações feitas podem ser usadas para demonstrar a existência de mistura de hidrometeoros com o objetivo de melhorar a concordância com os dados observados e ainda mais os métodos atuais de classificação de hidrometeoros. 
TABela 4.2: Comparação entre dados medidos e simulados. Caso 1

\begin{tabular}{|c|c|c|c|c|}
\hline \multicolumn{5}{|c|}{ Caso Graupel: $22 / 03 / 201219: 34$ GMT D=40 km A=6 km } \\
\hline & Medida & Sim. Chuv & Sim. Grau & Sim. Chuv-Grau \\
\hline$Z(d B Z)$ & 31.53 & $28.30-31.88$ & $30.43-32.32$ & $28.92-32.05$ \\
\hline$Z_{D R}(d B)$ & 0.33 & $0.417-0.484$ & $0.599-0.610$ & $0.433-0.484$ \\
\hline$K_{D P}\left({ }^{o} / k m\right)$ & $-0,36$ & $0.077-0.159$ & $0.071-0.075$ & $0.0899-0.159$ \\
\hline$\rho_{H V}$ & 0.94 & $0.9988-0.9990$ & 1.0 & $0.9988-0.9991$ \\
\hline
\end{tabular}

TABela 4.3: Comparação entre dados medidos e simulados. Caso 2

\begin{tabular}{|c|c|c|c|c|}
\hline \multicolumn{5}{|c|}{ Caso Graupel: $22 / 03 / 201220: 16$ GMT D $=60 \mathrm{~km} \mathrm{~A}=8 \mathrm{~km}$} \\
\hline & Medida & Sim. Chuv & Sim. Grau & Sim. Chuv-Grau \\
\hline$Z(d B Z)$ & 35.5 & $35.32-38.58$ & $32.32-35.57$ & $32.25-35.60$ \\
\hline$Z_{D R}(d B)$ & -0.44 & $0.547-0.603$ & $0.610-0.620$ & $0.488-0.545$ \\
\hline$K_{D P}\left(^{o} / \mathrm{km}\right)$ & -0.13 & $0.317-0.610$ & $0.0755-0.0764$ & $0.170-0.326$ \\
\hline$\rho_{H V}$ & 0.96 & $0.9984-0.9986$ & 1.0 & $0.9986-0.9989$ \\
\hline
\end{tabular}




\section{CONCLUSÕES}

Esta dissertação de mestrado desenvolveu duas metodologia para inferir o tipo de hidrometeoro a partir de medidas polarimétricas de um radar meteorológico banda X. A primeira parte, teórica, envolveu simulações numéricas com o código de espalhamento Mie. Na segunda fase, experimental, foram utilizados medidas do radar de dupla polarização do Projeto CHUVA e aplicado um algoritmo de identificação de hidrometeoros.

As simulações teóricas envolveram a utilização do modelo de espalhamento Mie (T-Matrix) (Vivekanandan et al. [1991]), que calcula para cada partícula a secção transversal de retro-espalhamento e absorção. E o código Mueller (Vivekanandan et al. [1991]) que lê as tabelas construídas pelo T-Matrix e calcula as variáveis polarimétricas a partir da definição da distribuição de tamanho das gotas de chuva, cristais de gelo, agregado, neve, granizo e graupel. O modelo T-Matrix e Mueller foram utilizados para estudar os efeitos dos diferentes tipos de hidrometeoros (gotas de água de chuva, granizo e graupel) em um função do comprimento de onda, ângulo de elevação e temperatura. Além disso, foi também analisado o efeito da distribuição de tamanhos de gotas, ou seja, distribuição exponencial descrita por Marshall and Palmer [1948] e a função gama proposta por Ulbrich [1983].

Utilizou-se como padrão a refletividade da banda $S$, para analisar os efeitos do comprimento de onda para cada tipo de hidrometeoro. Geralmente quando os valores de fator de refletividade são pequenos o comportamento das variáveis para cada compartimento de onda do radar são similares, as diferenças marcadas nota-se quando a refletividade começam a ser maiores, ou seja os hidrometeoros aumentam se tamanho e mudam sua geometria. A refletividade diferencial para cada hidrometeoro tem valores pequenos quando a refletividade é menor que $20 \mathrm{dBZ}$, quando as partículas de cada hidrometeoro aumenta seu valor. Para o caso de $K_{D P}$ os valores são positivos para os hidrometeoros estudados, também com valores maior 0 quando $Z$ é maior que $15 \mathrm{dBZ}$ para o caso do granizo. Da 
análise do coeficiente de correlação, pode-se concluir que para os chuva, graupel e granizo, quando as partículas são pequenas, o valor é 1, e conforme vão aumentando de tamanho, o valor diminui quando $Z$ e maior que $25 d B Z$.

Com relação ao efeito da temperatura, não foi possível observar variações significativas e é possível atestar que não existe dependência da temperatura com os diferentes tipos de hidrometeoros.

Já em relação ao ângulo de elevação foi possível observar uma variação a medida que o ângulo de elevação aumentava, em especial para $Z_{D R}, K_{D P}$ e $\rho_{H V}$. Observou-se que a medida que o ângulo de elevação aumentava e $\mathrm{Z}$ também aumentava, $Z_{D R}, K_{D P}$ e $\rho_{H V}$ diminuíam. Basicamente, a medida que o ângulo aumentava, a polarização vertical se aproximava da horizontal, logo diminuindo as diferenças. A partir dos gráficos mostrados nota-se que estas variações são mais sensíveis para água e para granizo do que para graupel.

Ao analisar as diferenças entre uma distribuição de tamanho exponencial (Marshall and Palmer [1948]) e uma gama (Ulbrich [1983]) observou-se que a medida que para o caso da água a medida que aumenta o tamanho das partículas e a refletividade, aumenta as diferenças entre as distribuições, devido ao uso do $N_{0}$ fixo. Para o caso do graupel o granizo nota-se que as diferenças diminuem devido ao diminuição da concentração com o aumento do tamanho.

Finalmente, foram realizadas simulações para verificar como as variáveis polarimétricas variavam quando mais de um tipo de hidrometeoro era observado dentro de um volume iluminado pelo radar. Para tanto, concentrou-se na região mista da nuvem, onde águagraupel e água-granizo podem co-existir. Os valores obtidos das variáveis polarimétricas, demonstram que quando a refletividade é baixa, ou seja, o tamanho da partícula é pequeno, o graupel o granizo tem predomínio, mas quando as partículas da mistura começam a crescer e a refletividade é maior de $30 d B Z$ nota-se um predomínio da água. Analisando a mistura de água e graupel quando $Z$ é maior de $30 \mathrm{~dB} Z$ as gotas de água tem domínio no sinal. Quando $Z$ é maior de $35 d B Z K_{D P}$ é positivo e é negativo quando $Z$ é menor que o valor antes dito. Já $\rho_{H V}$ é próximo de 1 quanto menor é $Z$ é observado mais graupel. Para a mistura de água-granizo, igualmente, $Z$ da água tem predomínio sobre o granizo quando $Z$ é maior que $45 \mathrm{dBZ}$. A variável $K_{D P}$ é maior que zero quando a refletividade é maior que $25 d B Z$ desde que $Z$ do granizo seja menor que $10 \mathrm{dBZ}$. O $Z_{D R}$ do granizo domina o da água quando $Z$ for menor que $45 \mathrm{~dB} Z$. 
$\mathrm{Na}$ análise experimental, dois casos foram estudados: 8 de fevereiro de 2012 e 22 de março de 2012. Estes casos fazem parte do experimento de campo do Projeto CHUVA denominado de CHUVA-GLM realizado no Vale do Paraíba.

No primeiro caso foi mostrada uma célula de tempestade isolada que tinha regiões de chuva fraca com valores de $Z$ variando entre 20 e $35 d B Z$ e núcleos mais intensos com $Z>50 \mathrm{dBZ}$, indicando regiões de chuva forte. Acima de $5 \mathrm{~km}$ de altura. Foi observado $Z>50 \mathrm{dBZ}, K D P<1^{\circ} / \mathrm{km}, Z_{D R}<1.0 \mathrm{~dB}$ e $\rho_{H V}$, o que indica a presença de granizo, graupel, gotas congeladas e cristais de gelo, acima da isoterma de $0^{\circ} \mathrm{C}$. Aplicando o algoritmo de classificação de Dolan and Rutledge [2009] obteve-se regiões de chuva, granizo, graupel e cristais de gelo na altura.

Para o segundo caso, foi apresentado a evolução temporal de uma linha de instabilidade que permitiu varreduras de RHI contínuas entre as 19 : 34 GMT e 20 : 16 GMT. Durante os primeiros 20 a 30 minutos observou-se uma tempestade que apresentou uma coluna vertical que se estendia da superfície até $7 \mathrm{~km}$ de altura com mais de $50 \mathrm{dBZ}$, indicando a presença de granizo e chuva forte. Mais tarde, esta coluna atingiu valores superiores a $65 d B Z$ o que pode ser um indicativo da presença de granizo molhado ou chuva com granizo molhado. $Z_{D R}$ nestas colunas era superior a $2.5 \mathrm{dBZ}$, já $K_{D P}$ apresentava valores maiores que $3.0^{\circ} / \mathrm{km}$, enquanto que $\rho_{H V}$ está próximo de 1 . Estas característica comprovam a presença de gotas de chuva grandes e granizo molhado em níveis mais altos. Já acima de da isoterma de $0^{\circ} \mathrm{C}$ observamos $Z>45 \mathrm{dBZ}, Z_{D R}<1.5 \mathrm{~dB}, K_{D P}<1.5^{\circ} / \mathrm{km}$ e $\rho_{H V}>0,88$ que são característicos de graupel, granizo e cristais de gelo. Utilizando o esquema de classificação de Dolan and Rutledge [2009], identificou-se que chuva se concentrava nos primeiros 3 a $4 \mathrm{~km}$ de altura, porém na região de máxima intensidade de $Z$, $Z_{D R}$ e $K_{D P}$, as regiões próximas da isoterma de $0^{\circ} \mathrm{C}$ até $6-7 \mathrm{~km}$ de altura foram classificadas com granizo e graupel. Já nos topo da tempestade, foi classificado como cristais de gelo de orientação vertical e graupel. Entretanto, nas regiões das correntes ascendentes foi possível encontrar graupel e água super-resfriada.

Comparando os resultados das simulações teóricas com o algoritmo de Dolan and Rutledge [2009] na região mista das tempestades, observou-se que algumas das regiões classificadas como graupel, por exemplo para o dia 22/03/2012, $19: 34$ GMT foi medido numa altura igual $6 \mathrm{~km}$ e uma distância do radar de $40 \mathrm{~km}, Z=31.53 \mathrm{dBZ}, Z D R=0.33 \mathrm{~dB}$, $K D P=-0.36^{\circ} / \mathrm{km}$ e $\rho_{H V}=0.94$ que ao comparar com os resultados obtidos das 
simulações teóricas e levando em conta as especificações do modelo, pode-se concluir que tem assinatura para presença da mistura água-graupel. 


\section{REFERÊNCIAS BIBLIOGRÁFICAS}

[1] Almeida, F. C., Muroe, G., Morales, C., Pereira, M., Barros, F., Sampaio, A. and De Oliveira, J. [1992]. An instrumented aircraftt for tropical precipitation physics research: description and opportunities., 11 th International Conference on Clouds and Precipitation, Montreal, Canada.

[2] Anagnostou, E. N., Anagnostou, M. N., Krajewski, W. F., Kruger, A. and Miriovsky, B. J. [2004]. High-resolution rainfall estimation from x-band polarimetric radar measurements, Journal of Hydrometeorology 5(1): 110-128.

URL: http://www.jstor.org/stable/24908965

[3] Atmospheric Radar Research Center, University of Oklahoma [2005]. Efficient ways to learn weather radar polarimetry, urlhttp://arrc.ou.edu/ guzhang/Polarimetry/variables.htm.

[4] Autores, V. [2017]. Tipos de radares meteorológicos, urlhttp://www.crahi.upc.edu/curs/.

[5] Battaglia, A., Saavedra, P., Morales, C. A. and Simmer, C. [n.d.]. Understanding three?dimensional effects in polarized observations with the ground?based admirari radiometer during the chuva campaign, Journal of Geophysical Research: Atmospheres $\mathbf{1 1 6}(\mathrm{D} 9)$.

URL: https://agupubs.onlinelibrary.wiley.com/doi/abs/10.1029/2010JD015335

[6] Black, R. A. and Hallett, J. [1986,1999]. Observations of the distribution of ice in hurricanes, Journal of the Atmospheric Sciences 43(8): 802-822.

URL: https://doi.org/10.1175/1520-0469(1986)043<0802:OOTDOI>2.0.CO;2 
[7] Boerner, W. M. [2017]. Polarimetric SAR Data Processing and Educational Tool Tutorial Lecture Notes on Basic Concepts in Radar Polarimetry., UIC-ECE Communications, Sensing and Navigation Laboratory, at the University of Rennes, DLR-HR

[8] Bringi, V. N. e Chandrasekar, V. [2001]. Polarimetric Doppler Weather Radar. Principles and Applications, Cambridge Press.

[9] Bringi, V. N., Rasmussen, R. M. and Vivekanandan, J. [1986]. Multiparameter radar measurements in colorado convective storms. part i: Graupel melting studies, Journal of the Atmospheric Sciences 43(22): 2545-2563.

URL: https://doi.org/10.1175/1520-0469(1986)043<2545:MRMICC>2.0.CO;2

[10] Bringi, V. N., Seliga, T. A. and Cooper, W. A. [1984]. Analysis of aircraft hydrometeor spectra and differential reflectivity $\left(Z_{D R}\right)$ radar measurements during the Cooperative Convective Precipitation Experiment, Radio Science 19: 157-167.

[11] Bringi, V. N., Vivekanandan, J. and Tuttle, J. D. [1986]. Multiparameter radar measurements in colorado convective storms. part ii: Hail detection studies, Journal of the Atmospheric Sciences 43(22): 2564-2577.

URL: https://doi.org/10.1175/1520-0469(1986)043<2564:MRMICC>2.0.CO;2

[12] Bringi, V.N. e Thurai, M. e. H. R. [2007]. Dual-Polarization Weather Radar Handbook, Selex-SI Gematronik.

[13] Costa, A. A., de Oliveira, C. J., de Oliveira, J. C. P. and da Costa Sampaio, A. J. [2000]. Microphysical observations of warm cumulus clouds in ceará, brazil, Atmospheric Research 54(2): 167 - 199.

URL: http://www.sciencedirect.com/science/article/pii/S0169809500000454

[14] de Oliveira Andrade, N. S., de Castro Santa Rosa, A. N. and de Carvalho Faria, P. C. [2017]. Matrizes de espalhamento utilizadas na Polarimetria SAR e o teorema da reciprocidade., UIC-ECE Communications, Sensing and Navigation Laboratory, at the University of Rennes, DLR-HR.

[15] Defensa Nacional [2012]. Novedades radar meteorológico argentino, urlhttp://defensanacional.argentinaforo.net/. 
[16] Dolan, B. and Rutledge, S. A. [2009]. A theory-based hydrometeor identification algorithm for x-band polarimetric radars, Journal of Atmospheric and Oceanic Technology 26(10): 2071-2088.

URL: https://doi.org/10.1175/2009JTECHA1208.1

[17] Dolan, B., Rutledge, S. A., Lim, S., Chandrasekar, V. and Thurai, M. [2013]. A robust c-band hydrometeor identification algorithm and application to a long-term polarimetric radar dataset, Journal of Applied Meteorology and Climatology 52(9): 2162-2186. URL: https://doi.org/10.1175/JAMC-D-12-0275.1

[18] Doviak, R. J. e Zrnic, D. [1993]. Polarimetric Doppler Weather Radar. Principles and Applications, Academic Press, Inc.

[19] Feingold, G. and Levin, Z. [1986]. The lognormal fit to raindrop spectra from frontal convective clouds in israel, Journal of Climate and Applied Meteorology 25(10): 13461363.

URL: https://doi.org/10.1175/1520-0450(1986)025<1346:TLFTRS>2.0.CO;2

[20] Fukao, S., Hamazu, K. and Doviak, R. J. [2014]. Radar for Meteorological and Atmospheric Observations, 2 edn, Springer.

[21] Garstang, M., Scala, J., Greco, S., Harriss, R., Beck, S., Browell, E., Sachse, G., Gregory, G., Hill, G., Simpson, J., Tao, W. and Torres, A. [n.d.]. Trace gas exchanges and convective transports over the amazonian rain forest, Journal of Geophysical Research: Atmospheres 93(D2): 1528-1550.

URL: https://agupubs.onlinelibrary.wiley.com/doi/abs/10.1029/JD093iD02p01528

[22] Grazioli, J., Tuia, D. and Berne, A. [2015]. Hydrometeor classification from polarimetric radar measurements: a clustering approach, Atmospheric Measurement Techniques 8(1): 149-170.

URL: https://www.atmos-meas-tech.net/8/149/2015/

[23] Heymsfield, A. J., Bansemer, A., Field, P. R., Durden, S. L., Stith, J. L., Dye, J. E., Hall, W. and Grainger, C. A. [2002]. Observations and parameterizations of particle size distributions in deep tropical cirrus and stratiform precipitating clouds: Results from in situ observations in trmm field campaigns, Journal of the Atmospheric Sciences 59(24): 3457-3491.

URL: https://doi.org/10.1175/1520-0469(2002)059<345\%:OAPOPS>2.0.CO;2 
[24] Heymsfield, A. and Willis, P. [2014]. Cloud conditions favoring secondary ice particle production in tropical maritime convection, Journal of the Atmospheric Sciences 71(12): 4500-4526.

URL: https://doi.org/10.1175/JAS-D-14-0093.1

[25] Joss, J., Waldvogel, A. and Collier, C. G. [1990]. Precipitation Measurement and Hydrology, American Meteorological Society, Boston, MA, pp. 577-606.

URL: https://doi.org/10.1007/978-1-935704-15-7-39

[26] Keenan, T. [2003]. Hydrometeor classification with a c-band polarimetric radar, 52: 23-31.

[27] Lawson, R. P., Woods, S. and Morrison, H. [2015]. The microphysics of ice and precipitation development in tropical cumulus clouds, Journal of the Atmospheric Sciences 72(6): 2429-2445.

URL: https://doi.org/10.1175/JAS-D-14-0274.1

[28] Libbrecht, K. G. [2005]. The physics of snow crystals, Reports on Progress in Physics 68(4): 855 .

URL: http://stacks.iop.org/0034-4885/68/i=4/a=R03

[29] Lim, S., Chandrasekar, V. and Bringi, V. N. [2005]. Hydrometeor classification system using dual-polarization radar measurements: model improvements and in situ verification, IEEE Transactions on Geoscience and Remote Sensing 43(4): 792-801.

[30] Liu, H. and Chandrasekar, V. [2000]. Classification of hydrometeors based on polarimetric radar measurements: Development of fuzzy logic and neuro-fuzzy systems, and in situ verification, Journal of Atmospheric and Oceanic Technology 17(2): 140164.

URL: https://doi.org/10.1175/1520-0426(2000)017<0140:COHBOP>2.0.CO;2

[31] Livingston, J. M. and Krider, E. P. [1978]. Electric fields produced by florida thunderstorms, Journal of Geophysical Research: Oceans 83(C1): 385-401.

URL: http://dx.doi.org/10.1029/JC083iC01p00385

[32] Machado, L. A. et al. [2014]. The Chuva Project: How Does Convection Vary Wendoss Brazil?, Bulletin of the American Meteorological Society 95: 1365-1380. 
[33] Machado, L., Morales, C., Angelis, C., Fisch, A. and Dias, M. A. S. [2011]. Cloud processes of the main precipitation systems in brazil: A contribution to cloud resolving modeling and to the gpm (global precipitation measurement), Relatório Parcial 1 .

[34] Marshall, J. S. and Palmer, W. M. K. [1948]. The distribution of raindrops with size, Journal of Meteorology 5(4): 165-166.

URL: https://doi.org/10.1175/1520-0469(1948)005<0165:TDORWS>2.0.CO;2

[35] Martin S. T. et al. [2017]. The green ocean amazon experiment (goamazon2014/5) observes pollution affecting gases, aerosols, clouds, and rainfall over the rain forest, Bulletin of the American Meteorological Society 98(5): 981-997.

URL: https://doi.org/10.1175/BAMS-D-15-00221.1

[36] Marzano, F. S., Botta, G. and Montopoli, M. [2010]. Iterative bayesian retrieval of hydrometeor content from x-band polarimetric weather radar, IEEE Transactions on Geoscience and Remote Sensing 48(8): 3059-3074.

[37] Marzano, F. S., Scaranari, D., Montopoli, M. and Vulpiani, G. [2008]. Supervised classification and estimation of hydrometeors from c-band dual-polarized radars: A bayesian approach, IEEE Transactions on Geoscience and Remote Sensing 46(1): 8598.

[38] Mason, B. [1971]. The Physics of Clouds, Second Edition. Oxford UniversityPress.

[39] Mattos, E. V., Machado, L. A. T., Williams, E. R. and Albrecht, R. I. [2016]. Polarimetric radar characteristics of storms with and without lightning activity, Journal of Geophysical Research: Atmospheres 121(23): 14,201-14,220. 2016JD025142.

URL: http://dx.doi.org/10.1002/2016JD025142

[40] Meischner, P. [2003]. Weather Radar-Principle and Advanced Applications.

[41] Morales, C. A. [1991]. Distribuição de tamanho de gotas de chuva nos trópicos: Ajustes de uma função gamma e aplicações., Master's thesis, Universidade de São Paulo, Instituto Astronômico e Geofísico, São Paulo.

[42] Navarro, K. M. M. [2012]. Development and implemetation of an attenuation correction algorithm for casa off the grid $x$-band radar network., Master's thesis, University of Puerto Rico Mayagüez Campus, Puerto Rico. 
[43] Rinehart, R. E. [1991]. Radar for meteorologists, Second Ed. University of North Dakota, Office of the President.

[44] Ryzhkov, A. V., Schuur, T. J., Burgess, D. W., Heinselman, P. L., Giangrande, S. E. and Zrnic, D. S. [2005]. The joint polarization experiment: Polarimetric rainfall measurements and hydrometeor classification, Bulletin of the American Meteorological Society 86(6): 809-824.

URL: https://doi.org/10.1175/BAMS-86-6-809

[45] Ryzhkov, A. V. and Zrnic, D. S. [1998]. Discrimination between rain and snow with a polarimetric radar, Journal of Applied Meteorology 37(10): 1228-1240.

URL: https://doi.org/10.1175/1520-0450(1998)037<1228:DBRASW>2.0.CO;2

[46] Ryzhkov, A. V. and Zrnic, D. S. [2005]. Radar polarimetry at s, c, and x bands: Comparative analysis and operational implications, 32nd Conf. on Radar Meteorology, Albuquerque, NM, Amer.Meteor. Soc, 9R.3, Amer.Meteor. Soc.

[47] Ryzhkov, A.V. e Giangrande, S. e. S. T. [2005]. Rainfall estimation with a polarimetric prototype of wsr-88d, Journal of Applied Meteorology 44(4): 502-515.

URL: https://doi.org/10.1175/JAM2213.1

[48] Sakuragi, J. and Biscaro, T. [2012]. Determinacao do vies do zdr e seu impacto na classificacao de hidrometeoros, XVII CONGRESSO BRASILEIRO DE METEOROLOGIA.

[49] Schneebeli, M., Sakuragi, J., Biscaro, T., Angelis, C. F., Carvalho da Costa, I., Morales, C., Baldini, L. and Machado, L. A. T. [2012]. Polarimetric x-band weather radar measurements in the tropics: radome and rain attenuation correction, Atmospheric Measurement Techniques 5(9): 2183-2199.

URL: https://www.atmos-meas-tech.net/5/2183/2012/

[50] Seliga, T. A. and Bringi, V. N. [1976]. Potential use of radar differential reflectivity measurements at orthogonal polarizations for measuring precipitation, Journal of Applied Meteorology 15(1): 69-76.

URL: https://doi.org/10.1175/1520-0450(1976)015<0069:PUORDR>2.0.CO;2

[51] Silva Dias, M. A. F. d., Cohen, J. C. P. and Gandu, A. W. [2005]. Interações entre nuvens, chuvas e a biosfera na Amazônia, Acta Amazônica 35: 215 - 222.

URL: http://www.scielo.br/scielo.php 
[52] Snyder, J. C., Bluestein, H. B., Zhang, G. and Frasier, S. J. [2010]. Attenuation correction and hydrometeor classification of high-resolution, x-band, dual-polarized mobile radar measurements in severe convective storms, Journal of Atmospheric and Oceanic Technology 27(12): 1979-2001.

URL: https://doi.org/10.1175/2010JTECHA1356.1

[53] Steiner, M. and Smith, J. A. [2002]. Use of three-dimensional reflectivity structure for automated detection and removal of nonprecipitating echoes in radar data, Journal of Atmospheric and Oceanic Technology 19(5): 673-686.

URL: https://doi.org/10.1175/1520-0426(2002)019<0673:UOTDRS>2.0.CO;2

[54] Stith, J. L., Dye, J. E., Bansemer, A., Heymsfield, A. J., Grainger, C. A., Petersen, W. A. and Cifelli, R. [2002]. Microphysical observations of tropical clouds, Journal of Applied Meteorology 41(2): 97-117.

URL: https://doi.org/10.1175/1520-0450(2002)041<0097:MOOTC>2.0.CO;2

[55] Stith, J. L., Haggerty, J. A., Heymsfield, A. and Grainger, C. A. [2004]. Microphysical characteristics of tropical updrafts in clean conditions, Journal of Applied Meteorology 43(5): 779-794.

URL: https://doi.org/10.1175/2104.1

[56] Stolzenburg, M., Rust, W. D. and Marshall, T. C. [1998]. Electrical structure in thunderstorm convective regions: 2. isolated storms, Journal of Geophysical Research: Atmospheres 103(D12): 14079-14096.

URL: http://dx.doi.org/10.1029/97JD03547

[57] Straka, J. M., Zrnić, D. S. and Ryzhkov, A. V. [2000]. Bulk hydrometeor classification and quantification using polarimetric radar data: Synthesis of relations, Journal of Applied Meteorology 39(8): 1341-1372.

URL: https://doi.org/10.1175/1520-0450(2000)039<1341:BHCAQU>2.0.CO;2

[58] Tessendorf, S. A., Miller, L. J., Wiens, K. C. and Rutledge, S. A. [2005]. The 29 june 2000 supercell observed during steps. part i: Kinematics and microphysics, Journal of the Atmospheric Sciences 62(12): 4127-4150.

URL: https://doi.org/10.1175/JAS3585.1

[59] Testud, J., Bouar, E. L., Obligis, E. and Ali-Mehenni, M. [2000]. The rain profiling algorithm applied to polarimetric weather radar, Journal of Atmospheric and Oceanic 
Technology 17(3): 332-356.

URL: https://doi.org/10.1175/1520-0426(2000)017<0332:TRPAAT>2.0.CO;2

[60] Thompson, Russel, D. [2002]. Atmospheric Processes and Systems, Routledge.

[61] Ulbrich, C. W. [1983]. Natural variations in the analytical form of the raindrop size distribution, Journal of Climate and Applied Meteorology 22(10): 1764-1775.

URL: https://doi.org/10.1175/1520-0450(1983)022<1764:NVITAF>2.0.CO;2

[62] Vivekanandan, J., Adams, W. M. and Bringi, V. N. [1991]. Rigorous approach to polarimetric radar modeling of hydrometeor orientation distributions, Journal of Applied Meteorology 30(8): 1053-1063.

URL: https://doi.org/10.1175/1520-0450(1991)030<1053:RATPRM>2.0.CO;2

[63] Vivekanandan, J., Ellis, S. M., Oye, R., Zrnic, D. S., Ryzhkov, A. V. and Straka, J. [1999]. Cloud microphysics retrieval using s-band dual-polarization radar measurements, Bulletin of the American Meteorological Society 80(3): 381-388.

URL: https://doi.org/10.1175/1520-0477(1999)080<0381:CMRUSB>2.0.CO;2

[64] Wendisch,M. et. al [2016]. Acridicon-chuva campaign: Studying tropical deep convective clouds and precipitation over amazonia using the new german research aircraft halo, Bulletin of the American Meteorological Society 97(10): 1885-1908.

URL: https://doi.org/10.1175/BAMS-D-14-00255.1

[65] Wolf, B e Anderson, A [2007]. Basics and advantages of polarimetric doppler radar, Colorado State.

[66] Yuter, S. [2015]. \{RADAR\} | precipitation radar, in G. R. North, J. Pyle and F. Zhang (eds), Encyclopedia of Atmospheric Sciences (Second Edition), second edition edn, Academic Press, Oxford, pp. 455 - 469.

URL: https://www.sciencedirect.com/science/article/pii/B9780123822253003285

[67] Zrnic, D. S. [1987]. Three-body scattering produces precipitation signature of special diagnostic value, 22: 76-86.

[68] Zrnic, D. S., Bringi, V. N., Balakrishnan, N., Aydin, K., Chandrasekar, V. and Hubbert, J. [1993]. Polarimetric measurements in a severe hailstorm, Monthly Weather Review 121(8): 2223-2238.

URL: https://doi.org/10.1175/1520-0493(1993)121<2223:PMIASH>2.0.CO;2 
[69] Zrnic, D. S. and Ryzhkov, A. V. [1999]. Polarimetry for weather surveillance radars, Bulletin of the American Meteorological Society 80(3): 389-406.

URL: https://doi.org/10.1175/1520-0477(1999)080<0389:PFWSR>2.0.CO;2 


\section{APENDICE}

\section{.1 Distribuição exponencial e gama dos hidrometeoros.}

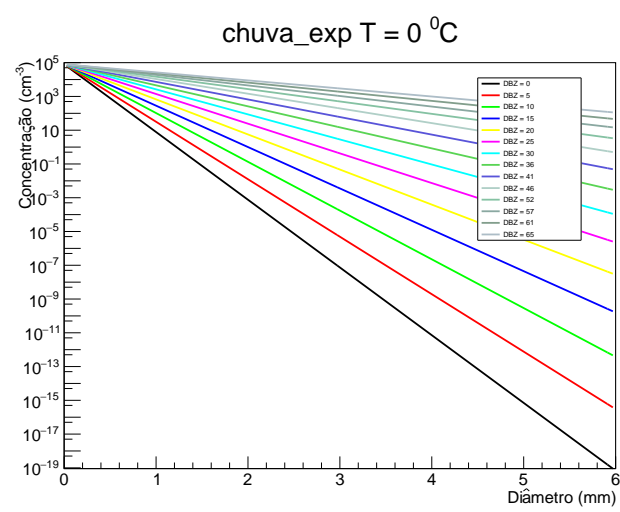

(a)

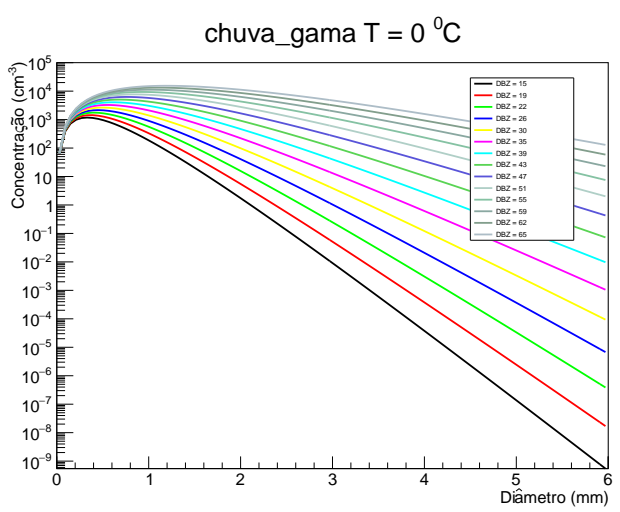

(b)

Figura 11: Distribuição de tamanhos de gotas de chuva para diferentes refletividades; (a) Distribuição Exponencial; (b) Distribuição Gama.

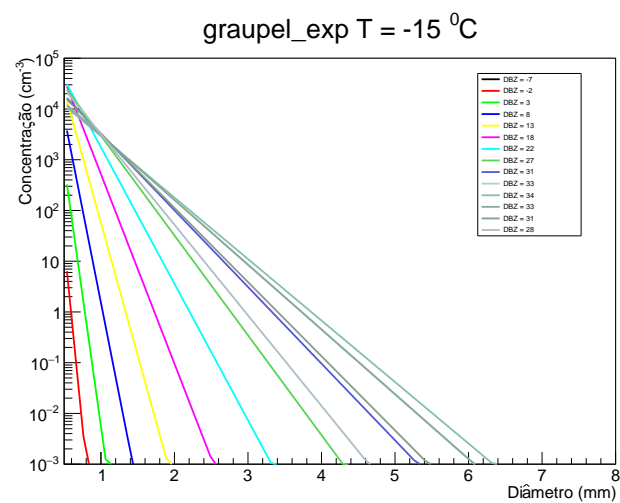

(a)

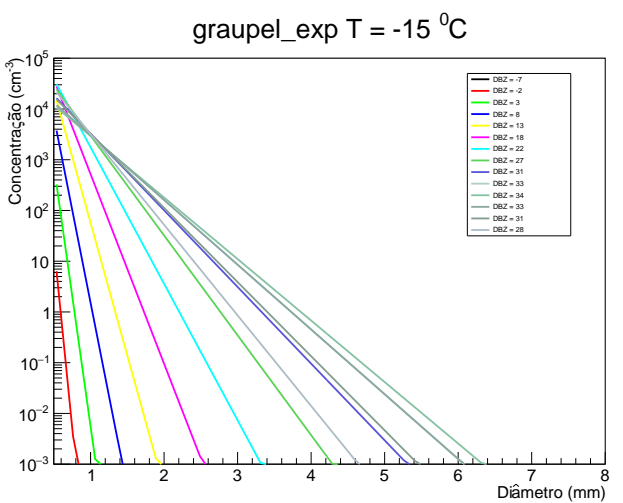

(b)

Figura 12: Distribuição de tamanho do graupel para diferentes refletividades; (a) Distribuição Exponencial; (b) Distribuição Gama. 


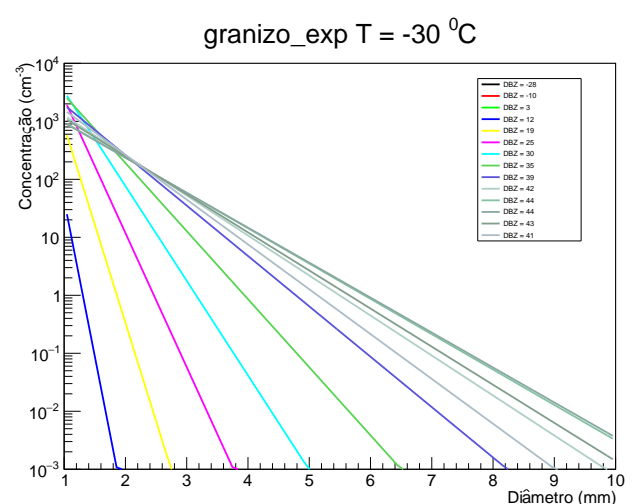

(a) granizo_gama $\mathrm{T}=-30{ }^{\circ} \mathrm{C}$

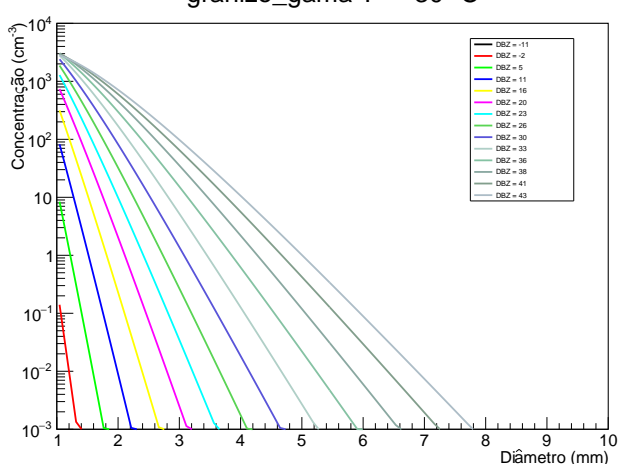

(b)

Figura 13: Distribuição de tamanho do granizo para diferentes refletividades; (a) Distribuição Exponencial; (b) Distribuição Gama. 
.2 Diferencas Exponencial- Gama dos hidrometeoros (ângulo de elevação)

\section{.2.1 Graupel}

TABEla 4: Diferenças entre as refletividades obtidas da simulação da graupel para a distribuição e a gama $Z_{\text {exp }}-Z_{\text {gama }}$, levando em conta o ângulo de elevação.

\begin{tabular}{||l|c|c|c|c|c|c|c|c|c||}
\hline \hline \multicolumn{1}{|r|}{$\begin{array}{c}\text { Theta } \\
\text { (dBZ) }\end{array}$} & 0 & 10 & 20 & 30 & 40 & 50 & 60 & 70 & 80 \\
\hline \hline 0 & $-4,71$ & $-4,71$ & $-4,71$ & $-4,72$ & $-4,72$ & $-4,72$ & $-4,72$ & $-4,72$ & $-4,72$ \\
\hline 5 & $-2,85$ & $-2,85$ & $-2,85$ & $-2,85$ & $-2,85$ & $-2,85$ & $-2,85$ & $-2,86$ & $-2,86$ \\
\hline 10 & $-0,99$ & $-0,99$ & $-0,99$ & $-0,99$ & $-0,99$ & $-0,99$ & $-0,99$ & $-0,99$ & $-0,99$ \\
\hline 15 & 0,86 & 0,86 & 0,87 & 0,87 & 0,86 & 0,87 & 0,86 & 0,87 & 0,87 \\
\hline 20 & 2,71 & 2,7 & 2,7 & 2,71 & 2,71 & 2,71 & 2,72 & 2,72 & 2,72 \\
\hline 25 & 4,51 & 4,51 & 4,52 & 4,52 & 4,53 & 4,54 & 4,55 & 4,55 & 4,55 \\
\hline 30 & 6,24 & 6,24 & 6,26 & 6,27 & 6,29 & 6,31 & 6,34 & 6,35 & 6,36 \\
\hline 35 & 7,76 & 7,77 & 7,79 & 7,82 & 7,87 & 7,91 & 7,95 & 7,99 & 8,01 \\
\hline 40 & 8,61 & 8,62 & 8,65 & 8,7 & 8,77 & 8,83 & 8,9 & 8,95 & 8,98 \\
\hline 45 & 8,14 & 8,15 & 8,19 & 8,25 & 8,32 & 8,4 & 8,47 & 8,53 & 8,57 \\
\hline 50 & 6,15 & 6,17 & 6,21 & 6,26 & 6,33 & 6,42 & 6,48 & 6,54 & 6,58 \\
\hline 55 & 2,99 & 3,01 & 3,04 & 3,08 & 3,15 & 3,21 & 3,27 & 3,32 & 3,35 \\
\hline 60 & $-0,88$ & $-0,87$ & $-0,85$ & $-0,8$ & $-0,75$ & $-0,7$ & $-0,65$ & $-0,63$ & $-0,6$ \\
\hline 65 & $-5,04$ & $-5,04$ & $-5,02$ & $-4,99$ & $-4,95$ & $-4,91$ & $-4,88$ & $-4,85$ & $-4,83$ \\
\hline \hline
\end{tabular}




\section{.2.2 Granizo}

TABELA 5: Diferenças entre as refletividades obtidas da simulação da granizo para a distribuição e a gama $Z_{\text {exp }}-Z_{\text {gama }}$, levando em conta o ângulo de elevação.

\begin{tabular}{||l|c|c|c|c|c|c|c|c|c||}
\hline \hline$Z(d B Z)$ & 0 & 10 & 20 & 30 & 40 & 50 & 60 & 70 & 80 \\
\hline \hline 0 & $-17,68$ & $-17,68$ & $-17,68$ & $-17,68$ & $-17,68$ & $-17,68$ & $-17,68$ & $-17,68$ & $-17,68$ \\
\hline 5 & $-8,01$ & $-8,01$ & $-8,01$ & -8 & $-8,01$ & $-8,01$ & $-8,01$ & $-8,01$ & $-8,01$ \\
\hline 10 & $-2,09$ & $-2,09$ & $-2,08$ & $-2,08$ & $-2,08$ & $-2,08$ & $-2,09$ & $-2,09$ & $-2,09$ \\
\hline 15 & 1,39 & 1,39 & 1,39 & 1,39 & 1,39 & 1,38 & 1,39 & 1,39 & 1,39 \\
\hline 20 & 3,5 & 3,5 & 3,51 & 3,5 & 3,5 & 3,5 & 3,51 & 3,5 & 3,5 \\
\hline 25 & 5,1 & 5,1 & 5,11 & 5,1 & 5,11 & 5,11 & 5,11 & 5,12 & 5,12 \\
\hline 30 & 6,64 & 6,64 & 6,64 & 6,64 & 6,65 & 6,66 & 6,67 & 6,67 & 6,67 \\
\hline 35 & 8,17 & 8,17 & 8,18 & 8,19 & 8,2 & 8,22 & 8,24 & 8,25 & 8,26 \\
\hline 40 & 9,41 & 9,42 & 9,43 & 9,45 & 9,48 & 9,52 & 9,55 & 9,57 & 9,59 \\
\hline 45 & 9,73 & 9,73 & 9,75 & 9,79 & 9,83 & 9,87 & 9,92 & 9,95 & 9,97 \\
\hline 50 & 8,58 & 8,58 & 8,61 & 8,65 & 8,69 & 8,74 & 8,79 & 8,83 & 8,84 \\
\hline 55 & 5,97 & 5,98 & 6,01 & 6,04 & 6,09 & 6,13 & 6,17 & 6,2 & 6,22 \\
\hline 60 & 2,31 & 2,31 & 2,34 & 2,37 & 2,41 & 2,45 & 2,49 & 2,51 & 2,53 \\
\hline 65 & $-1,93$ & $-1,92$ & $-1,91$ & $-1,88$ & $-1,85$ & $-1,82$ & $-1,79$ & $-1,77$ & $-1,75$ \\
\hline \hline
\end{tabular}

